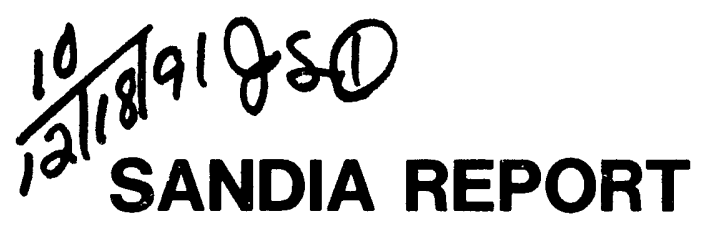

SAND90-0838 - UC-721

Unlimited Release

Printed November 1991

\title{
Combining Scenarios in a Calculation of the Overall Probability Distribution of Cumulative Releases of Radioactivity From the Waste Isolation Pilot Plant, Southeastern New Mexico
}

Martin S. Tierney

Prepared by

Sandia National Laboratories

Albuquerque, New Mexico 87185 and Livermore, California 94550

for the United States Department of Energy

under Contract DE-AC04-76DP00789 
Issued by Sandia National Laboratories, operated for the United States Department of Energy by Sandia Corporation.

NOTICE: This report was prepared as an account of work sponsored by an agency of the United States Government. Neither the United States Government nor any agency thereof, nor any of their employees, nor any of their contractors, subcontractors, or their employees, makes any warranty, express or implied, or assumes any legal liability or responsibility for the accuracy, completeness, or usefulness of any information, apparatus, product, or process disclosed, or represents that its use would not infringe privately owned rights. Reference herein to any specific commercial product, process, or service by trade name, trademark, manufacturer, or otherwise, does not necessarily constitute or imply its endorsement, recommendation, or favoring by the United States riovernment, any agency thereof or any of their contractors or subcontractors. The views and opinions expressed herein do not necessarily state or reflect those of the United States Government, any agency thereof or any of their contractors.

Printed in the United States of America. This report has been reproduced directly from the best available copy.

Available to DOE and DOE contractors from

Office of Scientific and Technical Information

PO Box 62

Oak Ridge, TN 37831

Prices available from (615) 576-8401, FTS 626-8401

Available to the public from

National Technical Information Service

US Department of Commerce

5285 Pcrt Royal Rd

Springfield, VA 22161

NTIS price codes

Printed copy: A05

Microfiche copy: A01 
SAND90-0838

Unlimited Release

SAND- $-90-0838$

Printed November 1991

\title{
COMBINING SCENARIOS IN A CALCULATION OF THE OVERALL. PROBABILITY DISTRIBUTION OF CUMULATIVE RELEASES OF RADIOACTIVITY FROM THE WASTE ISOLATION PILOT PLANT, SOUTHEASTERN NEW MEXICO
}

\author{
Martin S. Tierney \\ Safety and Reliability Analysis Division \\ Sandia National Laboratories \\ Albuquerque, New Mexico
}

\begin{abstract}
The Waste Isolation Pilot Plant (WIPP), in southeastern New Mexico, is a research and development facility to demonstrate safe disposal of defensegenerated transuranic waste. The U.S. Department of Energy will designate WIPP as a disposal facility if it meets the U.S. Environmental Protection Agency's standard for disposal of such waste; the standard includes a requirement that estimates of cumulative releases of radioactivity to the accessible environment be incorporated in an overall probability distribution. The WIPP Project has chosen an approach to calculation of an overall probability distribution that employs the concept of scenarios for release and transport of radioactivity to the accessible environmert. This report reviews the use of Monte Carlo methods in the calculation of an overall probability distribution and presents a logical and mathematical foundation for use of the scenario concept in such calculations. The report also draws preliminary conclusions regarding the shape of the probability distribution for the WIPP system; preliminary conclusions are based on the possible occurrence of three events and the presence of one feature: namely, the events "attempted boreholes over rooms and drifts," "mining alters ground-water regime," "waterwithdrawal wells provide alternate pathways," and the feature "brine pocket below room or drift." Calculation of the WIPP system's overall probability distribution is anticipated to require construction of conditional probability distributions for only five of sixteen possible scenario classes that can be obtained by combining the four postulated events or features.
\end{abstract}




\section{CONTENTS}

The Containment Requirements

3 CALCULATION OF THE OVERALL PROBABILITY DISTRIBUTION ...........................................

An Overview of Monte Carlo Methods in Performance Assessments ....................................

Quantifying the States of the System..................................................................................

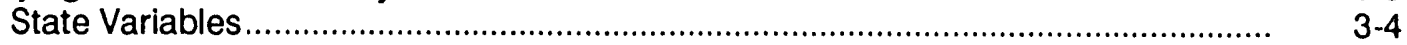

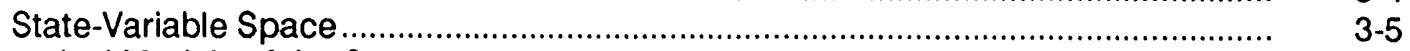

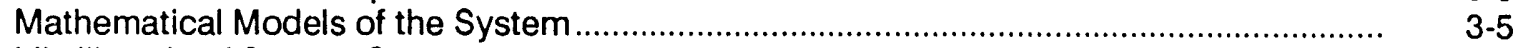

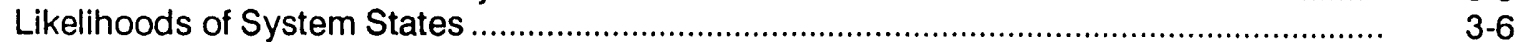

The Joint Cumulative Distribution Function ..............................................................

The Expectation Operator.........................................................................................

Practical Monte Carlo Simulation .......................................................................................

Estimators and Errors..................................................................................

Variance Reduction Schemes..................................................................... $\quad 3-12$

A Representation of the CCDF Based on Scenario Classes ................................................

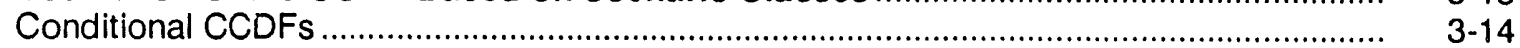

Partitioning State-Variable Space …………............................................................. $3-15$

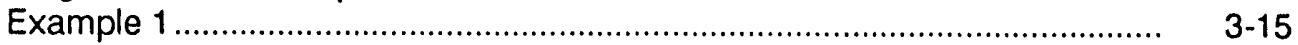

Example 2 .............................................................................................. 3

Generalization of the Partitioning Scheme …..................................................................... $3-22$

Number of Scenario Classes .................................................................................

Calculating Scenario-Class Probabilities............................................................... $\quad 3-24$

Features of the Partitioning Scheme

Undisturbed Performance .............................................................................. $\quad 3-26$

Screening on Elementary Probabilities ……....................................................... $3-26$

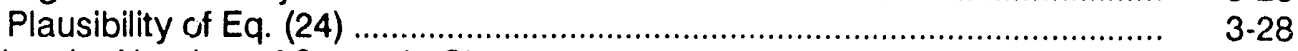

Reducing the Number of Scenario Classes ......................................................... $\quad 3-30$

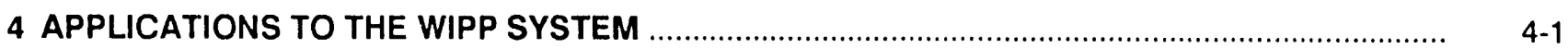

Events and Features That May Affect Releases from the WIPP............................................

Attempted Boreholes Over Rooms and Drifts ...............................................................

Explanation of Table 4-2 ......................................................................................... $4-5$

Brine Pocket Below Room or Drift ...................................................................................

Mining Alters Ground-Water Regime ................................................................................

Water-Withdrawal Wells Provide Alternate Pathways.............................................................

Preliminary Scenario Classes for the WIPP System ..............................................................

Classes Not Contributing to the CCDF ....................................................................... $4-13$

Classes That May Contribute to the CCDF .................................................................... $4-14$

Preliminary Conclusions Regarding the WIPP System's CCDF ............................................... 
APPENDIX A: $\quad$ WORKING DEFINITIONS OF SOME COMMON TERMS …................................ A-1

APPENDIX B: REPRESENTATION OF PROCESSES IN PERFORMANCE ASSESSMENT .......... B- B-1

APPENDIX C: INADVERTENT DRILLING AT THE WIPP SITE: AN EXAMPLE OF A

PROBABILITY MODEL OF AN ANTHROPOGENIC EVENT .................................. C-1

REFERENCES

R-1

\section{FIGURES}

Figure $\quad$ Page

1-1 WIPP Location in Southeastern New Mexico …...............................................................

1-2 Proposed WIPP Repository, Showing Both TRU Disposal Areas and

2-1 WIPP Disposal System: Repository/Shaft System and Controlled Area...........................

2-2 A General Complementary Cumulative Distribution Function (CCDF) ............................... 2-6

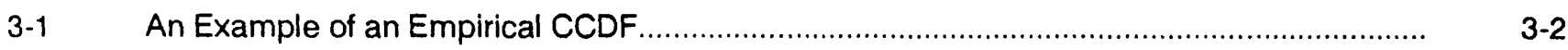

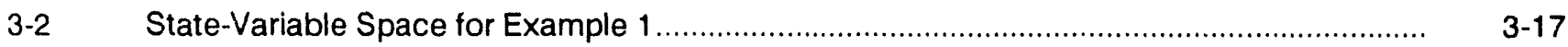

3-3 Logic Diagram for Identifying Scenario Classes in Example ? ......................................... 3-21

4-1 A Hypothetical but Qualitatively Correct Representation of the

\section{TABLES}

2-1 Release Limits for the Containment Requirements...................................................

4-1 Status of Agents Thought to Affect Releases from a Bedded-Salt Repository.....................

4-2 Variables in a Probability Model of the Event "Attempted Boreholes Over Rooms and Drifts"....

4-3 Variables in a Probability Model of the Event "Water-Withdrawal Wells Provide Alternate Pathways"

4-4 Preliminary Scenario Classes for the WIPP System. 


\section{INTRODUCTION}

The Waste Isolation Pilot Plant (WIPP) is a research and development facility to demonstrate safe disposal of defense-generated transuranic (TRU) waste that the U.S. Department of Energy (DOE) may designate as requiring deep geologic disposal (Figures $1-1$ and 1-2). The WIPP also provides a separate underground facility in which in-situ experiments may be conducted. All wastes placed in WIPP for intended disposal will be retrievable for periods required to demonstrate the safety of the disposal concept; these periods are not expected to exceed five years for TRU waste. Wastes used in the experimental program will be removed at the conclusion of the experiments, if necessary for compliance with applicable environmental standards or the WIPP waste acceptance criteria. If safety of the disposal concept is demonstrated and all applicable regulations are satisfied, the WIPP will become a disposal facility for TRU waste.

The WIPP Project will assess compliance with requirements of the U.S. Environmental Protection Agency's (EPA's) 40 CFR Part 191, Environmental Standards for the Management and Disposal of Spent Nuclear Fuel, High-Level and Transuranic Radioactive Wastes; Final Rule (the Standard, EPA, 1985). The part of the Standard most relevant to this report, Subpart B or the "Environmental Standards for Disposal," sets qualitative and numerical requirements on post-closure performance of the WIPP disposal system. Although Subpart B of the Standard was remanded to EPA by the U.S. Court of Appeals for the First Circuit, the WIPP Project will continue to respond to the Standard as first promulgated until a new Standard is in place (DOE and State of New Mexico, 1981).

An important requirement of Subpart B is called the "Containment Requirements" and is stated in $\S 191.13$ of the Standard. The Containment Requirements place numerical limits on likelihoods that cumulative releases of radioactivity to the accessible environment for 10,000 years after site closure will exceed certain specified numerical limits; they also suggest a general approach, called "performance assessment," to analyses that will test compliance with the numerical limits. The assessment as defined must provide a reasonable expectation that the probability of cumulative releases will not exceed the specified limits. The Containment Requirements are stated and interpreted in Chapter 2 of this report. An unusual feature of performance assessment is incorporation of estimates of cumulative releases of radioactivity into an overall probability distribution.

This report addresses the WIPP Project's approach to calculation of the overall probability distribution of cumulative releases of radioactivity that is required for performance assessment. Because the WIPP Project has already 


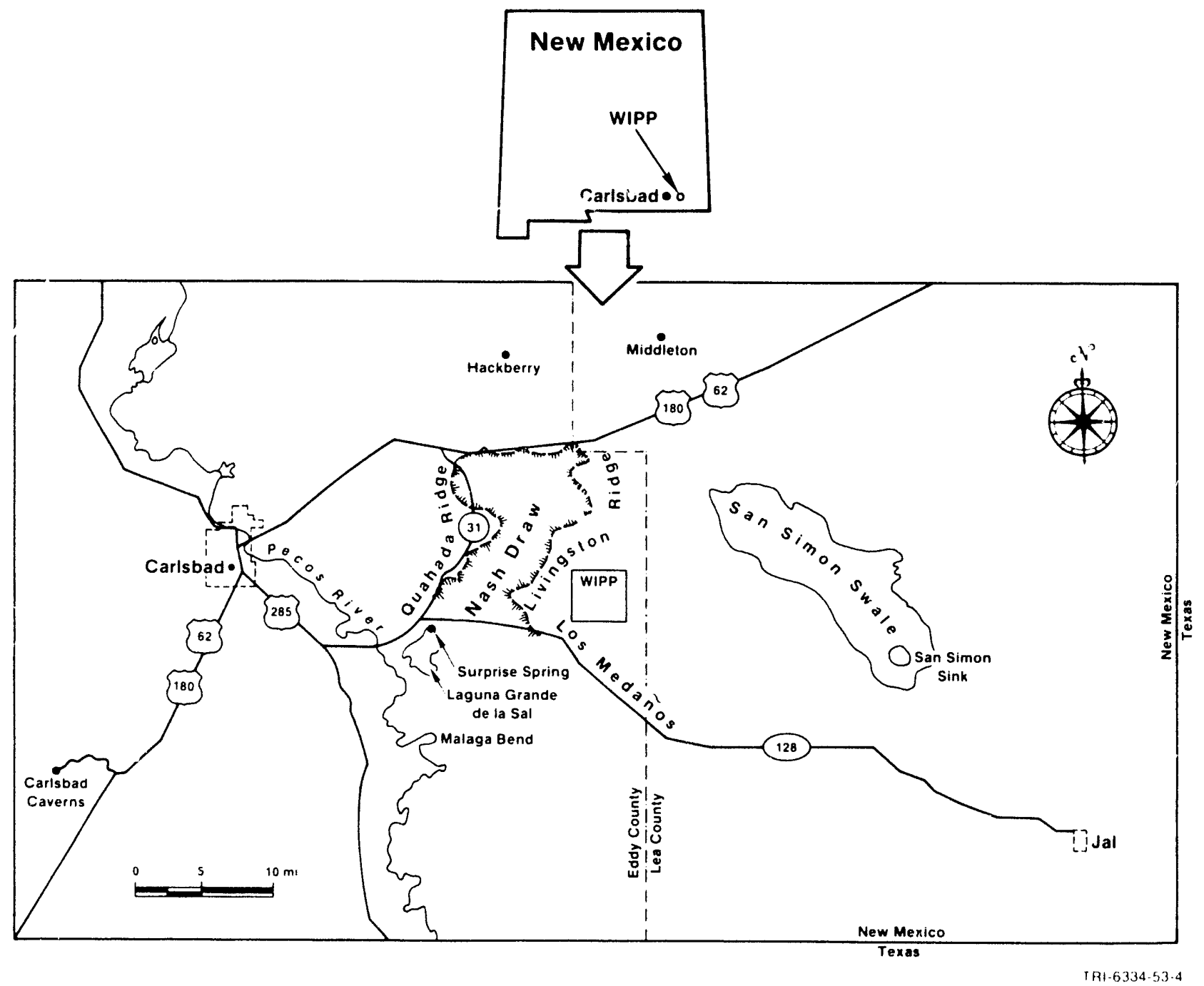

Figure 1-1. WIPP Location in Southeastern New Mexico (after Rechard, 1989). 


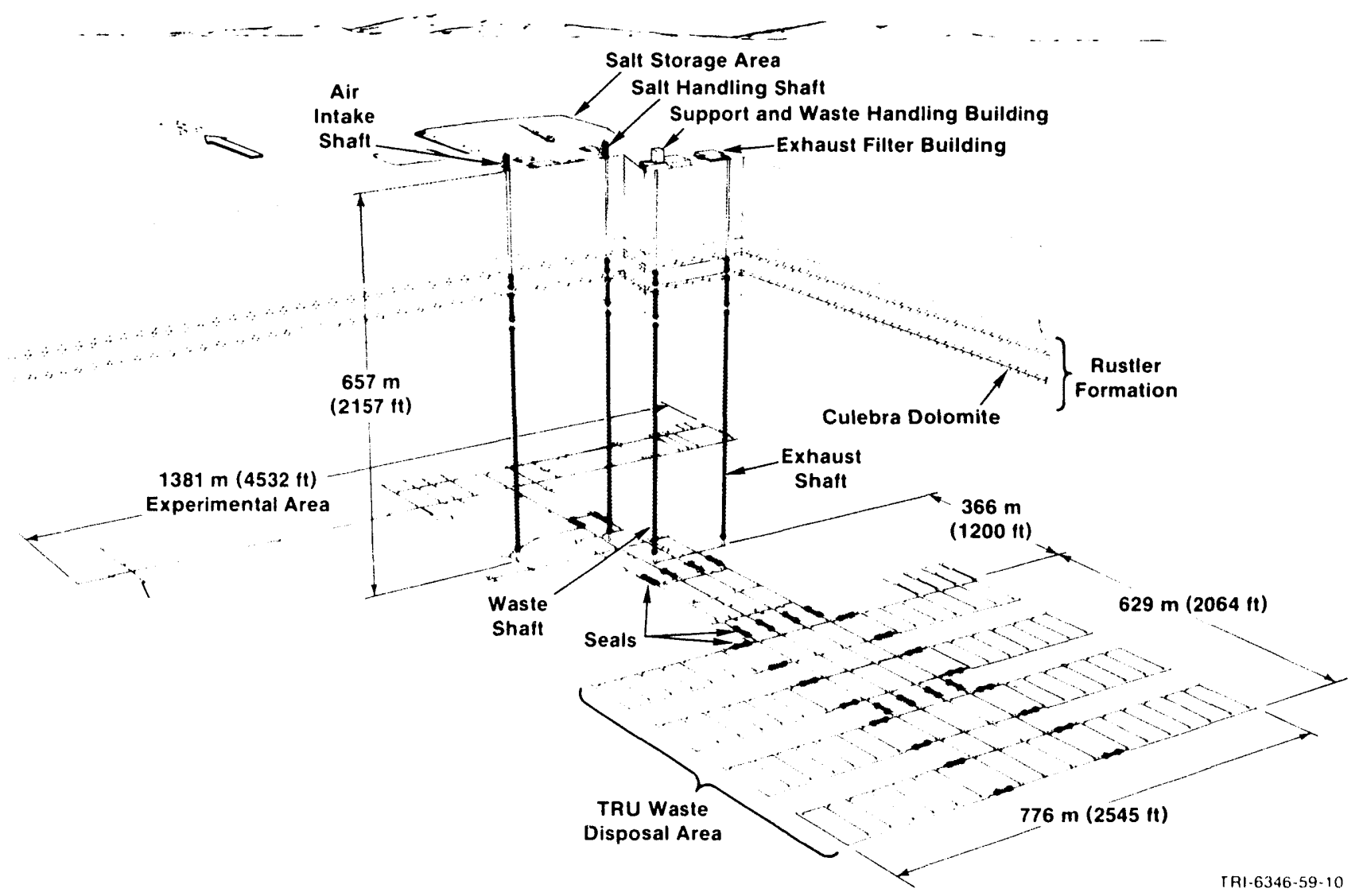

Figure 1-2. Proposed WIPP Repository, Showing Both TRU Disposal Areas and Experimental Areas (after Nowak et al., 1990). 
chosen a methodology for performance assessment (Marietta et al., 1989) that is based on the concept of "scenarios" for release and transport of radioactivity to the accessible environment (for the scenario concept, see Cranwell et al., 1982b; for a critique of the scerario concept, see Thompson et al., 1988), the present report emphasizes the manner in which the scenario concept can be used in calculating an overall probability distribution of cumulative releases.

A rather long Chapter 3 has been included here as a two-part introduction to logical and mathematical bases of a scenario-based calculation of the overall probability distribution: the first part is an overview of Monte Carlo methods in performance assessment, material which prepares the way for a discussion of scenario-based performance assessment in the second part of Chapter 3 .

Much material collected in the first part (Chapter 3) is common knowledge available in textbooks and journal articles. Ideas collected in the second part are not so familiar: some of these ideas can be found in a fragmented form in the waste-management 1iterature (Cranwell et al., 1982a and 1982b; Hunter et al., 1986; Section 8.3.5.13 of DOE, 1988; Thompson et al., 1988), but other ideas presented here appear to be previously undocumented concepts that have been uncritically accepted by investigators of the safety of geologic waste disposal. The purpose in including Chapter 3 in this document is to present in one place a clear and coherent account of technical arguments that underlie a scenario-based approach to performance assessment. In trying to present a clear and coherent account of the tec.mical basis for computing the overall probability distribution, certain terms, such as "event," "process," and "scenario," have to be defined more carefully than usual in the literature of geologic waste disposal; accordingly, special definitions of these terms are used consistently in the present report (Appendix A). A technical Appendix $B$ on repiesentation of prucess.s and treatment of process uncertainty is included by necessity. With one exception (Thompson et al., 1988), the waste-management literature is unclear concerring the details of the ways by which time-dependent processes could be incorporated mathematically in scenario-based performance assessments.

Terms and concepts of probability theory, e.g., random variable, mean, expectation, distribution function, are used throughout this report. Readers who are unfamiliar with these terms and concepts are urged to consult textbooks on the subject for their precise meanings; textbooks by Feller (1966) and Ross (1985) are primary references for Chapter 3.

Chapter 4 of this report is intended to be a sequel to two earlier reports. Hunter (1989) attempted a preliminary identification of processes, events, and features that might significantly affect releases of radioactivity from the 
WIPP system; whereas, Guzowski (1990) has constructed 16 scenarios from agents identified by Hunter (1989). The preliminary agents identified by Hunter are reviewed here (first part of Chapter 4), and requirements for probability models of some of chose preliminary agents are identified. An example of the term "probability model" is given for an anthropogenic event in Appendix $C$. Finally, preliminary scenario classes constructed by Guzowski are reviewed and revised (second part of Chapter 4), and some implications of these scenario classes for the shape of the WIPP system's overall probability distribution of cumulative releases of radioactivity are explored in the last part of that Chapter. 


\section{REGULATORY BASIS FOR THE OVERALL PROBABILITY DISTRIBUTION}

EPA's Containment Requirements set a quantitative, probabilistic standard for long-term performance of geologic repositories for high-level and TRU wastes. The Containment Requirements necessitate that the implementing agency make quantitative estimates of the performance of a geologic repository for 10,000 years into the future. The Containment Requirements also specify that the disposal system design must provide a "reasonable expectation" that the quantitative tests can be met. In the preamble to the Standard, the EPA states that this phrase reflects the fact that unequivocal numerical proof of compliance is neither necessary nor likely to be obtained. The standard is probabilistic because the EPA nas set numerical limits not upon cumulative releases of radioactivity to the accessible environment but upon the likelihood (i.e, probability) that those cumulative releases of radioactivity will exceed certain numerical values.

\section{The Containment Requirements}

Containment Requirements from the Standard (EPA, 1985) are quoted below with underlining added here to emphasize important terms.

191.13 Containment requirements.

(a) Disposal systems for spent nuclear fuel or high-level or transuranic radioactive wastes shall be designed to provide a reasonable expectation, based on performance assessments, that the cumulative releases of radionuclides to the accessible environment for 10,000 years after disposal from all significant processes and events that may affect the disposal system shall:

(1) Have a likelihood of less than one chance in 10 of exceeding the quantities calculated according to Table 1 (Appendix A); and

(2) Have a likelihood of less than one chance in 1,000 of exceeding ten times the quantities calculated according to Table 1 (Appendix A).

(b) Performance assessments need not provide complete assurance that the requirements of 191.13(a) will be met. Because of the long time period involved and the nature of the events and processes of interest, there will inevitably be substantial uncertainties in projecting disposal system performance. Proof of the future performance of a disposal system is not to be had in the ordinary sense of the word in situations that deal with much shorter time frames. Instead, what is required is a reasonable expectation, on the basis of the record before the implementing agency, that compliance with 191.13(a) will be achieved.

Several terms in the Containment Requirements have special meanings. The EPA defines "performance assessment" as 
... an analysis that: (1) Identifies the processes and events that might affect the disposal system; (2) examines the effects of these processes and events on the performance of the disposal system; and (3) estimates the cumulative releases of radionuclides, considering the assıciated uncertainties, caused by all significant processes and events. These estimates shall be incorporated into an overall probability distribution of cumulative release to the extent practicable. [EPA, 1985, §191.12(q)]

The term "'accessible environment' means: (1) the atmosphere; (2) land surface; (3) surface waters; (4) oceans; and (5) all of the lithosphere that is beyond the controlled area" [EPA, 1985, § 191.12(k)].

The "'controlled area' means: (1) a surface location, to be identified by passive institutional controls, that encompasses no more than 100 square kilometers and extends horizontally no more than five kilometers in any direction from the outer boundary of the original location of radioactive wastes in a disposal system; and (2) the subsurface underlying such a surface location" [EPA, 1985, § 191.12(g)]. (Figure 2-1)

EPA does not define the terms "process" and "event"; workers in the area of safety of geologic waste disposal usually take these terms to mean any natural or anchropogenic phenomenon that could cause or contribute to releases of radioactive materials from the repository and their transport to the accessible environment (Appendix A clarifies the distinction between these terms; IAEA, 1981 and Ross, 1987 list typical processes and events).

Containment Requirements refer to Table 1 of Appendix A of the Standard for the method by which cumulative releases to the accessible environment are to be calculated. Table 1 of Appendix A of the Standard is reproduced as Table 2-1 of this report. Appendix A of the Standard provides several notes that specify how Table 1 is to be used to calculate these cumulative releases. In particular, Note 6 of the Standard's Appendix A defines the measure of cumulative release of radioactivity to the accessible environment that is to be compared with limits specified in the Containment Requirements:

$$
M=\sum_{i} Q_{i} / L_{i}
$$

where $M$ may be called either normalized cumulative release or performance measure (DOE, 1988);

$\mathrm{Q}_{i}=$ cumulative radioactivity that is released to the accessible environment during the 10,000-year period following closure in the form of the $i^{\text {th }}$ radionuclide, owing to the action of processes and events that may affect the disposal system; and 


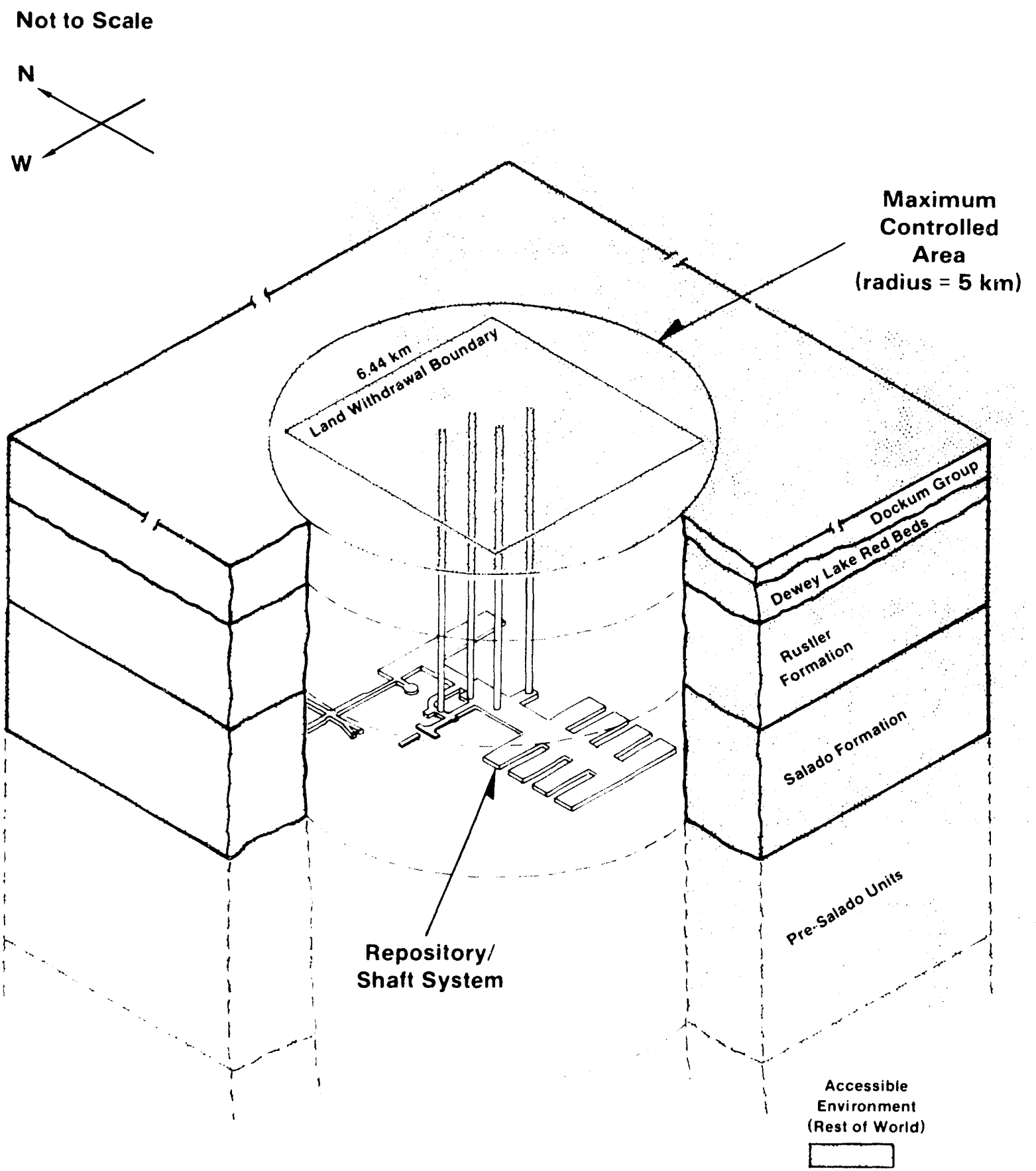

Figure 2-1. WIPP Disposal System: Repository/Shaft System and Controlled Area (Bertram-Howery and Hunter. 1989). The scale of the repository/shaft system is exaggerated. 
$\mathrm{L}_{i}=$ the release limit for the $i$ th radionuclide that is determined from Table 1 of the Standard, taking account of Notes 1 through 5 of Appendix A of the Standard.

In Eq. (1), the index $i$ runs over all radionuclides that have half-1ives greater than 20 years. For the case of the WIPP disposal system, which will contain transuranic (TRU) wastes, and if the $Q_{i}$ are expressed in units of curies ( $\mathrm{C} i$ ), the $\mathrm{L}_{i}$ are calculated by multiplying appropriate quantities in Table 1 of the standard by the ratio of number of curies of TRU wastes emplaced in WIPP to one million curies. For example, if the WIPP were to contain five million curies of transuranic wastes, the ratio would be 5 and $\mathrm{L}_{i}$ for plutonium-238 would be $5 \times 100 \mathrm{Ci}=500 \mathrm{Ci}$.

TABLE 2-1. RELEASE LIMITS FOR THE CONTAINMENT REQUIREMENTS (EPA, 1985, Appendix A, Table 1)

Radionuclide

Release Limit per 1,000 MTHM or Other Unit of Waste (Curies)

$\begin{array}{lr}\text { Americium-241 or }-243 & 100 \\ \text { Carbon } 14 & 100 \\ \text { Cesium-135 or }-137 & 1,000 \\ \text { lodine-129 } & 100 \\ \text { Neptunium-237 } & 100 \\ \text { Plutonium-238,-239,-240, or }-242 & 100 \\ \text { Radium-226 } & 100 \\ \text { Strontium-90 } & 1,000 \\ \text { Technetium-99 } & 10,000 \\ \text { Thorium-230 or }-232 & 10 \\ \text { Tin-126 } & 1,000 \\ \text { Uranium-233,-234,-235,-236 or }-238 & 100\end{array}$

Any other alpha-emitting radionuclide with a half-life greater than 20 years

Any other radionuclide with a half-life greater than 20 years that does not emit alpha particles

\section{An Interpretation of the Containment Requirements}

Published guidance for interpreting and implementirg Containment Requirements (EPA, 1985; NRC, 1986) explicitly recognizes that considerable uncertainty will be attached to estimates of normalized cumulative release because of the period of performance $(10,000$ years) and difficulties inherent in predicting future system behavior. Furthermore, the guidance-and-discussion sections of 
the Standard that relate to Containment Requirements clearly indicate that the normalized cumulative release [M of Eq. (1)] is not to be estimated and compared simply with a range of acceptable values. Instead, in guiding compliance with $\S 191.13$ of the Standard, the EPA assumes that

...whenever practicable, the implementing agency will assemble all of the results of the performance assessments to determine compliance with (section) 191.13 into a "complementary cumulative distribution function" that indicates the probability of exceeding various levels of cumulative release. When the uncertainties in parameters are considered in a performance assessment, the effects of the uncertainties considered can be incorporated into a single such distribution function for each disposal system considered. The Agency assumes that a disposal system can be considered to be in compliance with (section) 191.13 if this single distribution function meets the requirements of (section) 191.13(a). (EPA, 1985, Appendix B)

In other words, EPA assumes that the normalized cumulative release, $M$, will be treated as a random variable (instead of as a deterministic quantity) to which is attached a probability distribution function; it is this distribution function that is to be tested against the Containment Requirements.

Viewed as a random variable, the normalized cumulative release, $M$, would be associated normally with a probability density function (PDF) or an associated cumulative distribution function ( $C D F)$; Containment Requirements, however, place conditions on the associated complementary cumulative distribution function ( $C C D F$ ) which is one minus the CDF. Generally speaking, a ICDF can be any non-increasing function of one or more independent variables that is bounded between zero and one; some possible features of a general CCDF for a single independent variable are shown on Figure 2-2. In the present circumstances, a single independent variable, say $\mathrm{m}$, specifies possible normalized cumulative releases and ranges from zero to the maximum possible normalized release, i.e., the value taken by $\mathrm{M}$ in Eq. (1) when inventories of all radionuclides (with half-lives greater than 20 years) in the repository at closure time are substituted for the $Q_{i} s$. To show its functional dependence on variable $\mathrm{m}$, the $C C D F$ will hereinafter be denoted by

$$
G(m)=\operatorname{Pr}(M>m)
$$

where $\operatorname{Pr}(e\}$ stands for the probability that the statement "e" is true.

Note that $G(m)$ can be a defective distribution; i.e., the limit of $G(m)$ as $m$ approaches zero can be less than one if there is a non-zero probability that 


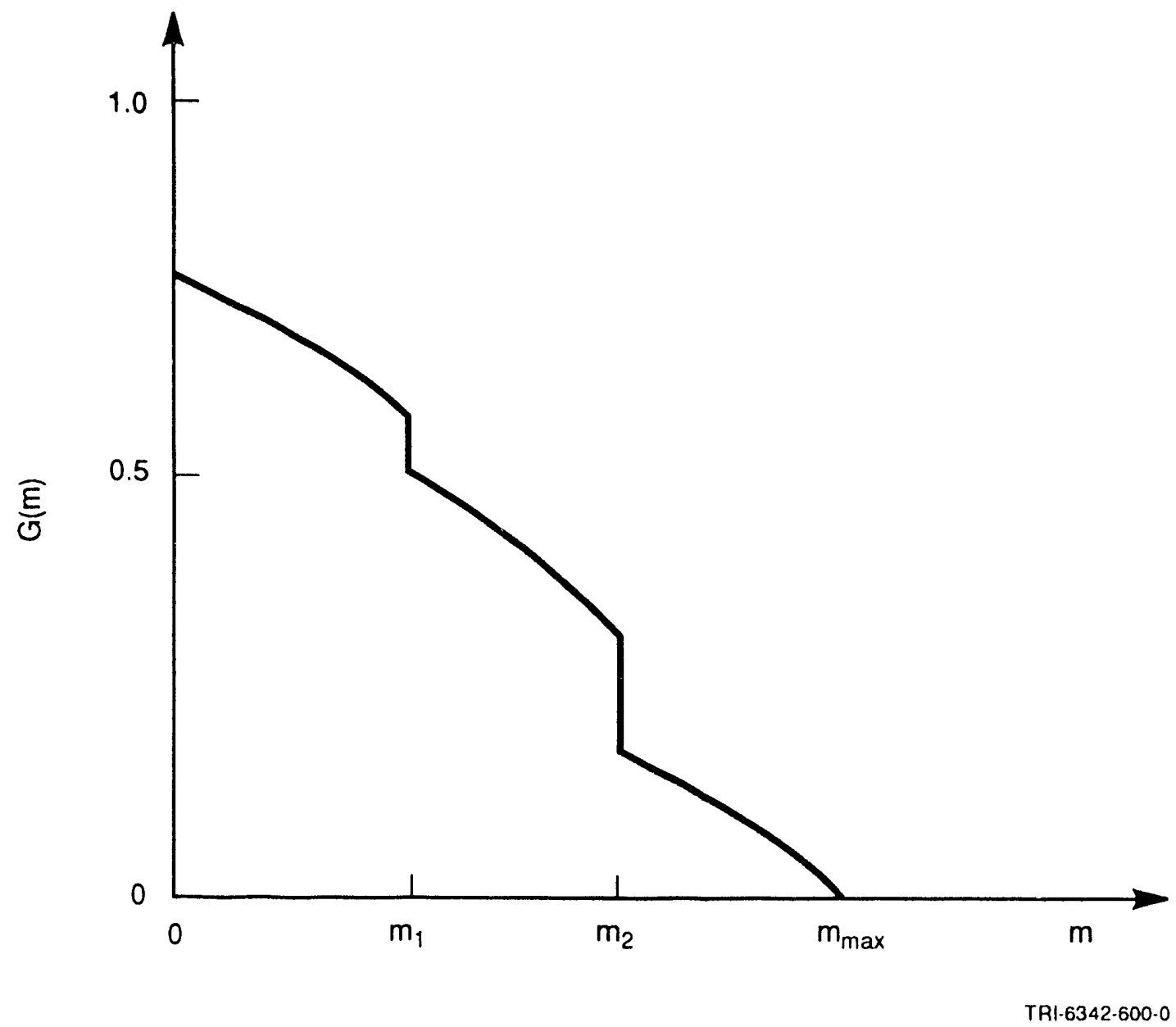

Figure 2-2. A General Complementary Cumulative Distribution Function (CCDF). Possible features shown are (1) a defect at $m=0$, i.e., $\operatorname{Pr}\{m>0\}<1.0$; (2) a finite support for the CCDF (probability that $M>m_{\max }=0$ ); and (3) discontinuities at $m=m_{1}$ and $m_{2}$. 
normalized cumulative releases can be identically zero. In general, $G(\mathrm{~m})$ can have other discontinuities at points $m>0$ as shown in Figure 2-2. The Containment Requirements now read, in notation of Eq. (2),

$$
G(1.0)<0.1 \text { and } G(10.0)<0.001 \text {. }
$$

It is apparent that the Containment Requirements constrain the CCDF at only two points, $m=1.0$ and $m=10.0$. In spite of this fact, the guidance-anddiscussion sections of the Standard (EPA, 1985, pp. 38070-38072, and Appendix B) seem to require that, if practicable, the entire CCDF be constructed and exhibited as part of the formal assessment of compliance with Containment Requirements. EPA, nevertheless, recognizes that not all events, processes, and features that may operate on or be present in a geologia waste-disposal system need to be incorporated in the construction of the CCDF. The Agency offers specific guidance for determining the relevant agents to be included in the performance assessments:

The Agency assumes that such performance assessments need not consider categories of events or processes that are estimated to have less than one chance in 10,000 of occurring over 10,000 years. Furthermore, the performance assessments need not evaluate in detail the releases from all events and processes estimated to have a greater likelihood of occurrence. Some of these events and processes may be omitted from the performance assessments if there is a reasonable expectation that the remaining probability distribution of cumulative releases would not be significantly changed by such omissions. (EPA, 1985, Appendix. B)

In this report, the chance that an agent will occur over 10,000 years will be called the elementary probability of the agent to distinguish the probability of occurrence of an agent from the probability of a scenario class (indeed, in a later section it will be shown that scenario-class probabilities can be formed from the agent's elementary probabilities). The elementary probabilities hereinafter will be denoted always by a lower case "P" with subscripts, viz. $p_{k}$ or $p_{k j}$. The specific, operational meaning of elementary probability depends upon whether the agent is an event, an undetected feature, or a process. If applied to a type of event, $p_{k}$ will stand for the probability that the $k^{\text {th }}$ type of event occurs at least once during the 10,000year period [so, $\left(1-p_{k}\right)$ is the probability that the event does not occur]. If applied to an undetected feature, $p_{k}$ will stand for the probability that the $k^{\text {th }}$ type of feature is present at closure of the repository $\left[s o,\left(1-p_{k}\right)\right.$ is the probability that the feature is not present]; if applied to a process, $p_{k j}$ will stand for the probability that only members of the $j$ th version of the $k^{\text {th }}$ process will be realized during the 10,000-year period of 
performance (by definition, the sum of $p_{k j}$ over all versions of the $k^{\text {th }}$ process must be one; the operational meaning of "version of a process" must be chosen so that this condition is satisfied [Appendix B]).

EPA's guidance on the scope of performance assessments (quoted on the preceding page) may now be paraphrased as follows: an agent need not be considered in calculation of the overall probability distribution if its elementary probability is less than 0.0001 , or if it reasonably can be established that inclusion of the agent in the performance assessment would lead to insignificant changes in the shape of the CCDF. 


\section{CALCULATION OF THE OVERALL PROBABILITY DISTRIBUTION}

In order to prepare for a technical discussion of the kinds of methods that might be used to construct a CCDF for normalized cumulative release, the reader is asked to imagine the following "thought experiment."

Construct a large number of replicas of the geologic repository and site (the system), preparing each replica according to the same set of blueprints and specifications so that any one replica could, for all practical purposes, be the real system that may eventually be constructed. Begin the operation of each replica at some common time and, at the end of a 10,000-year period (hereinafter called the period of performance), measure the amount of radioactivity that each replica has released to the accessible environment. Next, convert the amount of radioactivity released by each replica into a normalized cumulative release using Eq. (1). If the replicas were real systems, some uncertainty always would exist in initial states and physical conditions (including conditions of the system's geologic media) to which each replica was subjected during the period of performance; consequently, outcomes of the experiment, that is, the values of $M$ realized for each replica, would likely be different. Using outcomes of the experiment, observe the number of replicas for wich $M$ is zeio or $M$ exceeds any one of a predetermined set of numbers, say $m=10^{-2}, 10^{-1}, 1,10^{1}, 10^{2}, 10^{3}$. Next, plot a histogram giving relative frequency of the number of replicas whose outcomes exceed each of the predetermined set of numbers (i.e., the number of replicas exceeding a given number divided by total number of replicas). Such a histogram, called an empirical CCDF, might appear to be a crude version of the one shown (Figure 3-1). By increasing the fineness of the grid of predetermined numbers and by increasing the number of replicas in the experiment, step-like plots could be obtained that appear much like Figure 3-1; with further refinement, the steplike plots would ultimately approach a curve qualitatively similar to a piecewise continuous curve (Figure 2-2).

The "thought experiment" described above can be mimicked by performing repeated calculations with a suitable mathematical model of the system on a digital computer; the mathematical model need only be capable of generating a value of normalized cumulative release $M$ when given numerical specifications of initial and future states of the system. By choosing possible physical conditions and the initial state and subsequent states for the model system representing the site in a way the analyst thinks will reflect realistically their likelihood of occurrence during the period of performance, repeated runs with the mathematical model can generate an arbitrarily large number of sample Ms (repeated runs with a single mathematical model replace the simultaneous observation of outcomes for a large number of replicas of the system in the 
Chapter 3: Calculation of the Overall Probability Distribution

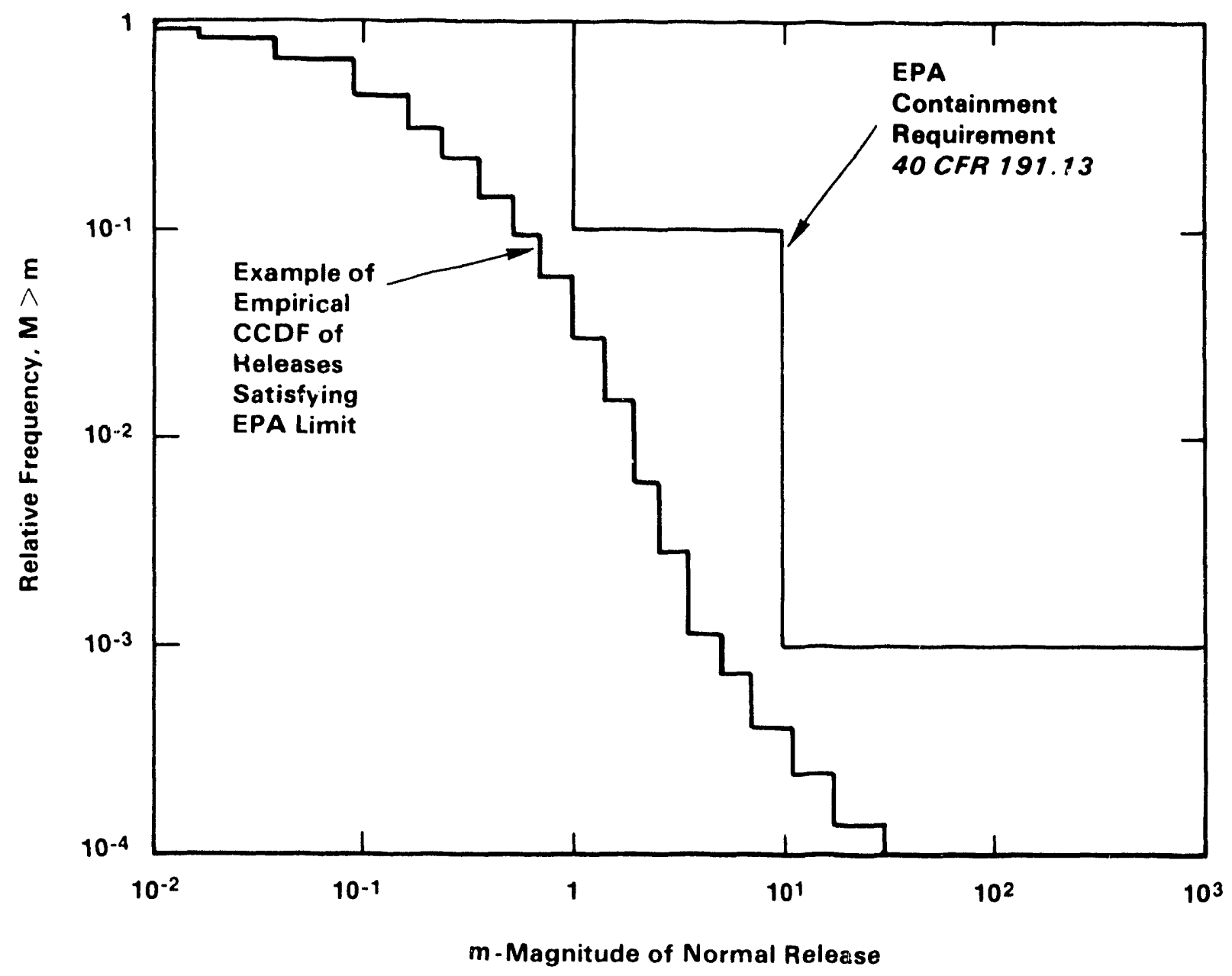

TRI-6334-46-2

Figure 3-1. An Example of an Empirical CCDF (modified from Rechard, 1989). 
"thought experiment"). The set of sample Ms generated can be plotted in the way indicated for outcomes of the "thought experiment" to give an empirical CCDF that can be compared with the Containment Requirements (Figure 3-1).

\section{An Overview of Monte Carlo Methods In Performance Assessments}

The procedure described above, mimicking the behavior of a complex system with a mathematical model, is "simulation." If some of the model's independent variables are assigned by drawing random samples of those variables from probability distributiors (or the equivalents of probabilty distributions, i.e., normalized functions on the space of variables), then the procedure is called "Monte Carlo simulation" (Ross, 1985, p. 434; Kalos and Whitlock, 1986). Monte Carlo simulation appears to be the only straightforward and practicable method for studying quantitative behavior of a complex system that is subject to an environment that is not accurately predictable by direct human investigation; it is especially applicable in performance assessments addressing a standard (the Containment Requirements) that asks for numerical measures of the effects on the system of events and processes that could occur over a period of 10,000 years.

The foregoing discussion of the "thought experiment" mentioned three things that are necessary for calculation of an empirical CCD $r^{\prime}$ by Monte Carlo simulation of the system: 1) a means of numerically specifying all possible physical conditions, initial states, and future states of the system; 2) a mathematical model that maps each quantified set of physical conditions, each initial state, and each future state of the system into a value of normalized cumulative release; and 3) a means of assigning numerical likelihoods to each quantified set of physical conditions, each initial state, and each future state of the system.

\section{QUANTIFYING THE STATES OF THE SYSTEM}

The behavior of a model system, i.e., a system that is idealized and mimicked by a mathematical model, is described usually by a finite number of quantities called dependent variables; these variables are called "dependent" because they are determined by other variables, generally called auxiliary variables, by means of mathematical relationships that define the model. If, as is usual with complicated models, the model is composed of many submodels, a hierarchy of interdependent auxiliary variables will be developed that extends from the level of the final dependent variables to those variables whose values must be supplied by the user of the total model; the latter kinds of variables can be 
called independent variables. (Note that "independent variables" are not necessarily statistically independent quantities.)

\section{State Variables}

The "state" of a system usually is described by its dependent variables. For example, in classical mechanics the state of a particle in motion in earth's gravitational field may be described by its position and velocity, six quantities which ultimately depend upon seven independent variables, namely, initial position, initial velocity, and time. In the present circumstances however, one dependent variable, the normalized cumulative release, is the result of integrations over time and space and incorporates outputs of many submodels; accordingly, the normalized cumulative release is a non-intuitive measure of the "state" of the system, and it is more convenient and meaningful to call the system's independent variables state variables. The number of state variables is necessarily finite, otherwise practical calculations with models would be impossible. Accordingly, the state variables may be assumed to be arranged as components of a finite-dimensional vector,

$$
\vec{v}=\left(v_{1}, v_{2}, v_{3}, \ldots, v_{N}\right)
$$

called the state-variable vector. The order in which a model's independent variables are listed in the state-variable vector is not imporiant; it is more important to understand that the components of the state-variable vector must be chosen so that they represent a unique configurztion of the model system for the entire period of performance; that is, the components must represent all numerical quantities that are considered necessary for a calculation of cumulative release of radioactivity that would attend the realization of a scenario. This means that components of the state-variable vector must include event variables (Appendix A), feature variables (Appendix A), and process variables (Appendix B) for each type of event, feature, and process that has been determined to be important in affecting releases of radioactivity from the sysiem.

At this point, the reader may object, at least in principle, that the number of components of the state-variable vector could be infinite because: a) processes normally are represented by continuous functions of time and, therefore, seem to require a non-denumerably infinite number of scalar variables for their specification; and b) state variables for an event include their times of occurrence and, given the fact that a likely event could occur an arbitrarily large number of times during the period of performance, an arbitrarily large number of scalar variables would be needed to specify these times of occurrence. Actually, the problem of an infinite or arbitrarily large number of state variables does not arise in practice because a) time- 
dependent processes always may be approximated by a finite amount of numbers by discretizing the time variable (Appendix B) or by representing the process by a finite sum of simple functions of time, e.g., a finite Fourier series; and $b$ ) the probability that one of the types of events of concern to the safety of a geologic repository will occur more than, say, ten times during the period of performance is vanishingly small. Moreover, if the frequency of an event is large, the event can be treated mathematically as a process, and its representation reduced to a finite number of scalar variables in the manner of treating a tiue process that was just described.

Thus, variables represented by the $\mathrm{N}$ components of the state-variable vector can be chosen so that an assignment of specific numerical values to those variables yields a possible, specific configuration of the model system throughout the period of performance; in other words, when assigned numerical values, components of $\vec{v}$ numerically represent a scenario, and different scenarios are obtained by assigning different numerical values to components of $\vec{v}$.

\section{State-Variable Space}

Allowing state variables, $v_{n}, 1 \leq n \leq N$, to assume potentially all. values in their natural ranges defines a subset of the $\mathrm{N}$-dimensional Euclidean space $\mathrm{R}^{\mathrm{N}}$; this subset will be called $S_{N}$, the state-variable space. In general, any point $\vec{\nabla} \varepsilon S_{N}$ will represent a possible scenario and any non-empty subset or $S_{N}$ can represent a scenario class. Scenario classes also will be denoted by $S$ but with an appropriate subscript, e.g., $s_{\alpha}$ or $s_{j}$. The symbol $d \vec{v}$ will denote an infinitesimally small scenario class centered upon some point $\vec{\nabla} \varepsilon \mathrm{S}_{\mathrm{N}}$.

\section{MATHFMATICAL MODELS OF THE SYSTEM}

Two different kinds of mathematical models of system behavior are necessary for performance assessments. The first kind can be called a consequence model because it maps an arbitrary scenario, specified by the state-variable vector $\vec{v}$ into the consequences of realizing that scenario, where consequences are measured in terms of cumulative discharges of radioactivity to the accessible environment over the period of performance. In other words, consequence models are deterministic algorithms that perform the transformation,

$$
\vec{v} \rightarrow\left[Q_{1}(\vec{v}), Q_{2}(\vec{v}), Q_{3}(\vec{v}), \ldots, Q_{I}(\vec{v})\right]
$$

where $Q_{i}(\vec{v})$ is the cumulative discharge of the $i^{\text {th }}$ radionuclide to the accessible environment during thi period of performance, and I denotes the number of radionuclide species that are potentially discharged and have halflives greater than 20 years. The normalized cumulative release then becomes a 
function of the state-variable vector [Eq. (1)]. Descriptions of some consequence models that have been used to predict cumulative releases of radioactivity from the WIPP system are given in Lappin et al., 1989 (Appendices D and E) and Rechard et al., 1990.

The second kind of mathematical model used in performance assessments can be loosely described as a probability model because it transforms system-specific empirical information (data), or comparable information about the system derived from expert opinion, into quantitative probabilities of system state variables that are needed for Monte Carlo simulations of the system's behavior. As will be seen in the following section, "Likelihoods of System States," uncertainties in system state variables are simulated by drawing random samples of the state-variable vector from a joint cumulative distribution function, which in turn is constructed from CDFs of each variable; the end-products of a probability model are analytic formulae or numerical algorithms for calculacing one or more CDFs for these variables and the associated elementary probabilities of the agents that affect the system's behavior.

Because different kinds of uncertain state variables (ranging from uncertain rock hydrologic parameters to times of occurrence of events) exist and the degree of uncertainty may vary widely among variables, many different approaches to the construction and numerical implementation of probability models are possible. An extended discussion of these techniques would exceed the scope of this report. An excellent review o.. probability models of some agents commonly associated with geologic waste disposal is provided by Hunter and Mann, 1989. Probability models of the significant agents associated with the WIPP system are being developed (an example is given in Appendix $C$ ).

\section{LIKELIHOODS OF SYSTEM STATES}

If considerable uncertainty exists in values to be assigned to a state variable, that variable may have to be treated as a random variable; i.e., a probability distribution may have to be associated with its possible range of values. Sources of uncertaincy in state variables are numexous: spatial and temporal uncertainties inherent in natural events, features, and processes; measurement errors in data that are used to connect the variable with reality; or simply uncertainty inherent in formulating correct theoretical relationships among variables. Whether any specific state variable needs to be treated as a random variable depends primarily on two things: 1) whether results of a calculation with a consequence model are sensitive to changes in the variable, and 2) whether the coefficient of variation of the variable is large (the coefficient of variation is the ratio of the variable's standard deviation to its mean value; it is a measure of the "spread" of the distribution of the variable). Generally speaking, if the coefficient of 
variation is small (as commonly is the case for physical constants, such as radionuclide half-lives, or dimensions of engineered features), the variable need not be treated as a randon variable. But if the coefficient of variation is large and results of calculations with consequence models are sensitive to changes in the variable, the variable should be treated as a random variable to capture the full range of model system behavior in the performanceassessment calculations.

Parameters that appear in probability models may have to be treated as random variables. These parameters often are quantified through the use of a limited amount of physical data or a limited sampling of expert opinions and may have large coefficients of variation; furthermore, the shape of the CCDF may be sensitive to probability-model parameters. This is the "closure problem" and is discussed further in Appendix C. For the sake of simplicity of argument, probability-model parameters are arbitrarily counted as fixed parameters in the remainder of the main text of this report.

Variables of consequence or probability models that may have to be treated as random variables can be identified by conducting sensitivity analyses of the models (Iman and Conover, 1980; Iman and Helton, 1985). Presuming that sensitivity analyses have been conducted for all submodeis prior to calculating a CCDF, there is no loss of generality in assuming that all $\mathrm{N}$ components of the state-variable vector are random variables. Following the usual convention (Feller, 1966), capital letters will be used hereinafter to label the state variables in their role as random variables, viz.,

$$
\vec{v}=\left(v_{1}, v_{2}, v_{3}, \ldots, v_{N}\right)
$$

\section{The Joint Cumulative Distribution Function}

Statistical properties of any reasonably well-behaved function of the state-variable vector $\vec{V}$ are determined by the joint cumulative distribution function associated with its components, $v_{n}, n=1,2,3, \ldots, N$. The joint $\mathrm{CDF}$ of the state variables is a function defined by

$$
F(\vec{v})=\operatorname{Pr}\left(v_{1} \leq v_{1}, v_{2} \leq v_{2}, v_{3} \leq v_{3}, \ldots, v_{N} \leq v_{N}\right)
$$

The function $F(\vec{v})$ can be visualized as a surface embedded in $N+1$ dimensional Euclidean space. The "relief" of the surface, i.e., the range of the $\mathrm{N}+1 \mathrm{st}$ dimension $F$, is bounded between zero and one. The joint probability density function (PDF) associated with $F(\vec{v})$ will be denoted by $F(d \vec{v})$ for reasons given below (but also see Feller, 1966, Chapter V). The joint PDF can be interpreted as the probability of occurrence of only those scenarios contained within the infinitesimal scenario class $d \vec{v}$. 
If correiations among components of $\vec{V}$ are known, the joint CDF in principle may be constructed from CDFs of individual variables: for example, if all components are independent random variables, the joint CDF is simply the product of individual CDFs. In most practical situations, however, some variables will be dependent; this fact, along with the presence of discrete random variables and possible use of numerical tables to represent some component CDFs, usually will dictate that the joint CDF takes a complicated analytic form, i.e., a form that may be comnunicated only by numerical algorithms. Furthermore, inclusion of discrete random variables specifying an event or feature (e.g., the binary variables 0 or 1 used to specify whether an event or feature does or does not occur) as components of the state-variable vector will introduce discrete components into the joint CDF, making it a discontinuous function of its arguments. For these technical reasons, the joint PDF associated with the joint CDF may not always be expressed in the familiar form of most textbooks,

$$
F(d \vec{v})=f(\vec{v}) d \vec{v}=f\left(v_{1}, v_{2}, v_{3}, \ldots, v_{N}\right) d v_{1} d v_{2} d v_{3} \ldots d v_{N}
$$

The joint CDF for the state-space variables is a natural measure of probability on the system's state-variable space $\mathrm{S}_{\mathrm{N}}$. The probability measure is normalized to one in the sense that

$$
\int_{S_{N}} F(d \vec{v})=1
$$

where here and elsewhere in this report the integration symbol can be interpreted to mean Lebesque-Stieltjes integration (Feller, 1966, Chapter V) of the argument function with respect to the measure $F$ over all points $\vec{v}$ contained in the set indicated at the bottom of the integration symbol. The normalization indicated above has the logical interpretation: "only scenarios from the class of all possible scenarios $\left(S_{N}\right)$ occur with certainty." Similarly, the probability that "only scenarios in the class $S_{\alpha}$ occur" is

$$
P\left(S_{\alpha}\right)=\int_{S_{\alpha}} F(d \vec{v})
$$

The quantity defined in Eq. (7) is called the probability of the scenario class $\mathrm{S}_{\alpha}$. In contrast with the always infinitesimally small probability of any given scenario [i.e., the PDF $F(d \vec{v})$ ], the probability of a scenario class $\mathrm{S}_{\alpha}$ is a definite number between zero and one; it is equal to one only for $\mathrm{S}_{\alpha}=\mathrm{S}_{\mathrm{N}}$. 


\section{The Expectation Operator}

Ideas and notations developed above can be used to express operations of Monte Carlo simulation in a formal but useful way. To begin, consider any reasonably well-behaved function of the state-variable vector $\vec{v}$, say $g(\vec{v})$. The mathematical expectation of this function is defined by the operation (Feller, 1966, Chapter V),

$$
E[g]=\int_{S_{N}} g(\vec{v}) F(d \vec{v})
$$

By specializing $\mathrm{g}(\vec{\nabla})$ in $\mathrm{Eq} .(8)$, one obtains the statistical properties (mean, variance, CDF) of the normalized cumulative release $M(\vec{v})$. Examples: If $g(\vec{v})=M(\vec{v})$, Eq. (8) gives $\bar{M}$, the mean value of the normalized cumulative release; if $g(\vec{V})=[M(\vec{V})-\bar{M}]^{2}$, Eq. (8) gives the variance of the normalized cumulative release (denoted by $\operatorname{Var}[M]$ ).

The CCDF for normalized cumulative releases follows from Eq. (8) on taking $g(\vec{v})=u[M(\vec{v})-m], m>0$, where $u(x)$ is the unit step function defined by $u(x)=0$ if $x \leq 0, u(x)=1$ if $x>0$. Thus, the CCDF can be formally represented by

$$
G(m)=E(u[M(\vec{v})-m]\},
$$

where the meaning of $\mathrm{E}[\cdot]$, the expectation operator, should be clear from inspection of $\mathrm{Eq}$. (8).

Because the result will be used later in discussion of ccriitional Monte Carlo simulation, note here that the probability of a scenario class, Eq. (7), can be expressed in terms of the expectation operator; this is demonstrated by first defining indicator functions,

$$
\begin{aligned}
\mathrm{I}\left(\overrightarrow{\mathrm{v}}, \mathrm{S}_{\alpha}\right) & =1 \quad \text { if } \overrightarrow{\mathrm{v}} \text { is contained in } \mathrm{S}_{\alpha}, \\
& =0 \quad \text { if } \overrightarrow{\mathrm{v}} \text { is not conta, ned in } \mathrm{s}_{\alpha},
\end{aligned}
$$

and noting the equivalence of Eq. (7) and

$$
P\left(S_{\alpha}\right)=E\left[I\left(\vec{v}, S_{\alpha}\right)\right] \text {. }
$$

In other words, the expectation of the indicator function for a scenario class $\mathrm{S}_{\alpha}$ gives the probability of that scenario class. 
The formalism defined above also applies to representation of the statistical properties of performance measures of conventional risk assessments such as cited by Thompson et al., 1988. Instead of the EPA's CCDF for cumulative releases to the accessible environment, some European programs for assessing risks of geologic disposal of radioactive wastes have chosen a quantity called "mean risk" as the performance measure for the system. Mean risk is the predicted radiation dose that would be received by individuals or populations who may reside near the system in the future; this quantity can be expressed in terms of expectation-operator formalism as

$$
\bar{R}(t)=\gamma E[H(\vec{v}, t)],
$$

where $H(\vec{v}, t)$ is the committed dose equivalent at time $t$, given the realization of a scenario specified by the state variable vector $\vec{\nabla}$, and $\gamma$ is the ICRP (International Commission on Radiologic 1 l Protection) risk factor (Thompson et al., 1988).

\section{PRACTICAL MONTE CARLO SIMULATION}

Statistical properties of any reasonably well-behaved function of the statevariable vector can be found by evaluating generalized integrals that are similar to Eq. (8). It is seldom possible to evaluate expressions of this kind by analytical means or by direct numerical integration: the dimension of integration is usually large, possibly involving tens or hundreds of variables, and one or both of the integrands, $g(\vec{v})$ and $F(d \vec{v})$, may be communicable only in terms of complex numerical algorithms or computer code. Monte Carlo methods are perhaps the only practical techniques for evaluating these expressions. The simplest possible Monte Carlo method exploits similarities between evaluation of a generalized integral and taking the mathematical expectation of a function of a random variable (Hammersley and Handscomb, 1964; Ross, 1985, Chapter 11) and taking the mathematical expectation and an arithmetic average of a suitably chosen set of sample values of the random function (Central Limit Theorem; Feller, 1966, Chapter VIII). The following is a brief outline of the simplest of the Monte Carlo methods, the so-called "random-sampling method," and some of its shortcomings.

\section{Estimators and Errors}

To calculate an estimate of expectation of $g(\vec{v})$ expressed by Eq. (8), begin by drawing $N_{S} \gg 1$ sample values of the state-variable vector, say $\vec{v}_{1}, \vec{v}_{2}, \vec{v}_{3}, \ldots, \vec{v}_{N_{s}}$, from the joint CDF of the system's state variables.

(Chapter 11 of Ross [1985] is a good introduction to techniques for "drawing" 
independent samples of a ranciom variable from its associated CDF.) Next, compute the quantitins $g\left(\vec{V}_{n}\right), 1 \leq n \leq N_{S}$, and form their arithmetic mean:

$$
\hat{g}=1 / N_{s} \sum_{n=1}^{N_{s}} g\left(\vec{V}_{n}\right)
$$

The quantity $\hat{g}$ is called an estimator of the expectation of $g(\vec{\nabla})$. Again, note that by an appropriate choice of $\mathrm{g}(\vec{v})$, one may calculate estimators of mean value, variance, and CCDF of normalized cumulative release $M(\vec{v})$, or the probability of a scenario class, $P\left(S_{\alpha}\right)$. The estimator of the CCDF of the normalized cumulative release,

$$
\hat{G}(m)=1 / N_{\substack{s \\ n}}^{N} u\left[M\left(\vec{V}_{n}\right)-m\right]
$$

is a mathematical statement of the procedure for forming the empirical CCDF: note the sinilarity between operations of Eq. (12) and the empirical construction of an empirical CCDF from results of the "thought experiment" described at the beginning of this chapter.

The estimator $\hat{g}$ is a random variable whose distribution approaches a normal distribution with mean value $\bar{g}$ and variance equal to $\sigma^{2} / \mathrm{N}_{S}$ as $\mathrm{N}_{S} \rightarrow \infty$ (Central Limit Theorem; Feller, 1966, Chapter VIII).

Here, $\sigma^{2}$ is the variance of $g(\vec{v})$, i.e.,

$$
\sigma^{2}=E\left\{[g(\vec{V})-\bar{g}]^{2}\right\}=E\left[g^{2}(\vec{V})\right]-(\bar{g})^{2} .
$$

Because $\hat{g}$ only estimates $\bar{g}, \hat{g}=\dot{g}+\varepsilon$, where $\varepsilon$ is the error associated with estimator $\hat{g}$. The error $\varepsilon$ is approximated, within a multiplicative

factor of $\sqrt{2}$ or $\sqrt{3}$, by the standard deviation of $\hat{g}$,

$$
\varepsilon \simeq \sigma /\left(N_{s}\right)^{1 / 2}
$$

The relative error in estimator $\hat{g}$ is defined by $|\varepsilon / \bar{g}|$.

Thus, to estimate error associated with estimator $\hat{g}$, one must either know or be able to calculate the standard deviation $\sigma$. The standard deviation is usually not known in advance. However, an estimate may be made by using $N_{S}$ samples of the state-variable vector $\vec{V}$ to form an estimator of sample variance, viz., 


$$
\hat{\sigma}^{2}=1 /\left(\mathrm{N}_{\mathrm{s}}-1\right) \sum_{\mathrm{k}=1}^{\mathrm{N}}\left[\mathrm{g}\left(\overrightarrow{\mathrm{V}}_{\mathrm{k}}\right)-\hat{\mathrm{g}}\right]^{2}
$$

this estimate may be used to compute an approximate error. If the approximate error is too large, one repeats the process just described by first increasing $\mathrm{N}_{S}$, then drawing the requisite number of additional samples, and calculating a new estimator and approximate error, continuing in this fashion until convergence to a tolerable level of error is achieved (Ross, 1985, p. 483).

The relative error incurred in construction of an empirical CCDF (Eq. 12) by the random sampling method is surprisingly easy to estimate: by specializing $g(\vec{V})=u[M(\vec{V})-m]$ and noting that the unit step function has the property $u^{2}(x)=u(x)$, one can write the variance of $g(\vec{V})$ as

$$
E\left(u^{2}[M(\vec{V})-m]\right)-G^{2}(m)=G(m)[1-G(m)] \text {. }
$$

For large enough values of $\mathrm{m}$, the relative error $\mathrm{G}$ in $\hat{G}(\mathrm{~m})$ can be estimated from Eq. (13) by

$$
\text { rel. error }=\left([1-G(m)] / N_{s} G(m)\right)^{1 / 2} \simeq\left[N_{s} G(m)\right]^{-1 / 2} \text {. }
$$

Eq. (14) can be used to estimate the sample size, $N_{S}$, needed to achieve a given relative error in the empirical CCDF at any point $m>0$ such that $G(m)$ 0 . Suppose that one wants to achieve a relative error of $100 \%$ at the point where $G(m)=.001$. By solving Eq. (14) for $N_{S}$, it is seen that about 1,000 samples must be taken. In a similar fashion, if a relative error of $30 \%$ is desired, one must take about 11,000 samples.

\section{Variance Reduction Schemes}

The foregoing estimates of sample size needed to achieve tolerable levels of error with the random sampling method illustrate that method's major drawback: a large number of sample runs must be made with consequence models, and if those models are implemented by large and complex computer codes (as they usually are in performance assessments), the sampling process may require unreasonably large expenditures of computer storage and time. Computer-time requirements may be reduced by turning to more sophisticated methods of sampling, such as stratification methods (Kalos and Whitlock, 1986) or the related Latin hypercube sampling (LHS) (Iman and Conover, 1982) method; use of these methods often will reduce variance in the estimator of $g(\vec{V})$ for a fixed sample size $\mathrm{N}_{S}$ below variance dictated by the random sampling method. 
The WIPP Project has used LHS in preliminary calculations of conditional empirical CCDFs for the normalized cumulative release of radioactivity from WIPP (Marietta et al., 1989; see the following section for the meaning of a conditional (CDF). Most of these preliminary calculations used $N_{\mathbf{S}} \simeq 50$, but so far no attempt has been made to estimate the relative error associated with such a sample size. The error associated with the LHS estimator is not estimated as easily as is the error associated with the random sampling method [Eq. (14)]. Iman and Helton (1985, pp. 2-5) suggest that "good results" are obtained with LHS when $\mathrm{N}_{S}$ is chosen to be greater than (4/3) N, where $N$ is the number of uncertain state variables. Iman (personal communication, 1990) states that the bases for the $(4 / 3) \mathrm{N}$ rule is purely empirical; it seems to give stable and reproducible results upon changing the "seed" vaiue in the random-number generator used in the sampling process.

\section{A Representation of the CCDF Based on Scenario Classes}

The WIPP Project has adopted a methodology for performance assessment that was developed at Sandia National Laboratories in the 1980s (Sandia methodology; Cranwell et al., 1982a and 1982b; Hunter et al., 1986; Campbell and Cranwell, 1988). A unique feature of the Sandia methodology is representation of the CCDF for normalized cumulative releases by a sum of conditional CCDFs weighted by scenario class probabilities. In terms of the notation of the previous section, the new representation takes the form

$$
G(m)=\sum_{j=1}^{J} G\left(m \mid s_{j}\right) P\left(s_{j}\right)
$$

where $G\left(m \mid S_{j}\right)$ can be interpreted as the probability that $M>m \geq 0$, given that only points (scenarios) in the set (scenario class) $s_{j}$ are taken (or occur), and $P\left(S_{j}\right)$ is the measure (probability) of the set (scenario class) $S_{j}$.

Representation of the CCDF in Eq. (15) is equivalent to representation by Eq. (9) provided that scenario classes satisfy certain conditions. To see this, let $\left(S_{j}\right\}, 1 \leq j \leq J$, be a partition of the state-variable space $S_{N}$ into $J$ sets of points (scenario classes) with the following properties:

$$
s_{j} \cap s_{k}=\varnothing \text { for } j \neq k, \text { and } \underset{j=1}{U} s_{j}=s_{N} \text {. }
$$

In the above, $\varnothing$ represents the empty set, the operation " $\bigcap$ "represents the intersection of sets, and the operation " $U$ " represents the union of sets. The first property in Eq. (16) is called the condition of exclusivity; logically speaking, it requires that each possible scenario be contained in 
one and only one scenario class $s_{j}, 1 \leq j \leq J$. The second property in Eq. (16) is called the condition of exhaustivity; logically speaking, it states that every possible scenario is contained in the union of classes $s_{j}, 1$ $\leq j \leq J$. The probabilities of the scenario classes in the partition $\left(S_{j}\right)$ are given by Eq. (10). It may be assumed without loss in generality that $P\left(S_{j}\right)>$ $0,1 \leq j \leq \mathrm{J}$; for if some of the $S_{j} s$ are such that $P\left(S_{j}\right)=0$, then they can be eliminated and the scenario classes renumbered, counting only classes for which $P\left(S_{j}\right)>0$. Obviously, scenario classes having zero probability play no role in representing the CCDF.

Assuming that the scenario classes in the partition $\left(S_{j}\right)$ satisfy conditions of exclusivity and exhaustivity, the normalization condition on $\mathrm{S}_{\mathrm{N}}$ and the indicator functions [Eq. (10)] can be used to show that

$$
\sum_{j=1}^{J} P\left(S_{j}\right)=1
$$

and, for any reasonably well-behaved function of the state variables, $g(\vec{v})$,

$$
E[g(\vec{V})]=\sum_{j=1}^{J} E\left[g \mid s_{j}\right] P\left(S_{j}\right),
$$

where $E\left[\cdot \mid S_{j}\right]$ stands for the expectation of the random variable $(\cdot)$ conditioned upon the fact that only points (scenarios) contained in the set (scenario class) $s_{j}$ are taken (or occur). Specifically,

$$
E\left[\begin{array}{lll}
g & \mid & S_{j}
\end{array}\right]=\frac{1}{P\left(S_{j}\right)} \int_{S_{j}} g(\vec{v}) F(d \vec{v}) .
$$

By setting $g(\vec{v})$ in Eqs. (17) and (18) equal to $u[M(\vec{v})-m]$, the new representation of the CCDF [Eq. (15)] is obtained.

\section{CONDITIONAL CCDFS}

The quantities $G\left(\mathrm{~m} \mid \mathrm{S}_{j}\right)$ [Eq. (15)] are called conditional CCDFs and can be constructed by Monte Carlo methods described in the last section. But nute that to construct a conditional CCDF, one must draw samples of the state variables not from the unrestricted joint CDF of all variables [Eq. (6)] but from a conditional joint CDF of those state variables whose types and ranges are restricted by the specifications of scenario class $s_{j}$. Inspection of Eq. (18) shows that these conditional joint CDFs may be formally expressed by 


$$
F_{j}(\vec{v})=\frac{1}{P\left(S_{j}\right)} I\left(\vec{v}, s_{j}\right) F(\vec{v}),
$$

where $I\left(\vec{v}, s_{j}\right)$ is the indicator function defined for use in Eq. (10).

Note that practical use of the representation of a CCD̈F by Eq. (15) will always require a fourth ingredient in addition to state-variables, a set of consequence models, and a joint CDF for state variables: namely, a set of logical rules that 1 ) define a partition of $\mathrm{S}_{\mathrm{N}}$ into mutually exclusive and exhaustive scenario classes $\left\{S_{j}\right\}$, and 2 ) define the indicator functions that appear in Eqs. (10) and (19), i.e., that allow a decision to be made whether a sample state-variable vector, $\vec{v}$, drawn from the unrestricted joint CDF belongs to a particular scenario class in the partition $\left\{S_{j}\right\}$. Given such a set of logical rules, one could in principle construct estimates of the scenarioclass probabilities, $P\left(S_{j}\right)$, and empirical, conditional CCDFs, $G\left(m \mid S_{j}\right)$, using the Monte Carlo methods described in the last section. In practice, though, it may prove difficult to devise rules defining indicator functions that are consistent with exclusivity and exhaustivity of scenario classes and, at the same time, permit an efficient use of Monte Carlo methods.

\section{Partitioning State-Variable Space}

Representation of a CCDF by Eq. (15) is valid for any partition of statevariable space that satisfies conditions of exclusivity and exhaustivity. Whether practical use can be made of the representation will depend upon the analyst's ability to construct a partition $\left(S_{j}\right)$ and an associated set of logical rules such that 1 ) scenaitio classes $S_{j}$ have relatively simple and intuitive meanings, and 2) resulting scenario-class probabilities $P\left(S_{j}\right)$ can be constructed easily from the probability models for agents that enter into definition of scenario class $s_{j}$. Partitions that satisfy criteria 1) and 2) will be called simple partitions. Here, "easily constructed" means use of any relatively simple analytic or straightforward numerical method other than Monte Carlo simulation. Use of time-consuming Monte Carlo methods to estimate scenario-class probabilities probably would eliminate any methodological and computational advantages that representation by Eq. (15) may have relative to a direct simulation of the total system that employs only Eq. (12) and the random sampling method.

The WIPP Project has chosen a simple partition of the WIPP system's statevariable space that is based on occurrence or non-occurrence of events and features (Marietta et al., 1989; Guzowski, 1990). This partitioning scheme is understood best by studying two examples.

Example 1. Consider the simplest possible situation in which only one process, specified by a single process variable $X$, and one event that is specified by 
two event variables, $N$ and $T$, occur. The process variable could represent the uncertain level of some process that is constant in time; event variable $\mathrm{N}$ is a binary random variable that specifies whether event does or does not occur in a time interval $\left[0, t_{\max }\right]$; and the event variable $\mathrm{T}$ represents the moment at which the event occurs. Suppose that $\mathrm{X}$ is independent of $(\mathrm{N}, \mathrm{T})$ and that CDFs for $X$ and $T$ are given, continuously differentiable functions,

$$
\begin{aligned}
& \operatorname{Pr}(X \leq x)=G(x), \quad x \in(-\infty,+\infty), \\
& \operatorname{Pr}(T \leq t)=H(t), \quad t \varepsilon[0, \infty) .
\end{aligned}
$$

The elementary probability that the event occurs in the time interval 10 , $\left.t_{\max }\right)$ is $\mathrm{p}=\mathrm{H}\left(\mathrm{t}_{\max }\right)$ and the binary variable $\mathrm{N}$ is distributed according to

$$
\begin{array}{ll}
\operatorname{Pr}(N=0)=1-p, & \text { (event does not occur) }, \\
\operatorname{Pr}(N=1)=p, & \text { (event occurs). }
\end{array}
$$

The state-variable space for this example (sketched on Figure 3-2a) is the union of two sheets, $S_{0}$ and $S_{1}$, where

$$
\begin{aligned}
& s_{0}=\{(x, n, t):-\infty<x<+\infty, n=0,0 \leq t<\infty), \\
& s_{1}=\{(x, n, t):-\infty<x<+\infty, n=1,0 \leq t \leq \infty\} .
\end{aligned}
$$

It is easily verified that $H(t)$ can be represented as the weighted sum of two conditional CDFs:

$$
H(t)=(1-p) H(t \mid N=0)+p H(t \mid N=1) \text {, }
$$

where

$$
\begin{aligned}
H(t \mid N=0) & =0, \text { if } t \leq t_{\max } \\
& =[H(t)-p] /(1-p), \text { if } t>t_{\max }
\end{aligned}
$$

and

$$
\begin{aligned}
H(t \mid N=1) & =H(t) / p, \quad \text { if } t \leq t_{\max } \\
& =1, \quad \text { if } t>t_{\max } .
\end{aligned}
$$

Thus, by treating variable $\mathrm{n}$ as though it is continuous instead of discrete, the joint CDF for state variables (of this problem) may be expressed in closed analytical form: 


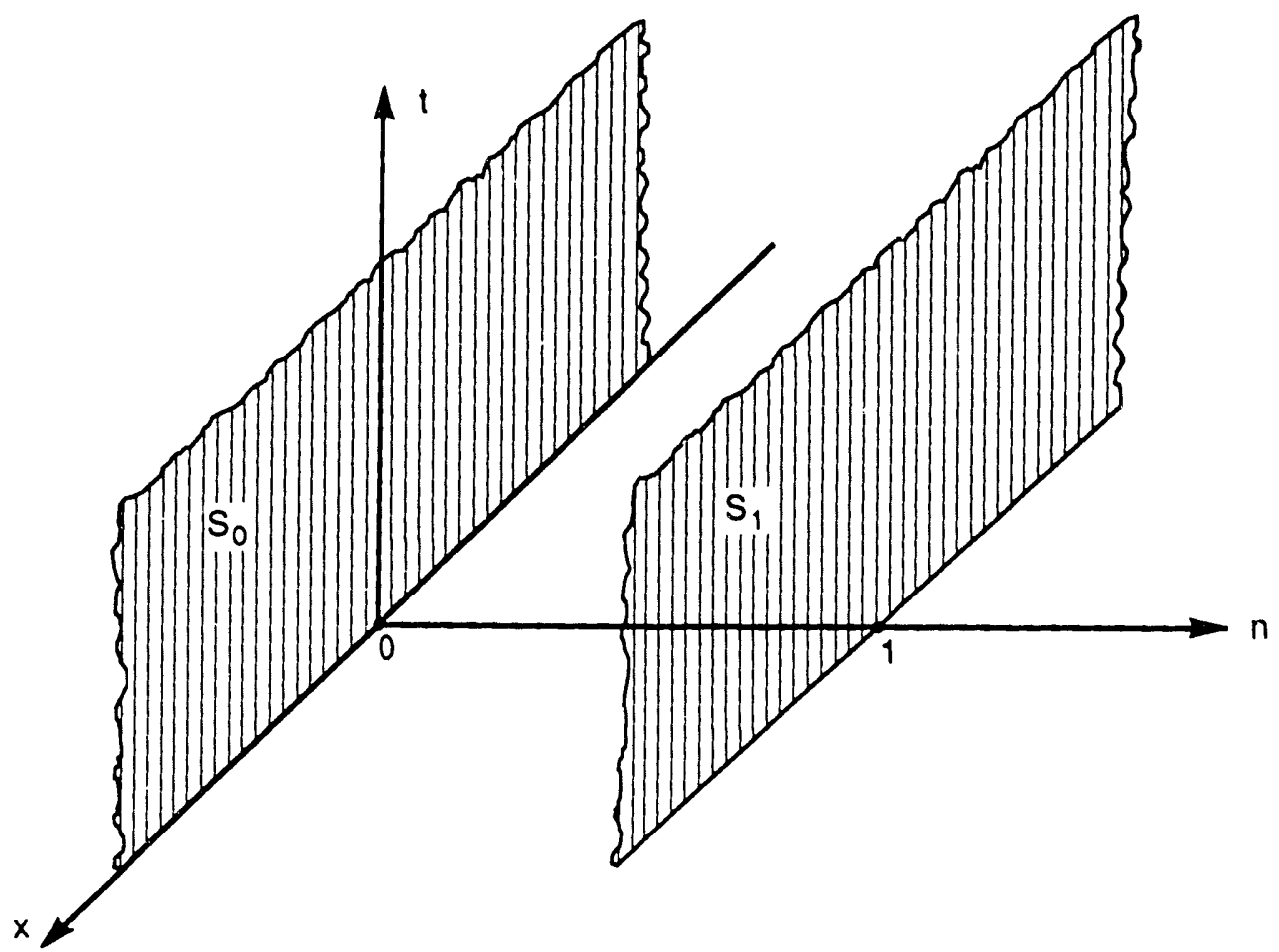

(a) Partitioned on Event Only.

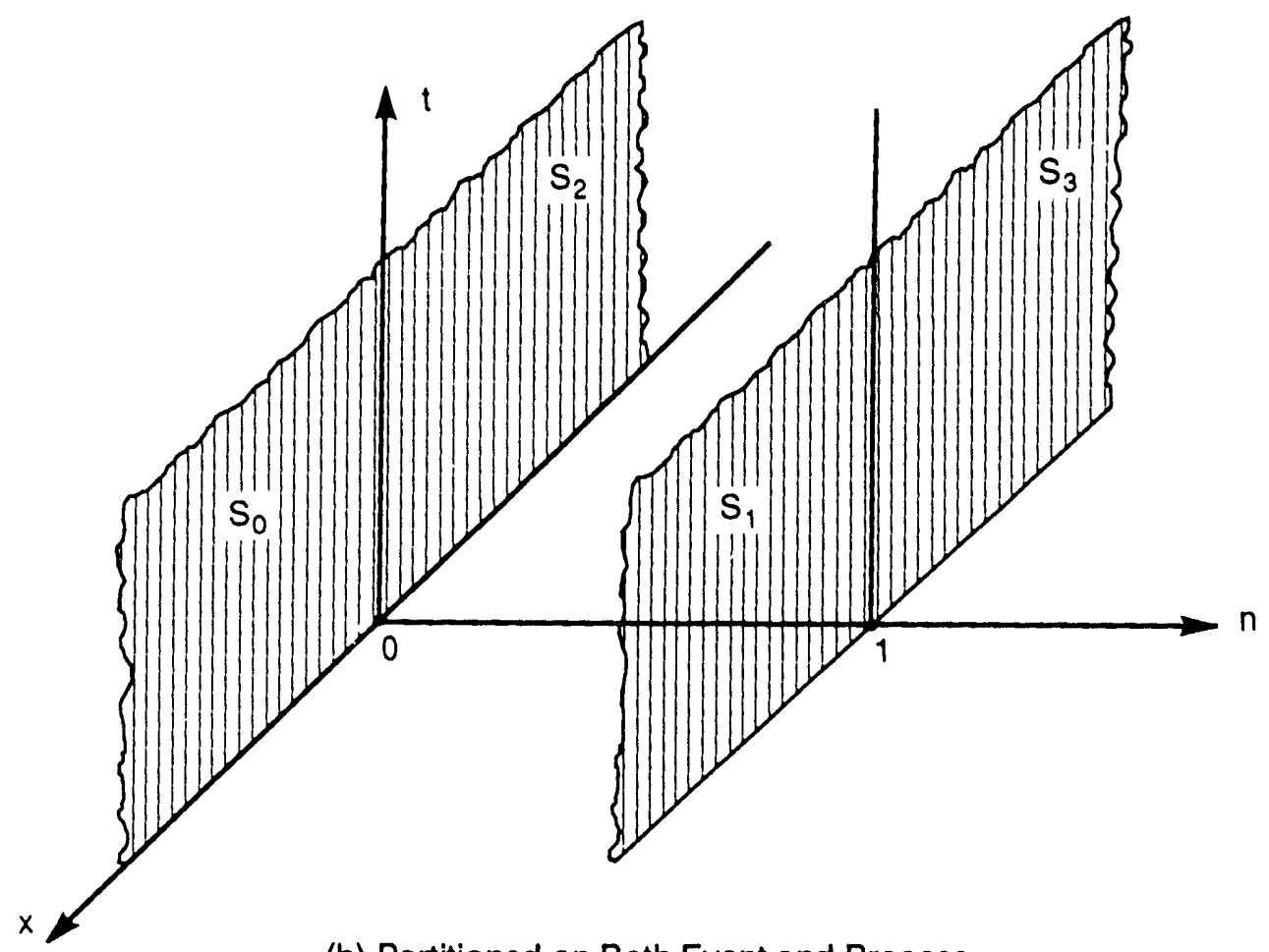

(b) Partitioned on Both Event and Process.

TRI.6342.601.0

Figure 3-2. State-Variable Space for Example 1. 


$$
F(x, n, t)=[(1-p) u(n) H(t \mid N=0)+p u(n-1) H(t \mid N-1)] G(x)
$$

and by taking derivatives, the associated joint PDF can be expressed as

$$
f(x, n, t)=\left[(1-p) \delta(n) H^{\prime}(t \mid N-0)+p \delta(n-1) H^{\prime}(t \mid N-1)\right] G^{\prime}(x) .
$$

In the two preceding equations, $u(\cdot)$ is the unit step function, $(\cdot)^{\prime}$ stands for ordinary derivative, e.g., $H^{\prime}(t)=d H / d t$, and $\delta(\cdot)$ stands for the Dirac delta function. [Recall that the Dirac delta function has the property,

$$
\begin{aligned}
\int_{A} g(\vec{v}) \delta(\vec{v}-\vec{x}) d \vec{v} & =g(\vec{x}) \text { if } \vec{x} \text { is contained in the set } A \text {, and } \\
& =0 \text { if } \vec{x} \text { is not contained in the set } A .]
\end{aligned}
$$

The reader can use these analytic forms and ordinary integration to verify that

$$
P\left(S_{0}\right)=\int_{S_{0}} f(x, n, t) d x d n d t=(1-p) \quad \text { and } P\left(S_{1}\right)-\int_{S_{1}} f(x, n, t) d x d n d t-p,
$$

and that the expected value of any function $g(x, n, t)$,

$$
E[g]=\int_{s_{0}} g(x, n, t) f(x, n, t) d x d n d t,
$$

can be expanded in terms of $P\left(S_{0}\right)$ and $P\left(S_{1}\right)$ as in Eqs. (17) and (18), i.e.,

$$
E[g]=(1-p) E\left[g \mid S_{0}\right]+p E\left[g \mid S_{1}\right]
$$

The three-variable model just described should illustrate the idea of partitioning state-variable space into mutually exclusive and exhaustive scenario classes on the basis of occurrence or non-occurrence of a binary agent. An extension of the model will be used next to illustrate the idea of creating new scenario classes by partitioning the space of process variables (Appendix B); this extension is included here only to show how processes might be included in the partitioning scheme; the WIPP Project has so far not attempted to create new scenario classes by partitioning of process variables.

For simplicity, suppose that the range of process variable $X$ (Figure $3-2 a$ ) is partitioned into two sets (or "bins"; Appendix B), $B_{1}$ and $B_{2}$, such that

$$
B_{1}=(x:-\infty<x<0) \text { and } B_{2}=(x: 0 \leq x<+\infty) \text {. }
$$


Introduction of two bins for the process leads to partitioning of statevariable space (Figure $3-2 b$ ) into four scenario classes arbitrarily labe!led $\mathrm{S}_{0}$ through $\mathrm{S}_{3}$.

Elementary probabilities of the two bins are evidently

$$
\rho_{1}=G(0) \text { and } \rho_{2}=1-G(0) \text {; }
$$

and $G(x)$ easily may be verified to be represented by

$$
G(x)=\rho_{1} G\left(x \mid B_{1}\right)+\rho_{2} G\left(x \mid B_{2}\right),
$$

where

$$
\begin{aligned}
G\left(x \mid B_{1}\right) & =G(x) / \rho_{1}, \quad \text { if } x<0, \\
& =1, \quad \text { if } x \geq 0 ; \text { and } \\
G\left(x \mid B_{2}\right) & =0, \quad \text { if } x<0, \\
& =\left[G(x)-\rho_{1}\right] / \rho_{2} \text { if } x \geq 0 .
\end{aligned}
$$

The expression for $G(x)$ given above can be inserted in the expression for the joint CDF for the three state variables, $F(x, n, t)$, and the latter can be expanded as a sum of terms to give

$$
\begin{aligned}
F(x, n, t)= & (1-p) \rho_{1} u(n) H(t \mid N=0) G\left(x \mid B_{1}\right)+p \rho_{1} u(n-1) H(t \mid N=1) G\left(x \mid B_{1}\right) \\
& +(1-p) \rho_{2} u(n) H(t \mid N=0) G\left(x \mid B_{2}\right)+p \rho_{2} u(n-1) H(t \mid N=1) G\left(x \mid B_{2}\right) .
\end{aligned}
$$

The associated joint PDF, $f(x, n, t)$, is formed from $F(x, n, t)$ by differentiation of all arguments:

$$
\begin{aligned}
f(x, n, t) & =(1-p) \rho_{1} \delta(n) H^{\prime}(t \mid N=0) G^{\prime}\left(x \mid B_{1}\right)+p \rho_{1} \delta(n-1) H^{\prime}(t \mid N=1) G^{\prime}\left(x \mid B_{1}\right) \\
& +(1-p) \rho_{2} \delta(n) H^{\prime}(t \mid N=0) G^{\prime}\left(x \mid B_{2}\right)+p \rho_{2} \delta(n-1) H^{\prime}(t \mid N=1) G^{\prime}\left(x \mid B_{2}\right) .
\end{aligned}
$$

These analytic forms and ordinary integration can be used to verify that

$$
\mathrm{P}\left(\mathrm{S}_{0}\right)=(1-\mathrm{p}) \rho_{1}, \quad \mathrm{P}\left(\mathrm{S}_{1}\right)=\mathrm{p} \rho_{1}, \mathrm{P}\left(\mathrm{S}_{2}\right)=(1-\mathrm{p}) \rho_{2}, \mathrm{P}\left(\mathrm{S}_{3}\right)=\mathrm{p} \rho_{2},
$$

and that the expected value of any function, say $g(x, n, t)$, can be expanded in terms of the $P\left(S_{j}\right), 0 \leq j \leq 3$, as the sum of terms, 


$$
\begin{aligned}
E[g]= & P\left(S_{0}\right) E\left[g \mid N=0, B_{1}\right]+P\left(S_{1}\right) E\left[g \mid N=1, B_{1}\right] \\
& +P\left(S_{2}\right) E\left[g \mid N=0, B_{2}\right]+P\left(S_{3}\right) E\left[g \mid N=1, B_{2}\right] .
\end{aligned}
$$

The operational meaning of conditional expectations such as $E\left[g \mid N=0, B_{1}\right]$ should be clear; for instance,

$$
E\left[g \mid N=0, B_{1}\right]=\int_{S_{0}} g(x, n, t) \delta(n) H^{\prime}(t \mid N=0) G^{\prime}\left(x \mid B_{1}\right) d x d n d t
$$

Example 2. This example attempts a generalization of Example 1 to more than one binary agent. Consider an idealized geologic disposal system in which releases of radioactivity may be caused by occurrence of any number of process's but only two kinds of events, labelled $E_{1}$ and $E_{2}$, and only one type of undetected feature, labelled $\mathrm{F}_{3}$. For instance, in the context of the WIPP system, event $E_{1}$ might be "onsite exploratory drilling," $E_{2}$ might be "offsite mining for potash," and $F_{3}$ might be "brine reservoirs under repository." The elementary probabilities of the two events and one feature are respectively $p_{1}, p_{2}$, and $p_{3}$. No partitioning of processes is made in this example.

Because only three kinds of events and features are considered in this example, scenario classes and scenario-class probabilities that arise from application of the partitioning scheme easily can be identified by construction of a logic diagram. Figure 3-3 shows one form of a logic diagram for the present example. (Guzowski, 1990, gives a different way of representing logic diagrams). There are eight scenario classes, each having a simple and intuitive meaning: for example, $\mathrm{S}_{4}$ has the physical meaning "brine reservoirs exist under repository and onsite exploratory drilling occurs, but no offsite mining for potash has occurred." A mathematical proof that these eight scenario classes are exclusive and exhaustive in the manner of Example 1 is not attempted here, but logic alone suggests that the classes must be mutually exclusive because no two of them can share the same components of the state-variable vector (the set of binary variables that specify whether two events and one feature occur or do not occur will have a different pattern for each class). Similarly, the classes must be exhaustive because their union accounts for all possible combinations of $E_{1}, E_{2}$, and $F_{3}$.

Probabilities of the eight scenario classes, $P\left(S_{j}\right), 1 \leq j \leq 8$, shown as polynomials of the elementary probabilities on the right-hand side of Figure 3-3, are formed by taking the product of the elementary probabilities that apply to the scenario class: for example, $\mathrm{P}\left(\mathrm{S}_{4}\right)=$ (probability of onsite exploratory drilling, $p_{1}$ ] $x$ [probability of no offsite mining for potash, $\left.\left(1-p_{2}\right)\right] x$ [probability of brine reservoirs under repository, $\mathrm{p}_{3}$ ]. The reader can easily verify that the sum of the eight scenario-class probabilities is one. 


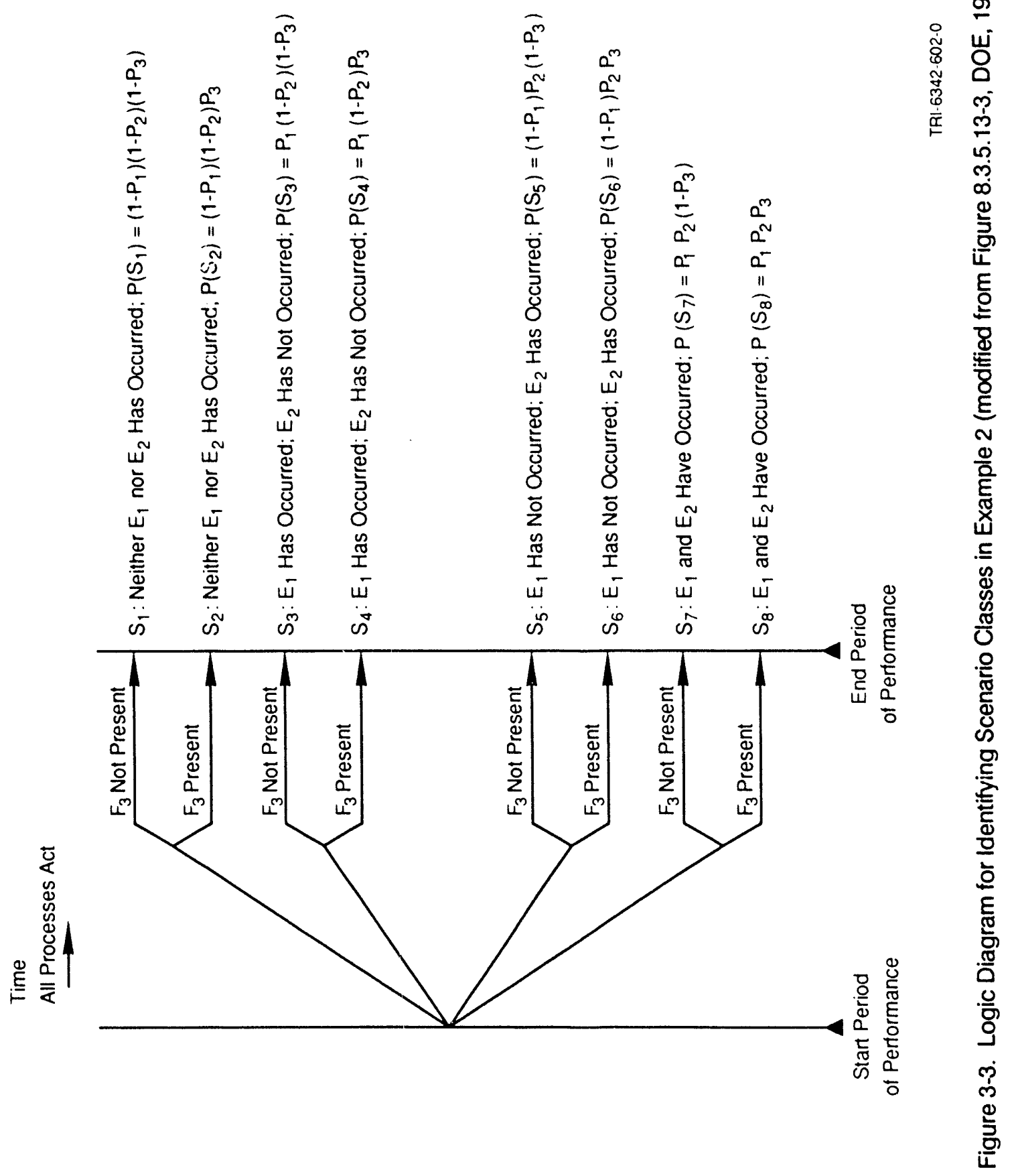


The conditional CCDFs associated with each of the eight scenario classes of this example can be estimated by Monte Carlo simulations that draw sample vectors from conditional distributions, $F_{j}(\vec{v})$, [Eq. (19)]. Note, however, that a partition of state-variable space on the basis of occurrence or nonoccurrence of discrete states of agents (in this case, binary states) allows the analyst to construct $F_{j}(\vec{v}) s$ without recourse to Monte Carlo simulation. The analyst will have to construct only a separate defining algorithm for each $F_{j}(\nabla)$; these algorithms could be constructed by selectively excluding from the algorithm for generating the unrestricted joint CDF, $F(\vec{v})$, the sub-algorithms for those CDFs for components of $\vec{v}$ that specify variables of agents that do not occur in the scenario class $S_{j}$, and by performing a renormalization of the appropriate CDFs that remain according to Eq. (19) using the analytically prescribed values of $P\left(S_{j}\right)$. For example, the defining algorithm for $F_{1}(\vec{v})$ could be obtained from the algorithm for $F(\vec{v})$ by bypasing all sampling of CDFs that apply to variables in agents $E_{1}, E_{2}$, and $F_{3}$ and assuring that the remaining CDFs were renormalized by the probability of $S_{1}$.

\section{GENERALIZATION OF THE PARTITIONING SCHEME}

The partitioning scheme that was illustrated by examples can be generalized to include any number of types of agents. The generalization takes the form of formulae for calculating 1) number of scenario classes that are associated with a given number of types of agents, and 2) scenario-class probabilities, based on the elementary pro'sabilities of the agents. Such a generalization becomes necessary when many types of agents must be considered in forming scenarios, and identification of the scenario classes by direct enumeration (or with the aid of logic diagrams) becomes impracticable. The formulae to be presented here will apply only to those agents that are statistically independent entities (i.e., having information about the occurrence or presence of one kind of agent does not change the elementary probabilities of other kinds of agents).

\section{Number of Scenario Classes}

In Example 2, a combination of two binary events and one binary feature resulted in $2^{3}=8$ scenario classes. It can be shown by simple enumeration that the combination of $\mathrm{K}$ different binary agents will result in $2^{\mathrm{K}}$ scenario classes.

In general, processes and alternative conceptual models are not binary agents. Time-dependent functions that specify an uncertain process (Appendix B) can be assumed to fall within one of $B \geq 1$ predetermined "bins"; and elementary probabilities, $P_{k b}$, that the $k^{\text {th }}$ type of process falls within the $b^{\text {th }}$ bin, 
$1 \leq \mathrm{b} \leq \mathrm{B}$, need orly have the property that their sum over all bins equals one. A similar situation applies to alternative conceptual models in that there may be more than two conceptual models of a process that are scientifi-ally acceptable (Appendix A). It is also noted in Appendix $A$ that there is no logical difference between a feature and an alternative conceptual model: hence it is possible to imagine a feature with more than two states.

Up to this point, events have been treated as binary agents, but in some performance-assessment studies it may be convenient to treat an event as an agent having more than two states. For example, instead of splitting an event into the categories "does not occur in performance period," and "occurs at least once in performance period," it may be advantageous to partition the state-variable space on the basis of the event's not occurring, occurring only once, occurring only twice, and occurring at least three times in the performance period. Thus, the following generalization of Example 2 is suggester.

Let: $\mathrm{K}_{2}=$ number of types of binary agents;

$\mathrm{K}_{3}=$ number of types of agents having 3 states;

$\mathrm{K}_{4}=$ number of types of agents having 4 states;

$K_{B}=$ number of types of agents having $B>2$ states.

Then, by simple enumeration and induction, there exist

$$
J=\left(2^{K_{2}}\right)\left(3^{K_{3}}\right)\left(4^{K_{4}}\right) \cdots\left(B^{K}\right)
$$

distinct combinations of the $\mathrm{K}_{2}+\mathrm{K}_{3}+\mathrm{K}_{4}+\ldots+\mathrm{K}_{\mathrm{B}}$ agents, each combination representing a scenario class.

Eq. (20) shows that the number of scenario classes increases exponentially with the number of types of independent agents to be considered in the performance assessment. This fact provides the reason why those agents that have insignificant effect on the shape of the total CCDF should be identified and eliminated prior to developing consequence models and making expensive Monte Carlo calculations for what could be an unreasonably large number of empirical, conditional CCDFs. The process of eliminating unimportant agents in performance assessments is called "screening." A qualitative methodology for screening is described in Cranwell et al., 1982b; the quantitative implications of screening of agents will be discussed in a later section ("Features of the Partitioning Scheme"). 


\section{Calculating Scenario-Class Probabilities}

Note that the eight scenario-class probabilities appearing on the right-hand side of Figure 3-3 can be found by expanding the following product,

$$
\left[\left(1-p_{1}\right)+p_{1}\right] \times\left[\left(1-p_{2}\right)+p_{2}\right] \times\left[\left(1-p_{3}\right)+p_{3}\right]
$$

as a sum of terms; i.e., after performing all multiplications in the above expression, one gets

$$
\begin{aligned}
& \left(1-p_{1}\right)\left(1-p_{2}\right)\left(1-p_{3}\right)+p_{1}\left(1-p_{2}\right)\left(1-p_{3}\right) \\
& \quad+\left(1-p_{1}\right) p_{2}\left(1-p_{3}\right)+\left(1-p_{1}\right)\left(1-p_{2}\right) p_{3} \\
& \quad+p_{1} p_{2}\left(1-p_{3}\right)+p_{1}\left(1-p_{2}\right) p_{3}+\left(1-p_{1}\right) p_{2} p_{3}+p_{1} p_{2} p_{3}
\end{aligned}
$$

Note that each term in Eq. (21) is one expression appearing in the logic diagram (Figure 3-3). This suggests the following generailization.

Recall the notation that was used in forming Eq. (20). Let $k_{2}$ be an index enumerating the distinct types of binary agents $\left(1 \leq k_{2} \leq k_{2}\right)$; denote the elementary probabilities of these agents by $p_{k_{2}}$ [so if $k_{2}$ applies to process, bin number one has probability $\mathrm{p}_{\mathrm{k}_{2}}$ and bin number two has probability $\left.\left(1-\mathrm{p}_{\mathrm{k}_{2}}\right)\right]$. In a similar fashion, let

$$
\begin{aligned}
& \mathrm{p}_{\mathrm{k}_{3} \mathrm{~b}}=\text { the elementary probability of the } \mathrm{b}^{\text {th }} \text { state }(1 \leq \mathrm{b} \leq 3) \text { in a } \\
& \text { three-state division of an agent of type } k_{3}\left(1 \leq k_{3} \leq k_{3}\right) \text {; } \\
& \mathrm{p}_{\mathrm{k}_{4} \mathrm{~b}}=\text { the elementary probability of the } \mathrm{b}^{\text {th }} \text { state }(1 \leq \mathrm{b} \leq 4) \text { in a four- } \\
& \text { state division of an agent of type } k_{4}\left(1 \leq k_{4} \leq k_{4}\right) \text {; }
\end{aligned}
$$

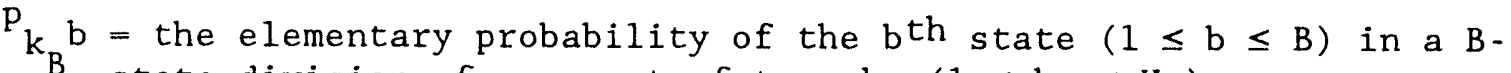

$$
\begin{aligned}
& k_{B} \text { state division of an agent of type } k_{B}\left(1 \leq k_{B} \leq k_{B}\right) \text {. }
\end{aligned}
$$


Then the scenario-class probabilities, $P\left(S_{j}\right)$, are given by the $J$ terms in the expansion of the following product, Eq. (22), as a sum of terms,

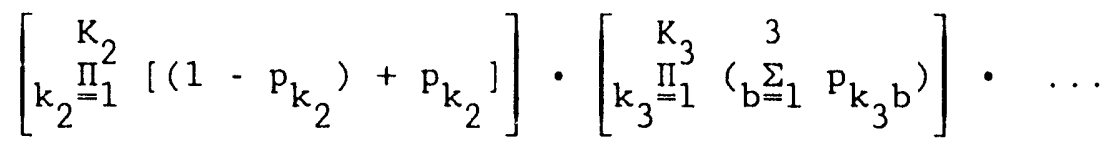

$$
\begin{aligned}
& \cdots\left[\begin{array}{l}
k_{B} \stackrel{\Pi^{B}}{=}\left(\stackrel{B}{=} \stackrel{\sum}{=}_{1} p_{k_{B} b}\right)
\end{array}\right] \text {. }
\end{aligned}
$$

In other words,

$$
\sum_{j=1}^{J} P\left(s_{j}\right)=\text { [expansion of Eq. (22) as a sum of terms]. }
$$

Note that each factor in the product [Eq. (22)] is identically equal to one. Therefore, the product of the factors is one, and so the expansion of the product as a sum must be one. This proves that the sum of the scenario class probabilities will always be one.

The bookkeeping involved in the use of Eq. (22) to construct scenario-class probabilities will be cumbersome if more than a few agents are involved. The analyst who is considering forming scenario classes with more than three or four agents might profitably turn to one of several available computer software packages for symbolic algebraic manipulations to form, identify, and interpret the scenario classes and keep track of the terms in the expansion of Eq. (22).

\section{FEATURES OF THE PARTITIONING SCHEME}

The present scheme for partitioning state-variable space into scenario classes has several potentially advantageous features: 1) it furnishes an operational definition of the term "undisturbed performance" used in the standard [EPA, 1985, § 191.12(p)]; 2) it permits an upper-bound estimate to be made of the error committed in the empirical CCDF by eliminating an agent on the basis of a small elementary probability; and 3 ) it suggests a logical way of reducing the number of scenario classes in a problem that is independent of knowledge of the elementary probabilities associated with the agents that comprise those classes. A simple example of the expansion of the product in Eq. (22) as a sum of terms will be used to illustrate some of these features. The example expansion is shown below for $k_{2}=2$ and $k_{3}=1$; i.e., two binary agents and one three-bin representation of a process are assumed. 


$$
\begin{aligned}
& \prod_{k_{2}=1}^{2}\left[\left(1-p_{k_{2}}\right)+p_{k_{2}}\right] \cdot\left(p_{11}+p_{12}+p_{13}\right) \\
& =\left(1-p_{1}\right)\left(1-p_{2}\right) p_{11}+\left(1-p_{1}\right) p_{2} p_{11}+p_{1}\left(1-p_{2}\right) p_{11}+p_{1} p_{2} p_{11} \\
& +\left(1-p_{1}\right)\left(1-p_{2}\right) p_{12}+\left(1-p_{1}\right) p_{2} p_{12}+p_{1}\left(1-p_{2}\right) p_{12}+p_{1} p_{2} p_{12} \\
& +\left(1-p_{1}\right)\left(1-p_{2}\right) p_{13}+\left(1-p_{1}\right) p_{2} p_{13}+p_{1}\left(1-p_{2}\right) p_{13}+p_{1} p_{2} p_{13} .
\end{aligned}
$$

At this point, the reader should recall that the 12 terms in the sum [righthand side of Eq. (23)] represent scenario-class probabilities that would serve as coefficients that multiply 12 empirical, conditional CCDFs in a representation of the overall probability distribution [according to Eq. (15)].

\section{Undisturbed Performance}

First, consider the terms [Eq. (23)] which have the form $\left(1-p_{1}\right)\left(1-p_{2}\right)$ $\mathrm{p}_{1 \mathrm{k}}, \mathrm{k}=1,2,3$ (these terms are arranged in the first column of the array on the right-hand side of the equation). Terms having this form are naturally interpreted as probabilities of "undisturbed-performance" scenario classes, i.e., those classes of scerarios in which none of the presumably disruptive agents occur during the period of performance. Classes of this kind have been called the "base-case" (Marietta et al., 1989; Guzowski, 1990) or the "nominal case scenario" (DOE, 1988, § 8.3.5.13) and can be used to operationally represent the concept of "undisturbed performance of the disposal system" mentioned in the Individual Protection Requirements ( $\S 191.15$ ) and the Ground Water Protection Requirements ( $\S 191.16$ ) of the Standard (EPA, 1985). But note that more than one "undisturbed-performance" scenario class may exist, depending upon the the number of processes that are involved in the problem and whether those processes are divided into bins in the manner indicated in Appendix B. The remaining terms in Eq. (23) have at least one factor of the form $P_{k}, k=1,2$. These terms naturally are interpreted as probabilities of "disturbed-performance" classes, i.e., those classes of scenarios in which at least one of the presumably disruptive events (or features) occurs during the period of performance.

\section{Screening on Elementary Probabilities}

Much of the following discussion of screening on elementary probabilities will make sense only if the reader recalls an assumption made earlier in this report: that the elementary probabilities, or the parameters of mathematical models used to determine elementary probabilities, are not uncertain (or 
imprecise) problem variables. That assumption is maintained throughout this section. Difficulties that arise when the elementary probabilities are uncertain problem variables are briefly mentioned in Appendix C ("Uncertainty in Probability Model Parameters").

With these cautions in mind, consider what happens to scenario classes and scenario-class probabilities when, in the light of new evidence, an agent heretofore regarded as playing a significant role in determining consequences comes to be regarded as either an impossibility (elementary probability $\rightarrow 0$ ) or a sure thing (elementary probability $\rightarrow 1$ ). The effects of taking these limits are seen most easily by letting them apply to one of the elementary probabilities, say $p_{1}$, that appears in the prototypical example, Eq. (23). On taking either limit, Eq. (23) becomes a sum of six terms,

$$
\left(1-p_{2}\right) p_{11}+p_{2} p_{11}+\left(1-p_{2}\right) p_{12}+p_{2} p_{12}+\left(1-p_{2}\right) p_{13}+p_{2} p_{13}
$$

that sum to one. This observation and Eq. (20) suggest the general result: elimination of a binary agent, whether by regarding it as impossible or a sure thing, results in a halving of the number of scenario classes (and therefore the number of conditional CCDFs that must be estimated by Monte Carlo simulation). Conversely, introduction of a binary agent results in a doubling of the number of scenario classes. In each instance, the sum of scenarioclass probabilities remains equal to one. But note the differences between impossibility and a sure thing in terms of practical computations. If an agent is impossible, none of its associated phenomenology needs to be included in the consequence models, thus resulting in a reduction of model-development effort and a simplification of computations. On the other hand, if an agent is regarded as a sure thing, its phenomenology is necessarily included in the CCDF calculations (in the form of consequence models and probability models for parametric uncertainty) in order to assure a realistic estimate of the form of the CCDF; in other words, the sure binary agent is a necessary part of an assessment of undisturbed performance.

The effects of eliminating all or part of the representation of a non-binary agent (i.e., an agent that is divided into more than two states) also may be inferred from Eqs. (23) and (20). Of course, an agent that is known to have no effect on cumulative releases to the accessible environment under any conditions (undisturbed or disturbed) never would be considered in the building of consequence models. Of more interest is the situation in which, for example, a few (but not all) of the regions of process-variable space (bins) associated with a process are judged in retrospect to have negligible elementary probabilities; then, by Eq. (20), the elimination of, say, A bins out of $B$ bins (where $1 \leq A<B$ ) will reduce the number of scenario classes by the fraction (B - A)/B. For example, if in Eq. (23) one takes $p_{13} \rightarrow 0$ (and 
as a consequence, $p_{11}+p_{12}=1$ ), then Eq. (23) becomes the sum of the $(2 / 3) \times 12=8$ terms contained in the first two rows of the array. Again, the sum of the 8 resulting scenario-class probabilities is one.

Because elementary probabilities are rarely exactly zero, elimination of an agent on the basis of small probability of occurrence will lead to an error in the overall CCDF. In other words, if $G_{K}(m)$ stands for the CCDF, which includes consideration of $\mathrm{K}$ different agents, and one of those agents is eliminated on the basis of a small elementary probability, say $\mathrm{p}_{\mathrm{k}_{1}}$, an absolute error of magnitude $\left|G_{K}(m)-G_{K-1}(m)\right|$ will be associated with the reduced CCDF $\mathrm{G}_{\mathrm{K}-1}(\mathrm{~m})$. It can be shown that $\mathrm{p}_{\mathrm{k}_{1}}$ is an upper bound to the absolute error; in other words

$$
\left|G_{K}(m)-G_{K-1}(m)\right| \leq p_{k_{1}}
$$

Plausibility of Eq. (24). Although a proof of the inequality in Eq. (24) is possible, only the plausibility of the inequality will be demonstrated here for the concrete case $K=3$ and elimination of one out of three binary agents; a simple demonstration is sufficient to show the essential features of the general proof. For brevity of notation, the dependence of $G$ on $m$ will be dropped. To begin, note that the total CCDF associated with three binary agents can be expanded in terms of eight scenario classes and written as

$$
\begin{aligned}
G_{3} & =\left(1-p_{1}\right)\left(1-p_{2}\right)\left(1-p_{3}\right) C_{1}+p_{1}\left(1-p_{2}\right)\left(1-p_{3}\right) C_{2} \\
& +\left(1-p_{1}\right) p_{2}\left(1-p_{3}\right) C_{3}+\left(1-p_{1}\right)\left(1-p_{2}\right) p_{3} C_{4} \\
& +p_{1} p_{2}\left(1-p_{3}\right) C_{5}+p_{1}\left(1-p_{2}\right) p_{3} C_{6}+\left(1-p_{1}\right) p_{2} p_{3} C_{7} \\
& +p_{1} p_{2} p_{3} C_{8},
\end{aligned}
$$

where $C_{i}, 1 \leq i \leq 8$, are shorthand for conditional CCDFs associated with each of eight scenario classes. Now suppose that agent number three is to be eliminated on the basis of small probability, i.e., p3 $\rightarrow 0$. The reduced, total CCDF can then be expanded in terms of four scenario classes:

$$
G_{2}=\left(1-p_{1}\right)\left(1-p_{2}\right) D_{1}+p_{1}\left(1-p_{2}\right) D_{2}+\left(1-p_{1}\right) p_{2} D_{3}+p_{1} p_{2} D_{4}
$$

where the $D_{j}, 1 \leq j \leq 4$, are shorthand for the conditional CCDFs associated with each of the four classes in the reduced problem. Next, note that because agent number three does not occur in the calculation of the conditional CCDFs 
$C_{1}, C_{2}, C_{3}, C_{5}$ or any of the $D_{j} s$,

$$
C_{1}=D_{1}, \quad C_{2}=D_{2}, \quad C_{3}=D_{3}, \quad C_{5}=D_{4} .
$$

Next, take the difference of Eqs. (25) and (26). On taking the equalities in Eq. (27) into account and rearranging terms,

$$
\begin{gathered}
G_{3}-G_{2}=p_{3}\left(\left(1-p_{1}\right)\left(1-p_{2}\right)\left[C_{4}-C_{1}\right]+p_{1}\left(1-p_{2}\right)\left[C_{6}-D_{2}\right]\right. \\
\left.+\left(1-p_{1}\right) p_{2}\left[C_{7}-D_{3}\right]+p_{1} p_{2}\left[C_{8}-C_{5}\right]\right) ;
\end{gathered}
$$

and so, by the triangle inequality (Abramowitz and Stegun, 1964, formula 3.2 .6$, p. 11),

$$
\begin{gathered}
\left|G_{3}-G_{2}\right| \leq p_{3}\left|\left(1-p_{1}\right)\left(1-p_{2}\right)\right| C_{4}-C_{1}\left|+p_{1}\left(1-p_{2}\right)\right| C_{6}-D_{2} \mid \\
\left.+\left(1-p_{1}\right) p_{2}\left|C_{7}-D_{3}\right|+p_{1} p_{2}\left|C_{8}-C_{5}\right|\right] .
\end{gathered}
$$

Because the $C_{i} s$ and $D_{j} s$ are conditional CCDFs (non-negative functions $\leq 1$ ), $\left|C_{i}-C_{j}\right| \leq 1$ and $\left|C_{i}-D_{j}\right| \leq 1$. Accordingly, Eq. (28) becomes

$\left|G_{3}-G_{2}\right| \leq p_{3}\left[\left(1-p_{1}\right)\left(1-p_{2}\right)+p_{1}\left(1-p_{2}\right)+\left(1-p_{1}\right) p_{2}+p_{1} p_{2}\right] ;$

and so, upon recognition that terms in $(\ldots)$ sum to one,

$$
\left|G_{3}-G_{2}\right| \leq P_{3} \text {. }
$$

The inequality in Eq. (24) can be extended to give an upper-bound estimate of the error incurred when more than one agent is eliminated. If $\mathrm{L}$ agents, $1 \leq \mathrm{L}$ $<\mathrm{K}$, are to be eliminated on the basis of their elementary probabilities, $\mathrm{p}_{\mathrm{k}_{1}}$,

$$
\begin{aligned}
& p_{k_{2}}, \ldots, p_{k_{L}}, \\
& \qquad\left|G_{K}(m)-G_{K-L}(m)\right| \leq p_{k_{1}}+p_{k_{2}}+p_{k_{3}}+\ldots+p_{k_{L}} .
\end{aligned}
$$

Some practical implications of these results follow: elimination of an agent having elementary probability $=0.0001$ (threshold allowed by the EPA, Chapter 2) will lead to a relative error in the CCDF of no more than 10 percent at the point where $G(\mathrm{~m})$ equals the regulatory value 0.001 [Eq. (3)], and elimination of ten agents that each have elementary probability $=0.0001$ would lead to no more than a 100 percent relative error at that point. The relative error in this case is seen to be independent of the Monte Carlo method used to 
construct the CCDF; therefore, it should be added to the relative error that arises when a finite number of sample state-variable vectors are used to construct the empirical CCDF [Chapter 3, Eq. (14)].

\section{Reducing the Number of Scenario Classes}

A careful, logical examination of the nature of agents that occur in a scenario class and ways in which those agents may interact to result in consequences that may be different from consequences of the undisturbed scenario classes may reduce the number of scenario classes. To see how such a reduction might be accomplished, consider the following simple example in which the total CCDF is expanded in terms of the 12 scenario classes whose probabilities are the terms in the sum on the right-hand side of Eq. (23):

$$
G(m)=\sum_{j=1}^{12} G_{j}(m) P_{j}
$$

where the $G_{j}(m) s$ are the 12 conditional CCDFs associated with the scenario classes, and the $\mathrm{P}_{j} \mathrm{~s}$ are shorthand for the 12 scenario-class probabilities, namely,

$$
\begin{aligned}
& \mathrm{P}_{1}=\left(1-\mathrm{p}_{1}\right)\left(1-\mathrm{p}_{2}\right) \mathrm{p}_{11}, \mathrm{P}_{2}=\left(1-\mathrm{p}_{1}\right)\left(1-\mathrm{p}_{2}\right) \mathrm{p}_{12} \\
& \mathrm{P}_{3}=\left(1-\mathrm{p}_{1}\right)\left(1-\mathrm{p}_{2}\right) \mathrm{p}_{13}, \text { the undisturbed-class probabilities, }
\end{aligned}
$$

and the disturbed-class probabilities

$$
\begin{aligned}
& \mathrm{P}_{4}=\left(1-\mathrm{p}_{1}\right) \mathrm{p}_{2} \mathrm{p}_{11}, \mathrm{P}_{5}=\left(1-\mathrm{p}_{1}\right) \mathrm{p}_{2} \mathrm{p}_{12}, \mathrm{P}_{6}=\left(1-\mathrm{p}_{1}\right) \mathrm{p}_{2} \mathrm{p}_{13}, \\
& \mathrm{P}_{7}=\mathrm{p}_{1}\left(1-\mathrm{p}_{2}\right) \mathrm{p}_{11}, \quad \mathrm{P}_{8}=\mathrm{p}_{1}\left(1-\mathrm{p}_{2}\right) \mathrm{p}_{12}, \mathrm{P}_{9}=\mathrm{p}_{1}\left(1-\mathrm{p}_{2}\right) \mathrm{p}_{13}, \\
& \mathrm{P}_{10}=\mathrm{p}_{1} \mathrm{p}_{2} \mathrm{p}_{11}, \quad \mathrm{P}_{11}=\mathrm{p}_{1} \mathrm{p}_{2} \mathrm{p}_{12}, \quad \mathrm{P}_{12}=\mathrm{p}_{1} \mathrm{p}_{2} \mathrm{p}_{13} .
\end{aligned}
$$

Now suppose that the agent having elementary probability $\mathrm{p}_{2}$ can be shown (by logical or physical reasoning) to have little or no effect on releases to the accessible environment except when it occurs in conjunction with the agent having elementary probability $p_{1}$ (e.g., the former may be an inert feature or neutral agent that requires the latter to make it a factor in determining the magnitude of the release to the accessible environment); the logical implication of this demonstration is that the three scenario classes involving only the occurrence of the agent with probability $\mathrm{p}_{2}$ will have associated conditional CCDFs that are identical with their undisturbed-class counterparts, i.e., 


$$
G_{4}(m)=G_{1}(m), \quad G_{5}(m)=G_{2}(m), \quad G_{6}(m)=G_{3}(m) .
$$

The need to calculate 3 of the 12 conditional CCDFs thereby is eliminated. Scenario-class probabilities $P_{4}, P_{5}$, and $P_{6}$ will add to the corresponding undisturbed-class probabilities to given new undisturbed-class probabilities,

$\mathrm{P}_{1}^{\prime}=\mathrm{P}_{1}+\mathrm{P}_{4}=\left(1-\mathrm{p}_{1}\right) \mathrm{P}_{11}, \mathrm{P}_{2}^{\prime}=\mathrm{P}_{2}+\mathrm{P}_{5}=\left(1-\mathrm{p}_{1}\right) \mathrm{p}_{12}, \mathrm{P}_{3}^{\prime}=\left(1-\mathrm{p}_{1}\right) \mathrm{p}_{13}$,

and the sum of all scenario-class probabilities is still one, as is easily verified.

The reader may use the framework of this example to investigate the way the the number of scenario classes may be reduced by examination of combinations of other kinds of inert or neutral agents. Of particular interest is the situation in which an agent is determined to be inactive except in the presence of a certain level of one of the processes. [Recall that levels of a process are specified by a finite number of "bins" in the representation of the CCDF by Eq. (15); the elementary probabilities of the bins in the example are the $p_{1 j}, 1 \leq j \leq 3$.]

The situation exemplified above arises in connection with the WIPP system where, for reasons cited (Chapter 4), the feature "brine pocket below rooms or drifts" is determined to be inert with respect to events "mining alters ground-water regime" and "water-withdrawal wells provide alternate pathways." 


\section{APPLICATIONS TO THE WIPP SYSTEM}

\section{Events and Features That May Affect Releases from the WIPP}

Hunter (1989) reexamined events, processes and features considered by previous workers to be significant agents of releases of radioactivity from a repository in bedded salt. The 24 agents examined plus one event added by Guzowski (1990) are named respectively and their types identified here (Table 4-1). Results of Hunter's preliminary screening of agents (column three of Table 4-1) and Guzowski's work indicate that only seven processes (if "seal performance" is regarded as a process), three events, and one feature should play significant roles in determining releases of radioactivity from the WIPP system.

The only independent processes (Appendix B) among the seven processes that survive (Table 4-1) are climatic change and, possibly, nuclear criticality. The possibility that nuclear criticality could occur at the hipP site is judged by Project investigators to be small. So far, WIPP investigators (Marietta et al., 1989; Hunter, 1989; Guzowski, 1990) have assumed that al1 surviving processes (Table 4-1) except nuclear criticality will occur with certainty at some level throughout the period of performance. Consequently, processes of climatic change, ground-water flow, seal performance, leaching, waste/rock interactions, and gas generation are assumed to act in every scenario for release of radioactivity from WIPP; in other words, they are phenomena common to all scenario classes and uniquely specify conditions for the undisturbed-performance scenario classes (called the "base case" by Guzowski, 1990). Consequence models of these six processes have received the most attention from WIPP investigators (Lappin et al., 1989, Appendices D and E; Rechard et al., 1990). Phenomenological and probability models of all six processes are still in the process of development.

The three events and one feature that survive (Table 4-1) are not assumed to occur with certainty during the period of performance; WIPP analysts (Marietta et al., 1989; Guzowski, 1990) have therefore used these four agents to form the basis of disturbed-performance scenario classes. Current calculations of the conditional CCDFs for these classes (Marietta et a1., 1989) have so far not been limited by the availability of consequence models; most of the consequence models that apply to the undisturbed-performance scenario classes can be adapted for use in determining consequences of disturbed-performance classes. What seems to be lacking in current preliminary performance assessments of the WIPP system are realistic (i.e., non-conservative) and acceptable probability models of these four agents. The following paragraphs will discuss some requirements of realistic probability models for the three events and one feature. 
TABLE 4-1. STATUS OF AGENTS THOUGHT TO AFFECT RELEASES FROM

A BEDDED-SALT REPOSITORY (modified from

Table 3 of Hunter, 1989)

Name of Agent

Type $(1)$

Dismissed(2)

Retained(3)

Dissolution Other Than Leaching

Migration of Brine Aquifer

Breccia-Pipe Formation

Migration of Intracrystalline

Brine Inclusions

Induced Diapirism

Diffusion Out of Repository

Exhumation, Sedimentation

Faulting

Glaciation

Igneous Intrusion

Meteorite Impact

Sabotage, Warfare

Subsidence

Thermal Effects

Ground-Water Flow

Climatic Change

$P \quad P U, N C$

p NC

p,e,f PU,LP,NC

p PU,NC

p PU

p PU

p NC

p,e,f PU,LP

p NC,RG

$p, e, f \quad$ LP

e LP

e RG

$\mathrm{p} \quad \mathrm{NC}$

$\mathrm{p} \quad \mathrm{NC}$

p r e $x$

p r $x$

(1) $p=$ process, $e=$ event, $f=$ feature.

(2) Reasons for dismissal (Hunter, 1989):

$\mathrm{PU}=$ physical unreasonability

$\mathrm{LP}=$ low probability

$\mathrm{NC}=$ negligible consequences

$R G=$ regulatory guidance

(3) Retained (Hunter, 1989). 
TABLE 4-1. STATUS OF AGENTS THOUGHT TO AFFECT RELEASES FROM A BEDDED-SALT REPOSITORY (continued)

\begin{tabular}{|c|c|c|c|}
\hline Name of Agent & Type(1) & Dismissed(2) & Retained (3) \\
\hline Drilling into Repository & $\theta$ & & $x$ \\
\hline Brine Pockets & $f$ & & $x$ \\
\hline Mining for Resources & $\boldsymbol{\theta}$ & & $x$ \\
\hline Seal Performance & p.e & & $x$ \\
\hline Leaching & $p$ & & $x$ \\
\hline Nuclear Criticality & $p$ & & $x$ \\
\hline Waste/Rock Interaction & $\mathrm{p}$ & & $x$ \\
\hline $\begin{array}{l}\text { Waste Effects (e.g. } \\
\text { gas generation, radiolysis) }\end{array}$ & $p$ & & $x$ \\
\hline $\begin{array}{l}\text { Placement of Water Withdrawal } \\
\text { Wells }(4)\end{array}$ & e & & $x$ \\
\hline \multicolumn{4}{|c|}{ (1) $p=$ process, $e=$ event,$f=$ feature. } \\
\hline \multicolumn{4}{|c|}{$\begin{array}{l}\text { (2) Reasons for dismissal (Hunter, 1989): } \\
P U=\text { physical unreasonability } \\
L P=\text { low probability } \\
N C=\text { negligible consequences } \\
R G=\text { regulatory guidance }\end{array}$} \\
\hline \multicolumn{4}{|l|}{ (3) Retained (Hunter, 1989). } \\
\hline (4) Event added (Guzowski, 1990). & & & \\
\hline
\end{tabular}

\section{ATTEMPTED BOREHOLES OVER ROOMS AND DRIFTS}

This problematic event deserves a rather detailed discussion of its meaning and ways in which it could be included in a realistic performance assessment. Hunter (1989) calls this event "drilling into repository." Guzowski (1990) splits the event into two dependent events, namely "drilling into a room or drift" (labelled E2 in Guzowski's notation) and "drilling through a room or drift and into a brine reservoir" (labelled El by Guzowski). 
In this report a broader definition of the event will be adopted. The event will be called "attempted boreholes over rooms and drifts," denoted by $E_{1}$, and defined as follows:

$E_{1}$ occurs if and only if at least one attempt is made in the period of performance to drill through the area which is the projection of WIPP rooms and drifts onto the surface of the controlled area.

Some probability models for estimating the elementary probability of $E_{1}$ and the distribution of the number of attempts during the period of performance are developed in Appendix $C$ of this report.

Defined in this way, $E_{1}$ includes a variety of possible outcomes and therefore a variety of possible consequences. Given the occurrence of $E_{1}$, the attempt(s) could be aborted before any significant penetration of the earth's surface occurs or drilling to the desired depth could occur. If the attempt is aborted, no consequences ensue. Given a successful attempt, drilling could by intention be completed when the borehole has penetrated 1) some but not all of the rock layers that lie above rooms and drifts, or 2) rooms and drifts themselves, or 3 ) rock layers that lie below the rooms and drifts. In case 1), probably no significan: consequences will occur; whereas, in cases 2) and 3), some waste material could be drawn to the surface along with drilling mud and borehole core materials, and recognition of such unusual conditions could lead to termination of drilling operations before reaching the intended depth. If drilling operations are not terminated on passing through the repository level and case 3 ) is intended, the borehole also could penetrate any pressurized brine pockets below the repository, possibly initiating flow of brine into rooms and drifts and a consequent transport of dissolved waste up the borehole, into overlying water-bearing rock layers and, possibly, to the surface. If pressurized brine pockets are not present or are not encountered, consequences of case 3 ) will probably be no different than consequences attending case 2).

Obviously, consequences of the occurrence of $E_{1}$ will depend upon other variables and factors besides the number and times of the attempts to drill during the period of performance: size of the borehole, manner of drilling, levels of radioactivity in wastes at the time of drilling, drilling crew's promptness in responding to unusual operational circumstances, and treatment of the borehole after drilling is completed (i.e., whether, by what means, and to what extent the borehole is sealed). Realistic, non-conservative probability models of $E_{1}$ should take account $C$ f all such variables and factors insofar as they are proven to be sensitive determinants of consequences and probabilities of outcomes of a drilling episode. WIPP investigators have studied various "worst case" consequences of the occurrence of $E_{1}, i . \ldots, a$ borehole that penetrates a room or drift in the repository and also penetrates 
pressurized brine in the Castile Formation; in these studies, the event occurs only once during the period of performance, and the time of occurrence is drawn from a uniform distribution on the interval from 0 to 10,000 years (Marietta et al., 1.989, Scenario E1).

\section{Explanation of Table 4-2}

An attempt has been made (Table 4-2) to make a structured list of some of the uncertain variables that could appear in a more realisti: probability model of $E_{1}$ (this 1 ist is intended merely to be suggestive of variables that might be used in a complete probability model of $E_{1}$; WIPP investigators may want to add to the 1ist, delete some of its entries, or create their own models depending upon outcomes of further sensitivity analyses of human-intrusion scenario classe:). The list of variables is structured so that it can be read as instructions for efficient sampling of variables in a Monte Carlo calculation of conditional CCDFs for disturbed-case scenario classes that postulate the occurrence of $E_{1}$. The 1 ist may also be read as a verbal event tree (similar to Figure C-3, Appendix $C$ ) or as a verbal flow chart for a computer program. Each of the more than 11 variables (Table 4-2) is assumed to have a probability distribution associated with it so that, for example, variable (4) would be specified by drawing a random number, comparing that number with the probability distribution of variable (4), and deciding whether the attempt is aborted or is successful.

Variable ( 1 ) is set automatically to one for calculations that assume occurrence of $E_{1}$, and variable (2) simply specifies how many attempts are made during the period of performance for this particular realization of an attempted-drilling scenario; variable (3) provides the time of occurrence of each attempt for possible use in calculating radioactivity in the repository at the time of each attempt and the current state of other processes. The logic of the probability model really begins with variable (4), which tells whether the attempt has been successful: if unsuccessful, the logic of the calculation is terminated, and one would go on to evaluate the next attemit [provided that variable $(2)>1$ ]; if successful, then one continues with the evaluation of the current attempt, and draws variable (5), intended depth of penetration of the borehole. Variable (5) is used to determine whether the bcrehole will or will not penetrate rooms and drifts. If the borehole does not penetrate rooms and drifts, the logic of the calculation is terminated, and one would go on to evaluate the next attempt [provided that variable (2) $>1$ ]. If the borehole penetrates rooms and drifts, variables (6) through (8) are drawn, and consequences (in terms of releases of radioactivity to the accessible environment) are calculated and saved as part of the contribution of this particular scenario to the conditional CCDF. If variable (8) indicates that drilling is terminated at the level of the repository, 


\section{TABLE 4-2. VARIABLES IN A PROBABILITY MODEL OF THE EVENT "ATTEMPTED BOREHOLES OVER ROOMS AND DRIFTS" (see text for an explanation)}

1. A binary variable for deciding whether the event does or does not occur during the period of performance.

If the event occurs, specify

2. The number of attempts made $(\geq 1)$ during the period of performance,

3. The time of occurrence of each attempt,

$$
\text { and, for each attempt, }
$$

4. A binary variable for deciding whether the attempt is aborted or is successful.

If an attempt is successful, specify

5. Depth of penetration of the borehole.

If the borehole penetrates the rooms and drifts, specify

6. Variables giving details of drilling operations (e.g., diameter of borehole, drilling fluids used, casing of the borehole, etc.):

7. Variables giving time required to recognize and respond to unusual drilling conditions (e.g., radioactivity of drilling mud or unusual debris in core); and

8. A binary variable for deciding whether drilling operations are (or are not) terminated at the level of the repository, given recognition of unusual drilling conditions.

If drilling is terminated at the level of the repository, specify

9. Variables giving details of the post-drilling treatment of the borehole (e.g., use and nature of seals and plugs).

If drilling is not terminated at the level of the repository, specify

10. A binary variable for deciding whether the borehole penetrates (or does not penetrate) a pressurized brine pocket.

If the borehole penetrates a pressurized brine pocket, specify

11. Variatles giving the time to recognize and respond to the fact that the borehole has punctured a pressurized brine pocket (i.e., the time required to close and seal the borehole), and variables giving details of the post-drilling treatment of the borehole.

variable (9) is drawn, conditions of the borehole after drilling operations have terminated are recorded for possible future use, and the logic of the calculation is terminated. Provided that variable (2) $>1$ and all attempts have not been evaluated, the next attempt is evaluated. 
If drilling is not terminated at the level of the repository, either through oversight or by intention as determined by variable (8), variable (10) is drawn and used to decide whether the borehole has punctured a pressurized brine pocket [note that a puncture would be impossible unless a feature to be discussed in the next section, "Brine Pocket Below Room or Drift," is present; i.e., variable (10) is conditioned on the presence of this feature]. If the borehole reaches its intended depth and has not punctured a pressurized brine pocket, the post-drilling conditions of the borehole are recorded for possible future use, the logic of the calculation for this attempt is terminated, and the next attempt is evaluated [provided that variable (2) $>1$ and all attempts have not been evaluated].

Finally, if the borehoie punctures a pressurized brine pocket as determined by variable (10), variables (11) are drawn along with variables associated with the feature "Brine Pocket Below Room or Drift" (next section). These variables are used to determine consequences of intercepting a brine pocket in terms of releases of radioactivity to the accessible environment; the consequences are added to consequences of previous attempts as part of the contribution of this scenario to the conditional CCDF, and the logic of the calculation for this attempt is terminated. One would then go on to evaluate the next attempt, provided that variable (2) $>1$ and all attempts have not yet been evaluated.

\section{BRINE POCKET BELOW ROOM OR DRIFT}

Hunter (1989) calls this feature "brine pockets" or "effects of brine pockets"; Guzowski (1990) calls it "drilling through room or drift and into brine reservoir" and labels it El. In this report, the feature will be called "brine pocket below room or drift" and denoted by $F_{2}$. The feature can be defined formally as follows:

$F_{2}$ is present if and only if the area which is the projection of all brine pockets onto the surface of the controlled area overlaps the area which is the projection of the WIPP rooms and drifts onto the controlled area.

Assuming that drilling attempts would be placed randomly in the controlled area, the elementary probability of $F_{2}$ becomes the fraction of the projected area of the WIPP rooms and drifts that is overlapped by the projected areas of all brine pockets under the controlled area. Time domain electromagnetic surveys at WIPP have indicated that roughly 50 percent of the WIPP's wastepanel area could be overlapped by the area of brine reservoirs in the Castile Formation (Earth Technology Corporation, 1988). Thus, the elementary probability of $F_{2}$ could be relatively large at the WIPP site. 
Feature $F_{2}$ is obviously inert: its presence alone, in the absence of other agents, will not alter consequences of the undisturbed-performance scenario classes in any known way. It becomes a significant agent only in conjunction with event $E_{1}$, and only if it is punctured by a borehole. Consequences of puncturing a brine pocket with a borehole, therefore, will depend not only upon physical characteristics of the pocket (e.g., depth and volume), but also upon other variables (Table 4-2): namely, details of drilling operations [variable (6) in Table 4-2]; time it takes the drilling crew to recognize and respond to the fact that the pocket has been breached [cited among variables (11) in Table 4-2]; and post-drilling treatment of the borehole [also cited among variables (11) in Table 4-2].

Distributions of physical parameters of brine reservoirs in the Castile Formation are unknown. Based on limited data, Lappin et al. (1989, Table 3-19) have tried to estimate ranges of physical characteristics of brine reservoirs in the Northern Delaware Basin. Ranges of initial pressures and effective thicknesses of reservoirs given in their summary table (Table 3-19) might be used to infer distributions of depth and volume for use in a probability model of $\mathrm{F}_{2}$.

\section{MINING ALTERS GROUND-WATER REGIME}

WIPP investigators disagree on the definition of this event. Hunter (1989) defines the event to be solution mining for potash outside WIPP's controlled area (with possible inadvertent intrusion of the mine into the controlled area); subsequent collapse of overburden of the mine could change hydraulic conductivity of water-bearing strata downgradient from the repository, and thereby possibly change consequences of any releases of radioactivity along water pathways. Guzowski (1990), who calls the event "potash mining outside the WIPP boundary" and labels it TS, declines to specify the type of mining (conventional versus solution mining) and emphasizes increased recharge to the water-bearing strata through the collapsed mine as the major factor that could alter the ground-water regime (as opposed to Hunter's emphasis on increases in hydraulic conductivity).

In this report, the event is called simply "mining alters ground-water regime," denoted symbolically as $E_{3}$, and defined as follows:

$E_{3}$ occurs if and only if at least one episode of mine-induced alterations of ground-water flow occurs during the period of performance.

Further discussion of probability models for $E_{3}$ at this time seems inappropriate in light of the experts' differing opinions concerning the nature of this event. The size and nature of the mining operation and its 
location relative to the WIPP controlled area would seein to be important factors for deciding whether significant alterations of ground-water flow could occur. Further calculations with computer models of the ground-water regime at the WIPP site may show that reasonably expected mining practices would have little effect on those properties of the ground-water system (e.g., distribution of groundwater travel times from the repository to the accessible environment) that determine consequences of a release of radioactive waste from the system along the ground-water pathway under undisturbed-performance conditions. A demonstration of insignificant effects would justify elimination of the event from consideration in performance-assessment calculations.

The current range of assumptions about the nature of $E_{3}$ indicates that it is intended to be a neutral event; its presence alone or in conjunction with other inert or neutral agents in disturbed-case scenario classes would not produce consequences that are different from consequences of undisturbedperformance classes, although it could affect consequences of a disturbed-case scenario class involving conjunctions of $E_{1}, F_{2}$, and $E_{4}$.

\section{WATER-WITHDRAWAL WELLS PROVIDE ALTERNATE PATHWAYS}

In addition to the two events and one feature thought to be significant by Hunter (1989), Guzowski (1990) has postulated a third event which he labels E3 and calls "emplacement of withdrawal well downgradient from repository." Although few details of the characteristics of this event are supplied, he apparently considers one or more small wat $r$-withdrawal wells drilled into the Culebra Dolomite Member and (because of $F$ or water quality) intended primarily for use as water for livestock; these wells would presumably be outside the controlled area, $5 \mathrm{~km}$ or more from the waste panels. Although a few wells of this kind would probably not affect the consequences of undisturbedperformance scenario classes (i.e., significantly change present water-table levels or rock hydrologic properties), they could possibly influence outcomes of disturbed-performance classes, i.e., in the event of a lccal release of radioactivity from the repository along ground-water pathways.

In this report, the event will be called "water-withdrawal wells provide alternate pathways," denoted symbolically by $E_{4}$, and defined as follows:

$\mathrm{E}_{4}$ occurs if and only if at least one water-withdrawal well is successfully drilled and operated in the vicinity of the WIPP controlled area during the period of performance.

Defined in this way, $\mathrm{E}_{4}$ is seen to include a variety of logically different events, and therefore a variety of consequences. But, for present purposes and pending further interpretations of the event by WIPP investigators, 
Guzowski's (1990) definition of conditions associated with the event will be maintained.

Guzowski (1990, p. 46) notes that $E_{4}$ is a neutral event: "...withdrawal wells by themselves will not affect the escape of radionuclides from the waste panels, ..." and "this event must be combined with other events and processes that result in the escape of radionuclides." Processes that operate in the undisturbed-performance scenario classes do not appear to lead to releases of radionuclides to the accessible environment:

The demonstration analysis for undisturbed conditions indicates no releases from the repository in either the 1,000-yr period for Individual Protection Requirements (para. 191.15) or the 10,000-yr period for Containment Requirements (para. 191.13). (Marietta et a1., 1989, p. V-1)

Thus, Guzowski's "other events and processes" must be events that can directly alter the undisturbed-performance classes, i.e., $E_{3}$ and $E_{1}$ in conjunction with feature $F_{2}$.

Guzowski (1990, p. 46) also remarks that "the number of wells, their geographic distribution, their pumping rate, their life expectancy, and their depth probably will be randomly selected as part of the consequence analysis of the scenarios that include this event." Some of these uncertain variables are listed in a structured form (Table 4-3).

Variable (1) (Table 4-3) is automatically set to one for those scenario classes that postulate the occurrence of $E_{4}$ in conjunction with other agents that lead to significant releases to the accessible environment. Variable (2), always $\geq 1$, specifies how many withdrawal vells are emplaced during the period of performance for this particular realization of a scenario involving the occurrence of $E_{4}$. The following procedure is repeated for each withdrawal well numbered by variable (2): draw variables (3) through (6) from their respective distributions to obtain a realization of conditions associated with the withdrawal well and use those variables to calculate consequences of the realization in terms of releases of radioactivity to the accessible environment; the consequences are saved as part of the contribution of this particular scenario to the conditional CCDF. (Note: because of ambiguity in the interpretation of EPA's definition of undisturbed performance, WIPP analysts also may wish to record consequences of withdrawal-well scenarios in a separate file for later use in evaluating compliance with EPA's Individual Protection Requirements and Ground Water Protection Requirements; these requirements are specified in $\S 191.15$ and $\S 191.16$ of the Standard [EPA, 1985].) 
TABLE 4-3. VARIABLES IN A PROBABILITY MODEL OF THE EVENT "WATER-WITHDRAWAL WELLS PROVIDE ALTERNATE PATHWAYS" [suggested by Guzowski (1990)] (see text for an explanation)

1. A binary variable for deciding whether the event does or does not occur during the period of performance.

\section{If the event occurs, specify}

2. The number of successful withdrawal wells $(\geq 1)$ emplaced during the period of performance,

3. The time of emplacement of each withdrawal well,

and, for each withdrawal well:

4. Variables giving coordinates of location relative to the center of the WIPP controlled area;

5. Variables that specify the water-bearing formation from which water is to be withdrawn; and

6. Variables giving the duration of water withdrawal (i.e., lifetime of the withdrawal well) and average pumping rate during the well's lifetime.

\section{Preliminary Scenario Classes for the WIPP System}

The three events and one feature inferred to be significant agents by Hunter (1989) and Guznwski (1990) can be combined to form $2^{4}=16$ scenario classes according to methods outlined (Chapter 3), provided that the four agents are statistically independent. Guzowski (1990, Figure 19) forms 16 scenario classes in tlis way in his report, but two events are included that clearly are dependent (events E1 and E2 in his notation). For this reason, a reexamination of Guzowski's preliminary scenario classes for the WIPP system based on the four agents seems advisable.

Table 4-4 is a list of the 16 scenario classes that arise from the four agents, $E_{1}, F_{2}, E_{3}$ and $E_{4}$. The terminology and notation introduced in earlier sections of this report will be used in a discussion of Table 4-4; the classes are denoted by $s_{j}, j=0,1,2, \ldots 16$, and numbered in an arbitrary fashion in column one. Agents involved in each class are named in column two: for instance, $E_{1} F_{2}$ means that the only disruptive agents involved in $S_{5}$ are "attempted boreholes over rooms and drifts" and "brine pockets below rooms and drifts." The probability of each class, $P\left(S_{j}\right)$, is given in column three (Table 4-4); these probabilities are formed from the elementary probabilities of agents $E_{1}, F_{2}, E_{3}$, and $E_{4}$, and are respectively denoted by $p_{1}, p_{2}, p_{3}$, and $p_{4}$. 
Assessments of the contribution of each scenario class to total CCDF for cumulative releases of radioactivity from the WIPP system are made in column four; the reasoning behind these assessments is provided below.

TABLE 4-4. PRELIMINARY SCENARIO CLASSES FOR THE WIPP SYSTEM (see text for an explanation)

\begin{tabular}{|c|c|c|c|}
\hline Class & Agents Involved (1) & Probability-P(S $\left(S_{j}\right)(2)$ & Contribution to $\operatorname{CCDF}(3)$ \\
\hline $\mathrm{S}_{0}$ & none (base case) & $q_{1} q_{2} q_{3} q_{4}$ & none \\
\hline$s_{1}$ & $E_{1}$ & $p_{1} q_{2} q_{3} q_{4}$ & $>0$ \\
\hline $\mathrm{S}_{2}$ & $\mathrm{~F}_{2}$ & $q_{1} p_{2} q_{3} q_{4}$ & none \\
\hline$s_{3}$ & $E_{3}$ & $q_{1} q_{2} p_{3} q_{4}$ & none \\
\hline $\mathrm{S}_{4}$ & $E_{4}$ & $q_{1} q_{2} q_{3} p_{4}$ & none \\
\hline $\mathrm{S}_{5}$ & $E_{1} F_{2}$ & $p_{1} p_{2} q_{3} q_{4}$ & $>0$ \\
\hline$s_{6}$ & $E_{1} E_{3}$ & $p_{1} q_{2} p_{3} q_{4}$ & $>0$ \\
\hline $\mathrm{S}_{7}$ & $E_{1} E_{4}$ & $p_{1} q_{2} q_{3} p_{4}$ & $>0$ \\
\hline $\mathrm{S}_{8}$ & $\mathrm{~F}_{2} \mathrm{E}_{3}$ & $q_{1} p_{2} p_{3} q_{4}$ & none \\
\hline $\mathrm{S}_{9}$ & $\mathrm{~F}_{2} \mathrm{E}_{4}$ & $q_{1} p_{2} q_{3} p_{4}$ & none \\
\hline$s_{10}$ & $E_{3} E_{4}$ & $q_{1} q_{2} p_{3} p_{4}$ & none \\
\hline$s_{11}$ & $E_{1} F_{2} E_{3}$ & $p_{1} p_{2} p_{3} q_{4}$ & $>0$ \\
\hline$s_{12}$ & $\mathrm{E}_{1} \mathrm{~F}_{2} \mathrm{E}_{4}$ & $p_{1} p_{2} q_{3} p_{4}$ & $>0$ \\
\hline$s_{13}$ & $E_{1} E_{3} E_{4}$ & $p_{1} q_{2} p_{3} p_{4}$ & $>0$ \\
\hline$s_{14}$ & $\mathrm{~F}_{2} \mathrm{E}_{3} \mathrm{E}_{4}$ & $q_{1} p_{2} p_{3} p_{4}$ & none \\
\hline$s_{15}$ & $E_{1} F_{2} E_{3} E_{4}$ & $p_{1} p_{2} p_{3} p_{4}$ & $>0$ \\
\hline (1) & \multicolumn{3}{|c|}{$\begin{array}{l}\text { Agents involved from the set }\left\{E_{1}, F_{2}, E_{3}, E_{4}\right\} \text {. The } 7 \text { processes identified by Hunter (1989) } \\
\text { and Guzowski (1990) are assumed to be acting in all scenario classes. }\end{array}$} \\
\hline (2) & \multicolumn{3}{|c|}{ For brevity in the table, $q_{i}=\left(1-p_{i}\right), i=1,2,3,4$. } \\
\hline $\begin{array}{l}T \\
c \\
t \\
f\end{array}$ & \multicolumn{3}{|c|}{$\begin{array}{l}\text { The contribution of scenario class } S_{j} \text { to the total CCDF } G(m) \text { is "none" if logic or bounding } \\
\text { calculations show that the conditional CCDF } G\left(m \mid S_{j}\right) \text { vanishes for all } m>0 \text {. Otherwise, } \\
\text { the contribution is " }>0 \text { " and } S_{j} \text { may contribute to the form of the total CCDF. See the text } \\
\text { for the reasoning behind the assignment of the contributions listed in this column. }\end{array}$} \\
\hline
\end{tabular}




\section{CLASSES NOT CONTRIBUTING TO THE CCDF}

The reasoning behind the assessment of "none" (column four of Table 4-4) is explained in this section. To shorten the wording of these assessments, a certain convention will be used. The phrase "Sj makes no contribution" should be interpreted as an abbreviation of the phrase "the conditional CCDF for scenario class $S_{j}$ takes values that are negligible, say $<<10^{-3}$, for all $m>$ $0 . "$

Scenario class $\mathrm{S}_{0}$ (the base case or the undisturbed-performance class) is assumed to make no contribution on the basis of some preliminary calculations of : ts consequences (Marietta et al., 1989); these calculations, made with currently available consequence models and a fairly wide range of the variables that specify the significant processes, show that no releases from the repository will occur during the period of performance.

Scenario class $S_{2}$ will make no contribution to the total CCDF because only agent $F_{2}$ is involved; $F_{2}$ is an inert feature, and so $S_{2}$ would have consequences identical to those of $\mathrm{S}_{0}$.

Scenario class $S_{3}$ will make no contribution because only event $E_{3}$ is involved and, under present assumptions about the nature of $E_{3}$, that event is neutral. Consequently, $\mathrm{S}_{3}$ would have consequences identical to those of $\mathrm{S}_{0}$.

Scenario class $\mathrm{S}_{4}$ will make no contribution because only event $\mathrm{E}_{4}$ is involved and $\mathrm{E}_{4}$ is a neutral event. Consequently, $\mathrm{S}_{4}$ would have consequences identical to those of $\mathrm{S}_{0}$.

Scenario class $S_{8}$ will make no contribution because $F_{2}$ is an inert feature; consequently, $S_{8}$ would have consequences identical to those of $S_{3}$, and therefore identical to those of $\mathrm{S}_{0}$.

Scenario class $S_{9}$ will make no contribution because $F_{2}$ is inert and $E_{4}$ is neutral; consequences of $\mathrm{S}_{9}$ would therefore be identical to those of $\mathrm{S}_{0}$.

Scenario class $S_{10}$ will make no contribution because $E_{4}$ is a neutral event; consequences of $\mathrm{S}_{10}$ would be identical to those of $\mathrm{S}_{3}$, and therefore identical to those of $\mathrm{S}_{0}$.

Scenario class $\mathrm{S}_{14}$ will make no contribution because $\mathrm{F}_{2}$ is inert and $\mathrm{E}_{4}$ is neutral; consequences of $\mathrm{S}_{14}$ therefore would be identical to those of $\mathrm{S}_{3}$, which in turn are identical with those of $\mathrm{s}_{0}$. 


\section{CLASSES THAT MAY CONTRIBUTE TO THE CCDF}

Scenario class $S_{1}$ could contribute to the shape of the total CCDF because of a significant probability that waste could be brought to the surface during an occurrence of $E_{1}$. This assessment assumes that no significant releases of radioactivity along ground-water pathways will result from an occurrence of $E_{1}$ when not in conjunction with $F_{2}$.

Scenario class $S_{5}$ could contribute to the shape of the total CCDF: waste could be brought to the surface during an occurrence of $E_{1}$ and/or a brine pocket could be punctured during exploratory drilling, possibly leading to release of radioactivity along ground-water pathways.

Scenario class $S_{6}$ could contribute to the shape of the total CCDF. Because only local releases could attend the occurrence of $E_{1}$ and $E_{3}$ is currently assumed to be a neutral event, consequences of $\mathrm{s}_{6}$ would be identical to those of $\mathrm{s}_{1}$.

Scenario class $S_{7}$ could contribute to the shape of the total CCDF. Because $E_{4}$ is neutral, consequences of $S_{7}$ would be identical to those of $s_{1}$.

Classes $\mathrm{S}_{11}$ and $\mathrm{S}_{12}$ could contribute to the shape of the total CCDF regardless of whether $E_{3}$ or $E_{4}$ are assumed to be neutral events.

Scenario class $\mathrm{S}_{13}$ could contribute to the shape of the total CCDF. Because only local releases attend occurrence of $E_{1}$ and $E_{4}$ is neutral, the consequences of $\mathrm{S}_{13}$ would be identical to those of $\mathrm{S}_{6}$, which in turn are identical with those of $\mathrm{s}_{1}$.

Finally, class $S_{15}$ could contribute to the shape of the total CCDF regardless of whether $E_{3}$ and $E_{4}$ are assumed to be neutral events.

\section{Preliminary Conclusions Regarding the WIPP System's CCDF}

According to assessments of contributions made (column four of Table 4-4), conditional CCDFs will have to be calculated by Monte Carlo simulation for only five scenario classes: $\mathrm{s}_{1}, \mathrm{~s}_{5}, \mathrm{~s}_{11}, \mathrm{~s}_{12}$, and $\mathrm{s}_{15}$. Because classes $\mathrm{s}_{6}$, $\mathrm{S}_{7}$, and $\mathrm{S}_{13}$ will have the same conditional CCDFs as class $S_{1}$, there is no need to simulate consequences of these classes; however, in forming the total CCDF as a weighted sum of the conditional CCDFs [Eq. (15), Chapter 3], the conditional CCDF for class $\mathrm{S}_{1}$ should be weighted with

$$
P\left(S_{1}\right)+P\left(S_{6}\right)+P\left(S_{7}\right)+P\left(S_{13}\right)=p_{1}\left(1-p_{2}\right)
$$


as can be verified by summing the appropriate entries (column three of Table 4-4). The conditional CCDFs for classes $S_{5}, S_{11}, S_{12}$, and $S_{15}$ are weighted in the normal manner, i.e., with their respective probabilities (column three of Table 4-4).

The classes $S_{1}, S_{5}, S_{11}, S_{12}$, and $S_{15}$ may all have non-zero consequences, so the weighted sum of the conditional CCDFs associated with these classes will form that part of the total CCDF that represents the probability that the performance measure, $M$, is greater than zero; a hypothetical but qualitatively correct representation of the weighted sum of the conditional CCDFs for these classes is shown in Figure $4-1$ as the step-like curve, $G(m), m>0$. This curve represents the part of the total CCDF that will be tested against the Standard.

Note that the testable part of the CCDF, G(m), $m>0$, is a "defective distribution" (Feller, 1966, Figure 8, p. 112); i.e., its intercept on the $\mathrm{m}=$ 0 axis is less than 1 . In fact, summation of appropriate probabilities (column three of Table 4-4) will show that if the conditional CCDFs for classes $S_{1}, S_{5}, S_{11}, S_{12}$, and $S_{15}$ are not defective distributions, the intercept of the total CCDF on the $m=0$ axis is

$$
\begin{aligned}
\operatorname{Pr}(M>0) & =P\left(S_{1}\right)+P\left(S_{5}\right)+P\left(S_{6}\right)+P\left(S_{7}\right) \\
& +P\left(S_{11}\right)+P\left(S_{12}\right)+P\left(S_{13}\right)+P\left(S_{15}\right) \\
& =P_{1} .
\end{aligned}
$$

In the general case, one or more conditional CCDFs for the indicated scenario classes may prove to be defective distributions, and the intercept of the total CCDF on the $m=0$ axis may be less than $p_{1}$.

Eq. (30) indicates that under current assumptions about significant agents affecting releases of radioactivity from the WIPP, the system's total CCDF will be bounded above by the elementary probability of event $E_{1}$, "attempted boreholes over rooms and drifts." From this result, the discrete part of the total CCDF, i.e., the probability that no releases of radioactivity from the WIPP system will occur, is greater than or equal to $\left(1-p_{1}\right)$, with equality holding if none of the conditional CCDFs for scenario classes $s_{1}, s_{5}, s_{11}$, $S_{12}$, and $S_{15}$ is a defective distribution (Figure 4-1).

The foregoing analysis of the qualitative shape of the WIPP system's total CCDF substantiates the current inference of WIPP analysts (Bertram-Howery and Swift, 1990) that showing compliance of the WIPP system with the Standard will require a deeper understanding of the physical and probabilistic circumstances associated with future exploratory drilling at the WIP site. 


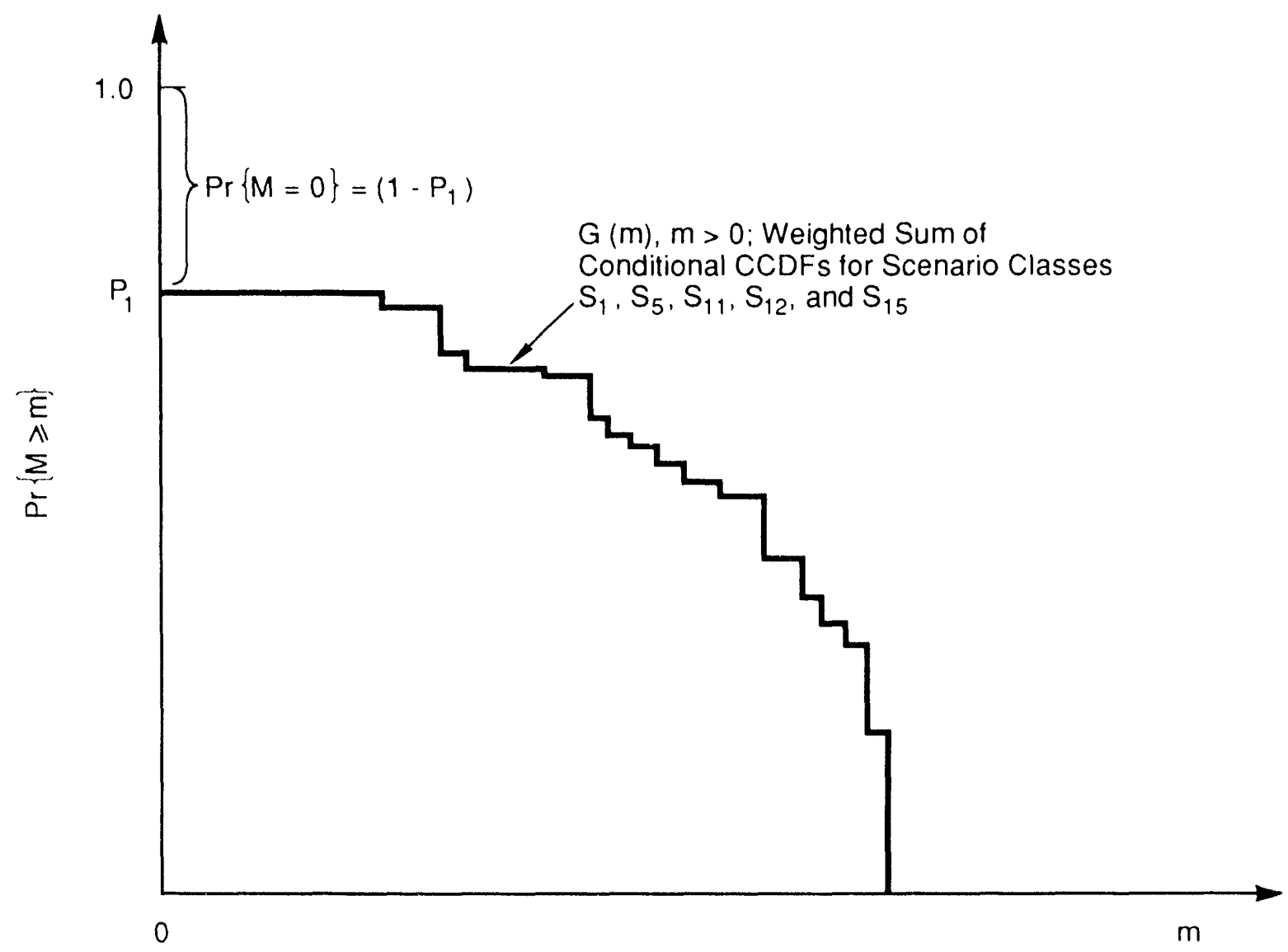

Magnitude of Normalized Cumulative Release

TRI.6342.604.0

Figure 4-1. A Hypothetical but Qualitatively Correct Representation of the Total CCDF for the WIPP System (see text for an explanation). 


\section{APPENDIX A: \\ WORKING DEFINITIONS OF SOME COMMON TERMS}




\title{
APPENDIX A: WORKING DEFINITIONS OF SOME COMMON TERMS
}

\author{
Certain terms that frequently appear in the waste-management literature, \\ such as "event," "process," and "scenario," are used in special ways in this \\ report. Special working definitions of these terms were necessary for the \\ purposes of keeping the main text brief, maintaining precision in \\ communication, and facilitating translation of regulatory language into \\ concepts usable in a quantitative performance assessment. With one \\ exception (scenario), all terms defined below will follow these meanings \\ throughuut the report.
}

\section{Event}

An event is any natural or anthropogenic phenomenon that takes place during an interval of time that is short compared to the period of performance of the system. For all practical purposes, events are phenomena that occur instantaneously or comparatively rapidly; therefore, to ask whether an event does or does not occur during a finite period of time is meaningful. Examples of events are earthquakes, extrusive volcanism, and exploratory drilling.

Event Variables. In general, an event is specified by giving 1) number of times the event occurs during a fixed interval of time (including zero times, or non-occurrence of the event), 2) times of occurrence relative to the beginning of that fixed interval of time, and 3 ) one or more magnitude variables associated with each time of occurrence (e.g., for exploratory drilling: location of the borehole, size of the borehole, and depth of the borehole).

\section{Process}

A process is any natural or anthropogenic phenomenon that takes place continuously during intervals of time that are comparable to the period of performance of the system. Examples of processes are climatic change, erosion, corrosion, and human population growth. If a process is judged to be acting within or upon a system, it must act (perhaps at insignificant levels) throughout the period of performance. Therefore, to ask whether a process occurs or does not occur during a finite period of time is not meaningful; to ask whether the magnitude(s) of a process will exceed prescribed levels during predetermined intervals of time is meaningful (see Appendix $B$ for process variables and ways of representing processes in performance assessment). 


\section{Feature}

The noun "feature" is not used in the EPA's Standard, but the term "undetected feature" is explicitly used in the standard list of phenomenon potentially relevant to geologic repositories (IAEA, 1981) and has a meaning clearly different from the meanings of "event" or "process."

Here, a feature is any object or condition that 1) could exist within the defined boundaries of the system at the beginning of the period of performance, 2) could cause or promote releases of radioactivity to the accessible environnent (i.e., affect the outcome of the performance assessment), and 3 ) has not been positively identified at the time of the performance assessment. To ask whether a feature is or is not present at the beginning of the period of performance is obviously meaningful. An immediate example of a feature is a suspected brine reservoir under the WIPP's waste-disposal area; other examples are dikes, breccia pipes, fault zones, undetected boreholes, and deviations from planned waste-emplacement patterns.

Feature Variables. A feature is usually specified by giving 1) a binary variable that determines its presence or absence, and 2) one or more magnitude variables (e.g., for a brine reservoir: its depth, its volume, and its projected area).

\section{Alternative Conceptual Models}

A conceptual model is a set of hypotheses formed by an investigator in the process of understanding the nature of some phenomenon. A conceptual model is said to be scientifically acceptable if the hypotheses 1) are logically consistent with one another, 2) agree with existing facts and data concerning the phenomenon in question, and 3) can be tested for their truth content or falsified by empirical observation or further application of logic (testable hypotheses). In addition, a conceptual model whose ultimate purpose is to make quantitative predictions about the phenomenon in question must be capable of being mathematicized in some way, e.g., cast in terms of equations or computer code.

For purposes of this report, alternative conceptual models are simply multiple, scientifically acceptable, and quantifiable sets of hypotheses about the nature of some definite type of event, process, or feature.

Logical Connection with Events, Processes, and Features. The concept of alternative conceptual models'is interchangeable with the concepts of event and feature as the latter have been defined in this report. For practical purposes, there is no need to ionsider alternative conceptual models of 
events: each model of an event can be viewed as a different type of event and the elementary probability that the model of the event is the "correct" one can be incorporated in the elementary probability that the event occurs during the period of performance. For the same reason, there is no need to consider alternative conceptual models of features: each model of a feature can be viewed as a different type of feature. It, therefore, makes no difference whether one speaks of a set of different ways of realizing a broadly defined event (or feature) or alternative conceptual models of the same broadly defined event (or feature).

There are logical problems with application of the concept of alternative conceptual models to processes; discussion of these problems is beyond the scope of this report. The author has not yet found an example of a set of alternative models of a process that cannot be constructed by forcing certain parameters that appear in one of the alternatives, a "master" model, to vanish or to become large.

\section{Agent}

The noun agent is used frequently in this report as a collective name for any of the following things: event(s), process(es), feature(s), and alternative conceptual models of a process. A binary agent is obviously an agent having two logical states: e.g., an event that does not occur or occurs more than once during the period of performance; a feature that is present or not present at the beginning of the period of performance; a process that is divided into two bins (Appendix $B$ ); or an alternative conceptual model with no more than two distinct sets of hypotheses.

\section{Scenario}

A scenario is a sequence of definite types of events and processes that act upon or occur within the system in the presence of definite types of features, at prescribed points in time (events) or with prescribed durations of time (processes), with prescribed magnitudes, and in a prescribed order. In simple terms, a scenario is a definite, quantitative description of a potential history of the model system throughout the period of performance; it may be pictorially and mathematically viewed as a single point in the space of all independent variables of the mathematical models used to describe the system.

As a corollary to the definition of scenario, scenario class may be defined as a set of scenarios that have some specified attributes in common (e.g., same types of agents), or the set of scenarios that results when one or more of the prescribed points in time, durations of time, magnitudes, or orders of occurrence associated with the agents are allowed to vary over subsets of 
their natural ranges of numerical values instead of being tied to specific numerical values. In pictorial and mathematical terms, a scenario class can be imagined as a cloud of points in the space of all independent variables of the mathematical models used to describe the system.

Note or Usage of Scenario. Some authors of methodologies for testing compliance with the Standard (e.g., Cranwell et al., 1982b; Hunter et al., 1986) do not make a distinction between scenario and scenario class, although they usually intend the meaning of the latter term when they refer to "scenario." Distinction between the two terms is not merely academic: the likelihood of realizing any scenario is always vanishingly small; whereas, the likelihood that only scenarios from a given scenario class are realized is a finite number between zero and one (Chapter 3). Nevertheless, because use of "scenario" to mean both a broadly defined and a wellspecified account of states of the system during the period of performance is too deeply ingrained in the waste-management literature to ignore, the terms scenario and scenario class will be used interchangeably in this report and reliance will be placed upon the context of the discussion to make cleur which meaning is intended. 
APPENDIX B:

REPRESENTATIUN OF PROCESSES

IN PERFORMANCE ASSESSMENT 


\section{APPENDIX B: REPRESENTATION OF PROCESSES IN PERFORMANCE ASSESSMENT}

The word "process" in this report means "any natural or anthropogenic phenomenon that takes place continuously during intervals of time that are comparable to the period of performance of the system" (Appendix A). This appendix outlines one way in which processes can be represented mathematically in performance-assessment calculations. Particular attention is given to representations of processes that are consistent with the performance-assessment methodology adopted by the WIPP Project, i.e., the scenario-based, conditional Monte Carlo simulations described in the second part of Chapter 3 .

The mathematical representation to be discussed here applies only to independent processes that appear in a performance-assessment calculation. Roughly speaking, an independent process is one whose likelihood of occurrence is not changed or affected by the occurrence of any of the other kinds of agents that may affect the waste-disposal system. Climatic change appears to be the only potentially significant and independent process associated with the WIPP system (Chapter 4); so far, all other potentially significant processes that have been identified with the WIPP system, e.g., groundwater flow and leaching, would obviously not affect (but would be affected by) the process of climatic change. Given a realization of an independent process such as climatic change, realizations of other processes that are even partially influenced by it (e.g., groundwater flow) usually may be obtained through the use of mathematical models whose independent variables are independent process variables and a fixed but finite number of other kinds of uncertain variables (e.g., rock material properties) that are independent statistically of the process variables.

\section{Representation by Finite-Dimensional Vectors}

An independent process ideally is specified by one or more continuous (or piecewise continuous) functions of time, say $x_{1}(t), x_{2}(t), x_{3}(t)$, $\ldots, x_{I}(t)$, defined on a time interval that includes the interval $\left[0, t_{m}\right]$, where $t_{m}$ marks the end of the period of performance. For example, in an assessment of the effects of a changing regional climate on waste-disposal site nerformance, the ideal situation would be knowledge of the two quantities, regional air temperature $\left({ }^{\circ} \mathrm{C}\right)$ and regional precipitation rate $(\mathrm{mm} / \mathrm{yr})$, as functions of time over the next 10,000 years. Of course, regional air temperature and regional precipitation rate would be but two of the inputs to computer-implemented models that are intended to provide 
output variables of more relevance to site performance, e.g., percolation flux at the level of the waste repository or recharge rates to aquifers. The analyst may wish to deal with these derived outputs from computer models as specifiers of the process instead of directly using the basic process variables; in either situation, process variables may be viewed ideally as a set of functions of time.

Even if measurements of a process variable over the period of performance were possible, practical considerations, such as finite response times of instruments used to measure process variables and discrete approximations necessary for calculations with digital computers, will usually dictate that continuous functions of time representing a process variable be measured not on the entire interval $\left[0, t_{m}\right]$ but at a finite number of points within that interval, say $t_{1}, t_{2}, t_{3}, \ldots, t_{J}$. The process must be mathematically represented by a finite series of numbers that may be arranged as elements of an IxJ rectangular matrix or, more relevant to the present discussion, serially arranged as the the IxJ components of a vector:

$$
\begin{gathered}
\vec{x}=\left[x_{1}\left(t_{1}\right), x_{1}\left(t_{2}\right), \ldots, x_{1}\left(t_{J}\right) ; x_{2}\left(t_{1}\right), x_{2}\left(t_{2}\right), \ldots, x_{2}\left(t_{J}\right) ; \ldots ;\right. \\
\left.x_{I}\left(t_{1}\right), x_{I}\left(t_{2}\right), \ldots, x_{I}\left(t_{J}\right)\right] .
\end{gathered}
$$

for the sake of brevity, components of $\vec{x}$ will hereinafter be simply denoted by $x_{k}, 1 \leq k \leq K$, where $K=(I x J)$. Components of $\vec{x}$ defined in Eq. (B.1) can be regarded as a subset of components of the system's state-variable vector $\vec{v}$ defined in Chapter 3.

Allowing $x_{k}, 1 \leq k \leq k$, to run over their natural ranges defines a subset of $K$-dimensional Euclidean space which here is called $W_{K}$, the process-variable space. Clearly, $W_{K}$ is a subset of the state-variable space $S_{N}$ defined in Chapter 3 .

\section{Representation of Process Uncertainty}

At present, experts are unwilling to make quantitative extrapolations of processes such as climatic change or human population growth to the distant future (witness the reliability of ordinary weather predictions for more than a few days in advance of the prediction date). At best, an investigator can use only indirect evidence and expert judgment to predict likelihoods that the process variables will fall within given ranges in given time ir.tervals. Predictions of these likelihoods usually begin by treating process variables as random variables; the investigator may then attempt to associate a joint cumulative distribution function ( $C D F$ ) with these random variables, much in the same way as a joint $C D F$ was assigned to the system's state-variable vector 
(Chapter 3) [indeed, the joint CDF for components of vector (B.1) forms part of the joint CDF for the system's state-variables]. But, unlike construction of the joint CDF for the system's state-variable vector which may include use of some empirical observations of the system parameters, construction of the joint CDF for process variables usually will be a matter of using professional judgment 100 percent of the time along with techniques such as the Maximum Entropy Formalism (Jaynes, 1978; Cook and Unwin, 1986; Unwin et al., 1989) for quantifying that judgment.

\section{Notation for the Joint CDF}

Observing the usual convention for distinguishing between an ordinary variable and its random-variable counterpart, the vector $\vec{x}$ will hereinafter denote a specific point in $W_{K}$, process-variable space, and $\vec{x}$ will denote the vector whose components are random variables $\left(X_{k}\right), 1 \leq k \leq$ $K$. The joint $C D F$ for the process variables then is defined by the function,

$$
H(\vec{x})=\operatorname{Pr}\left(x_{1} \leq x_{1}, x_{2} \leq x_{2}, x_{3} \leq x_{3}, \ldots, x_{K} \leq x_{K}\right)
$$

where $\operatorname{Pr}(e)$ stands for the probability that statement "e" is true. The function $H(\vec{x})$ can be visualized as points of a surface imbedded in $K+1$ dimensional Euclidean space; the "relief" of the surface along the $(K+1)$ th dimension, $H(\vec{X})$ is bounded between zero and one.

To go into the practical ways of constructing empirical versions of (B.2) would exceed the scope of this report; in most cases, the joint CDF is representable only as a computer-implemented algorithm. In the following discussion, such an algorithm will be assumed to have developed and used to draw iridependent sample values, $\vec{x}$, for the process variables.

The joint $\mathrm{CDF} H(\vec{x})$ is a probability measure on $W_{K}$ that defines the statistical properties of any reasonably well-behaved function, $f(\vec{x})$, of the process-variables. In particular, for $f(\vec{x})=1$, the normalization is

$$
\int_{W_{K}} H(d \vec{x})=1
$$

and for any $f(\vec{x})$, the expectation,

$$
E[f]=\int_{W_{K}} f(\vec{x}) H(d \vec{x}) .
$$

The integrals in Eqs. (B.3) and (B.4) represent Lebesque-Stieltjes integration (Feller, 1966, Chapter V) of the integrands over the set $W_{K}$. In 
Chapter 3, "Likelihoods of System States," it is noted that, when $\mathrm{K}$ is large or when the integrands are complex functions of their arguments, Monte Carlo methods are virtually the only practical methods for estimating these integrals. Accordingly, the operations with integrals to be expressed in the remainder of this appendix should be interpreted as operations with the appropriate Monte Carlo estimators (see "Practical Monte Carlo Simulation," Chapter 3). For example, Eq. (B.4) could be interpreted as an application of the random-sampling estimator

$$
E[f] \simeq N^{-1} \sum_{n=1}^{N} f\left(X_{n}\right),
$$

where the $x_{n}, 1 \leq n \leq N$, are independent samples drawn from $H(\vec{x})$, the joint $\mathrm{CDF}$ for the process-variables.

\section{Elementary Probabilities of a Process}

In theory, partitioning the process-variable space $W_{K}$ into $B+1$ subsets is always possible (e.g., $W_{\beta}, \beta=1,2,3, \ldots, B+1$ ), much in the same way that the state-variable space was partitioned into scenario classes in the second part of Chapter 3 ; in this instance, however, subsets will be called bins for the process in question. All that is needed to make a partition into bins is a set of $B$ rules that enable one to determine whether a sample of the process-variable vector $\overrightarrow{\mathrm{X}}$ is or is not contained in any one of the subsets $\mathrm{W}_{\beta}$; the rules should also ensure that subsets are disjoint (i.e., intersection of any two of the subsets is empty) and complete (i.e., union of all subsets is $W_{K}$ ). The former requirement on the rules assures a practical way of defining indicator functions of the form

$$
\begin{aligned}
I\left(x, W_{\beta}\right) & =1 \text { if } \vec{x} \varepsilon W_{\beta}, \\
& =0 \text { if } \vec{x} \not W_{\beta} .
\end{aligned}
$$

A purely hypothetical example will illustrate these ideas. Suppose one defines two bins for the climatic-change process mentioned above by the rule: "regional precipitation exceeds $1,000 \mathrm{~mm} / \mathrm{yr}$ over any 500 -year period." The first bin is the set

$\mathrm{W}_{1}=\langle\mathrm{X}$ : regional precipitation exceeds $1,000 \mathrm{~mm} / \mathrm{yr}$ over any 500 -year period) and the second bin is the complement of the first in $W_{K}$ :

$W_{2}=\{\vec{x}$ : regional precipitation does not exceed $1,000 \mathrm{~mm} / \mathrm{yr}$ over any 500 -year period\}. 
How to operate with the indicator functions defined in Eq. (B.5) for the bins $W_{1}$ and $W_{2}$ should be obvious: draw a sample of $\vec{X}$ from the joint CDF for process variables and determine whether appropriate components of $\overrightarrow{\mathrm{X}}$ exceed $1,000 \mathrm{~mm} / \mathrm{yr}$; if these components are $\geq 1,000 \mathrm{~mm} / \mathrm{yr}$, set $\mathrm{I}\left(\overrightarrow{\mathrm{X}}, 1_{1}\right)$ equal to one and $\mathrm{I}\left(\vec{X}, W_{2}\right)$ equal to zero; if components are $<1,000 \mathrm{~mm} / \mathrm{yr}$, set $\vec{I}(X$, $\left.W_{1}\right)$ equal to zero and $I\left(\vec{X}, W_{2}\right)$ equal to one. Using these rules for indicator functions, elementary probabilities of bins $W_{1}$ and $W_{2}$ can be calculated,

$$
\mathrm{P}_{\beta}=\int_{\mathrm{W}_{\mathrm{K}}} \mathrm{I}\left(\overrightarrow{\mathrm{x}}, \mathrm{W}_{\beta}\right) \mathrm{H}(\mathrm{d} \overrightarrow{\mathrm{x}}), \quad \beta=1,2 .
$$

Note that $p_{1}+p_{2}=1$, so that in this two-bin example, one would only have to calculate one of the elementary probabilities. If neither $\mathrm{p}_{1}$ nor $\mathrm{p}_{2}$ are zero, the associated conditional joint CDFs can be defined,

$$
\mathrm{H}\left(\overrightarrow{\mathrm{x}} \mid \mathrm{W}_{\beta}\right)=\left(1 / \mathrm{p}_{\beta}\right) \mathrm{I}\left(\overrightarrow{\mathrm{x}}, \mathrm{W}_{\beta}\right) \mathrm{H}(\overrightarrow{\mathrm{x}}), \beta=1,2 .
$$

Eqs. (B.6) and (B.7), and the obvious logical relationship,

$$
I\left(\vec{x}, W_{K}\right)=I\left(\vec{x}, W_{1}\right)+I\left(\vec{x}, W_{2}\right)=1 \text { for all } \vec{x} \varepsilon W_{K} \text {, }
$$

give

$$
\mathrm{H}(\overrightarrow{\mathrm{x}})=\mathrm{p}_{1} \mathrm{H}\left(\overrightarrow{\mathrm{x}} \mid \mathrm{w}_{1}\right)+\mathrm{p}_{2} \mathrm{H}\left(\overrightarrow{\mathrm{x}} \mid \mathrm{w}_{2}\right) .
$$

Eq. (B. 8) is, in effect, a representation of the joint CDF for the climaticchange process in which the probability, $p_{1}$, of meeting the rule "regional precipitation exceeds $1,000 \mathrm{~mm} / \mathrm{yr}$ over any 500 -year period" is explicitly exhibited. If that probability turns out to be less than the EPA threshhold probability of 0.0001 (Chapter 2), the need for sampling from those parts of the process-variable space that comprise set $W_{1}$ could be eliminated. In the long run, eliminating the need to sample from certain regions of the process-variable space could lead to more efficient calculations of the empirical CCDF for cumulative releases of radioactivity.

The example above considered only one rule. The generalization to $B>1$ rules is easy to see: Eqs. (B.6) and (B.7) are unchanged, except that $\beta=$ $1,2, \ldots, B+1$, and $E q$. (B. 8) generalizes to

$$
\begin{aligned}
\mathrm{H}(\overrightarrow{\mathrm{x}}) & =\sum_{\beta=1}^{\mathrm{B}+1} \mathrm{P}_{\beta} \mathrm{H}\left(\overrightarrow{\mathrm{x}} \mid \mathrm{W}_{\beta}\right) .
\end{aligned}
$$


Because almost all quantities appearing in Eq. (B.9) must be estimated by time-consuming Monte Carlo simulation, any benefits that could be realized by partitioning a process-variable space in this way are doubtful. The WIPP Project has so far not attempted to use such a representation in accounting for the process of climate change in its preliminary performance assessments. 


\section{APPENDIX C: \\ INADVERTENT DRILLING AT THE WIPP SITE: \\ AN EXAMPLE OF A PROBABILITY MODEL OF AN ANTHROPOGENIC EVENT}




\section{APPENDIX C: \\ INADVERTENT DRILLING AT THE WIPP SITE: AN EXAMPLE OF A PROBABILITY MODEL OF AN ANTHROPOGENIC EVENT}

In this appendix, several probability models are constructed for some uncertain variables associated with the event, "attempted boreholes over rooms and drifts" (Chapter 4). The models are intended to illustrate the idea of a probability model and also the kinds of reasoning an analyst might employ in constructing a probabilistic representation of variables that specify an anthropogenic event. Discussion will focus on construction of probability distributions for the number of attempts made to drill during the period of performance and the first time an attempt is made to drill through the WIPP site. Other necessary event variables associated with successful attempts to drill, such as borehole depth and diameter, will not be treated here.

The evint under consideration can be described as follows: Supposing that the WIPP system eventually is constructed and operated, it is possible that at some time in the 10,000-year period following closure of the system, people will ignore or misread the evidence of markers and monuments that remain on the site of the former WIPP and will decide to conduct exploratory drilling operations within the former controlled area. Consequences of a decision to drill at the WIPP would depend upon the proposed location and depth of the boreholes (among other variables) and could be anything from a failed attempt and abandonment of the drilling program to joint penetration of a waste panel and underlying brine pocket by a successful borehole. Thus, consequences in terms of releases of radioactivity to the accessible environment could be anything from none to release of some waste products (in borehole cores) at the surface or release of some dissolved waste products via pressurized brine flowing from the pocket, through the punctured waste panel, to overlying bodies of groundwater. The probability of realizing any of these consequences is a product of terms, the first term of which is always the probability that inadvertent attempts are made to drill the WIPP site during the next 10,000 years.

\section{Failure-Rate Functions}

Probably the most direct way of constructing a probability model for inadvertent drilling of the WIPP site is a careful examination of conditions that must be placed on the form of the failure-rate function associated with the to-be-determined CDF for the first time of attempted drilling. The 
failure-rate function (sometimes called the "hazard rate" or "intensity rate" (Elandt-Johnson and Johnson, 1980, p. 51]) is defined by

$$
r(t)=-d / d t \ln [1-F(t)]
$$

where $t$ is time elapsed since the system was placed in operation, $d / d t(\cdot)$ is the time derivative, $\ln [\cdot]$ is the natural logarithm, and $F(t)$ denotes the $C D F$ for the first time, say $T$, at which the disturbing event occurs, $1 . e .$, $F(t)=\operatorname{Pr}(T \leq t)$. For the sake of brevity, the random variable $T$ hereinafter will be called simply the time of drilling (in place of the correct but awkward "time of attempted drilling"); in other words, the distinction between an attempt to drill and the act of drilling will be ignored.

The quantity $r(t) d t$ is the probability that the time of drilling occurs in a time interval ( $t, t+d t$ ), given that no attempts occurred prior to time $t$ (Ross, 1985, p. 193). Note that the failure-rate function uniquely determines the CDF for the first time of drilling: Eq. (C.1) can be integrated to give

$$
F(t)=1-\exp \left(-\int_{0}^{t} r(r) \mathrm{d} \tau\right)
$$

\section{Some Examples}

1) If $r(t)=k$, a constant $>0, F(t)$ is the exponential distribution,

$$
F(t)=1-\exp (-k t)
$$

In this case, $1 / k$ is the average time until first drilling occurs. Also note that for any finite time, say $t_{m}<\infty$, Eq. (C.3) implies that $F\left(t_{m}\right)<1$; in other words, a non-zero probability exists that drilling will not occur in the time interval $\left(0, t_{m}\right)$. If the times of drilling are assumed to follow a counting process known as a renewal process (Ross, 1985, Chapter 7), a non-zero probability also exists that drilling will occur more than once in the time interval $\left(0, t_{m}\right)$; the probability that the site is drilled $n$ times, $n=0,1,2,3, \ldots$, in $\left(0, t_{m}\right)$ is given by the Poisson distribution,

$$
\operatorname{Pr}(N=n)=\left[\left(k t_{m}\right) n / n !\right] \exp \left(-k t_{m}\right)
$$

If $t_{m}$ denotes the period of performance, the elementary probabilit, of the event is simply $1-\operatorname{Pr}(N=0)=1-\exp \left(-k t_{m}\right)$. 
Because this fact will be used in the sequel, note that Eqs. (C.3) and (C.4) generalize to non-constant failure-rate functions $r(t)$ (the inhomogeneous Poisson process [Ross, 1985, pp. 221-222]), provided that the renewalprocess assumption is made and the quantity

$$
m\left(t_{m}\right)=\int_{0}^{t_{m}} r(\tau) d r
$$

is finite $(\neq \infty)$. An inhomogeneous Poisson process is obtained by merely replacing $\left(k t_{m}\right)$ in Eqs. (C.3) and (C.4) with $m\left(t_{m}\right)$. The elementary probability of the event then is simply $1-\exp \left[-m\left(t_{m}\right)\right]$. If $m\left(t_{m}\right)$ is infinite, the event is sure to happen in the interval $\left(0, t_{m}\right)$ and it can happen an infinite number of times.

2) Marietta et al. (1989, Table 3-10) assume that the time of drilling is uniformly distributed on the interval $\left(0, t_{m}\right)$, where $t_{m}=10,000$ years; i.e., $F(t)=t / t_{m}, 0 \leq t \leq t_{m}$. From Eq. (C.1), the failure-rate function in this case is $1 /\left(t_{m}-t\right)$, a function whose integral over the interval $\left(0, t_{m}\right)$ diverges; hence use of a uniform distribution for the time of drilling is tantamount to assuming that drilling will occur with certainty during the period of performance. Marietta et al. (1989) ignore the possibility that drilling could occur more than once in the interval $\left(0, t_{m}\right)$.

3) The empirical failure-rate function for many statistical properties of engineered and biological systems often follows the "bathtub-shaped" or "U" shaped curve (Figure C-1) (the curve is adopted from Harr, 1987; see that text for its interpretation in terms of engineered systems). The agedependent mortality of human beings is similar in shape, as is the observed frequency of birt. defects in children born to human mothers as a function of the mother's age. This example is included to emphasize the point that failure-rate functions often can reflect the underlying causes of system failure more directly than the system's associated CDF for first time to failure.

\section{Models of First Time of Inadvertent Drilling}

The concept of failure-rate function will be used to construct four versions of a CDF for first time of drilling of the WIPP site during the next 10,000 years. Only the weakest of assumptions about the factors that could determine the time of first drilling will be used in the constructions, and 


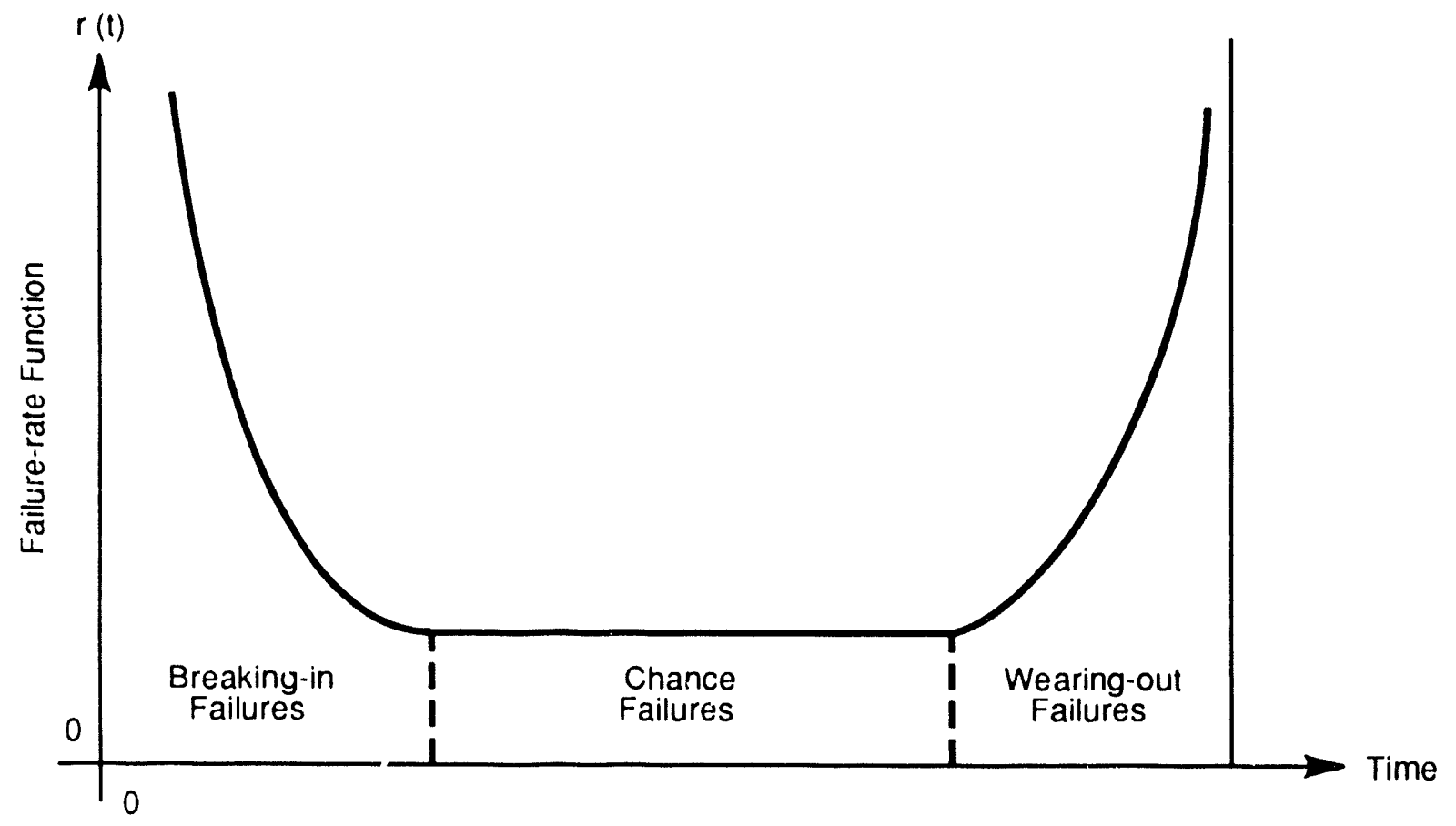

TRI-6342.603.0

Figure C-1. Bathtub Failure-Rate Function for Many Engineered and Biological Systems (adopted from Harr, 1987).

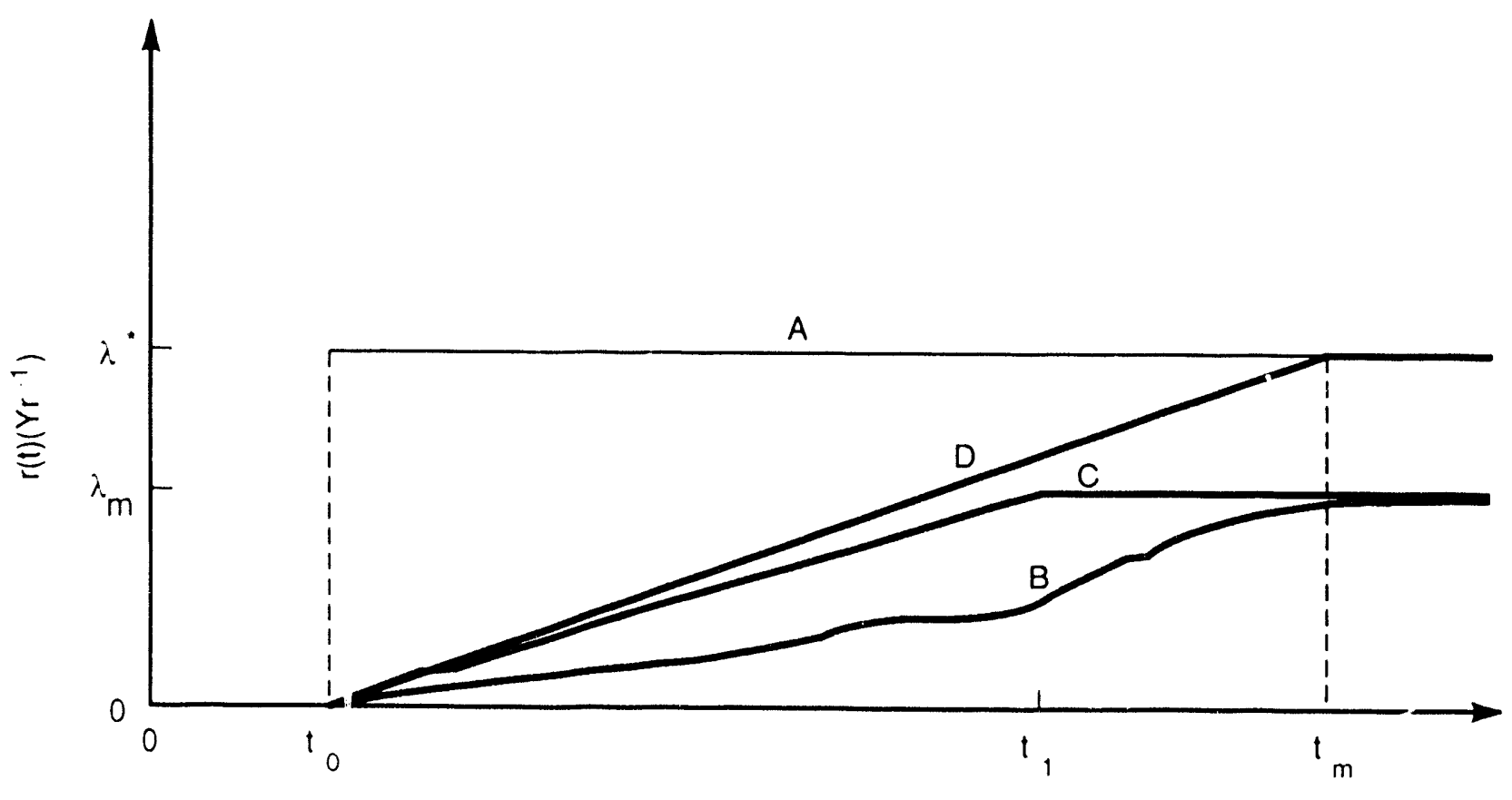

Time in Years

TRI-6342-606-0

Figure C-2. Four Models of a Failure-Rate Function for Inadvertent Attempts to Drill at the WIPP Site (see text for an explanation). 
constraints imposed by the regulatory agency (EPA) in Appendix B of the Standard (EPA, 1985) will be included.

Four possible failure-rate functions (Figure C-2, curves labelled A-D) are considered as functions of time elapsed since site closure $(t=0)$. Varicus time intervals of concern are also shown on Figure C-2:

$$
\begin{aligned}
& {\left[0, t_{0}\right] \text { the period of institutional control during which any attempts }} \\
& \text { to drill at the site would be prevented by governmental } \\
& \text { authorities. } \\
& {\left[t_{0}, t_{1}\right] \text { an ill-cefined period of passive control during which the }} \\
& \text { presence of markers or monuments at the site could warn } \\
& \text { potential drillers of the hazards of disturbing the site, } \\
& \text { thereby discouraging them from taking further action. } \\
& {\left[t_{1}, t_{m}\right] \text { a period of no predictable control; it starts at an ill-defined }} \\
& \text { time } t_{1} \text { at which markers and monuments have become ineffective } \\
& \text { as warning devices, and ends at } t_{m}=10,000 \text { years, the end of } \\
& \text { the period of performance. }
\end{aligned}
$$

Regulatory constraints and common sense have dictated the ordering of times $t_{0}, t_{1}, t_{2}$, and $t_{m}$ (Figure $C-2$ ). Institutional control is limited by the Standard to no more than 100 years (EPA, 1985, Appendix B) and it seems reasonable to assume that modern technology can create markers and monuments that are durable and can be read (perhaps with increasing error) for periods much longer than 100 years. Nevertheless, ignoring regulatory constraints for the moment, circumstances can be imagined in which $t_{0}>t_{1}, t_{1}>t_{m}$, or both $t_{0}$ and $t_{1}$ are greater than $t_{m}$. Models of human intrusion that are $m$. sophisticated than those to be constructed here might treat the parameters $t_{0}$ and $t_{1}$ as random variables whose distributions would be determined by expert opinion.

\section{Period of Institutional Control}

It seems reasonable to suppose that the likelihood of inadvertent drilling of the site during the period of institutional control is virtually zero; accordingly, the failure-rate function during this period can be modeled by $r(t)=0$, as indicated for all four curves (Figure C-2). Thus, by Eq. (C.2), $F(t)=0$ for $0 \leq t<t_{0}$. 


\section{Period of Passive Control}

Once the period of institutional control has lapsed (i.e., for $t>t_{0}$ ), $F(t)$ $>0$ must be assumed, even though markers may be in place and their symbols may still be readable. The need for this assumption stems mainly from remarks in Appendix B of the Standard (EPA, 1985):

... the agency (EPA) believes that passive institutional controls can never be assumed to eliminate the chance of inadvertent and intermittent intrusion into these disposal sites.

A consequence of this assumption and $\mathrm{Eq} .(\mathrm{C} .2)$ is that the failure-rate function must be $>0$ during a finite fraction of the period of passive control. The EFA nevertheless allows the implementing agency to place a definite upper bound on the failure-rate function during this period:

..., the Agency assumes that the likelihood of such inadvertent and intermittent drilling need not be taken to be greater than 30 boreholes per square kilometer per 10,000 years for geologic repositories in proximity to sedimentary rock formations, or more than 3 boreholes per square kilometer per 10,000 years for repositories in other geologic formations. (EPA, 1985, Appendix B)

Thus, for the WIPP system, an upper bound of

$$
\begin{aligned}
& \lambda *=\frac{30 \text { boreholes }}{10^{6} \mathrm{~m}^{2} \cdot 10^{4} \mathrm{yr}} \times \text { (area of WIPP panels } \simeq 1.2 \times 10^{5} \mathrm{~m}^{2} \text { ) } \\
& \simeq 3.6 \times 10^{-4} \mathrm{yr}^{-1}
\end{aligned}
$$

can always be placed on the failure-rate function for inadvertent drilling.

Curve A. The bounding lire, $r(t)=\lambda *, t>t_{0}$, (Curve A, Figure C-2) represents the most conservative of those models of inadvertent drilling at the WIPP site which take account of EPA guidance. In this model, the time of first drilling is exponentially distributed on the interval $\left(t_{0}, \infty\right)$, the mean time to first drilling is 2,878 years, a 3 -percent chance of no drilling in 10,000 years exists, and (assuming that drilling is a renewal process) the expected number of drilling events in 10,000 years is about 3.6 .

Though conservative, Curve $A$ is unrealistic because the warning effects of markers and monuments that would be present during the period of passive control are ignored, and because of the possibly unrealistic value of the maximum exploration rate, $\lambda^{*}$, set by EPA guidance. The EPA's maximum exploration rate was developed apparently from data on successful dirilings 
in sedimentary rocks in the 1970s and early 1980s; such data may not reflect rates of exploration (including unsuccessful attempts to drill) hundreds to thousands of years into the future when mineral resources have been depleted or new mineral needs have been identified.

Curve B. A qualitative representation of the envelope (bounding curve) of more realistic failure-rate functions for inadvertent drilling at the WIPP site is sketched as Curve $B$ on Figure $C-2$. The main features of this curve are that it starts from zero at $t=t_{0}$ and gradually increases until, at the beginning of the period of no predictable control, it asymptotically approaches some maximum exploration rate, say $\lambda_{\mathrm{m}}$. The line of reasoning that produced this form for the envelope of realistic failure-rate functions begins with the observation that the failure-rate function can be expressed as the following product:

[exploratior, rate (successful and unsuccessful borehole/m ${ }^{2} \cdot y r$ )] $x$ (area of WIPP panels in $\mathrm{m}^{2}$ )

$x$ (probability per encounter that a decision to drill is made).

Or, in terms of symbols to be used for variables in the product,

$$
r(t)=\lambda(t) \Pi_{d}(t)
$$

where $\pi_{d}$ denotes the probability per encouviter at time that a decision to drill is made. Eq. (C.5) represents a failure-rate function which is bounded above by the envelope $\lambda_{m} \Pi_{d}(t)$, with

$$
\begin{gathered}
\lambda_{\mathrm{m}}=\max _{(\lambda(t)) .} \\
t_{0} \leq t<t_{\mathrm{m}}
\end{gathered}
$$

If the form of the envelope were known, it could be used as an obviously conservative surrogate for the true failure-rate functions.

By making mostly weak assumptions about the natural and human factors that enter into a decision to drill a borehole at WIPP in the far future, it can be shown that $\Pi_{d}(t)$, the probability per encounter that a decision to drill is made, is an increasing function of time that is zero until $t=t_{0}$ and approaches one as $t$ exceeds a certain characteristic time. This demonstration 
will be based on a decision tree (similar to a logic diagram) sketched in Figure C-3. Six decision points on the tree, at its branch points (labelled 1-6), have the followilg meanings:

(1) Are markers/monuments evident? Note that markers/monuments may have been removed or covered with sediments prior to an episode of exploration of the site. A "yes" answer (the positive [+] branch of the tree) has probability $\rho_{1}$ and a "no" answer (the minus [-] branch) has probability $\left(1-\rho_{1}\right)$.

(2) Are symbols representing messages on markers/monuments readable by contemporaries of their creators? In other words, prior to the time of the exploratory episode, have the physical symbols representing the messages been so altered by vandals or erosion that even a person who knew the meanings of the symbols would have trouble reading them? The positive (+) branch has probability $\rho_{2}$ and the minus (-) branch has probability $\left(1-\rho_{2}\right)$.

(3) Should drilling commence, given an unreadable message? The positive (+) branch has probability $\rho_{3}$ and the minus (-) branch has probability $\left(1-\rho_{3}\right)$.

(4) Are symbols representing messages on markers/monuments understood by explorers or their contemporaries? This question accounts for a possible inability to understand the message, i.e., the possibility that symbolic meanings may become extinct with the passage of time. The positive (+) branch has probability $\rho_{4}$ and the minus (-) branch has probability $\left(1-\rho_{4}\right)$.

(5) Should drilling commence, given a message that is not understood? The positive (+) branch has probability $\rho_{5}$ and the minus (-) branch has probability $\left(1-\rho_{5}\right)$.

(6) Does drilling commence, given that the message is understood? The positive ( + ) branch has probability $\rho_{6}$ and the minus (-) branch has probability $\left(1-\rho_{6}\right)$. Current moral and legal standards of behavior, if preserved into the far future, would dictate that the rational and responsible person would always choose the minus (-) branch unless ovfrriding social or political reasons for ignoring the message exist. Accordingly, a choice of the positive $(+)$ branch cannot be considered as an inadvertent action and, though it would lead to an attempt to drill, should not be counted in the computed, overall probability of inadvertent drilling. 


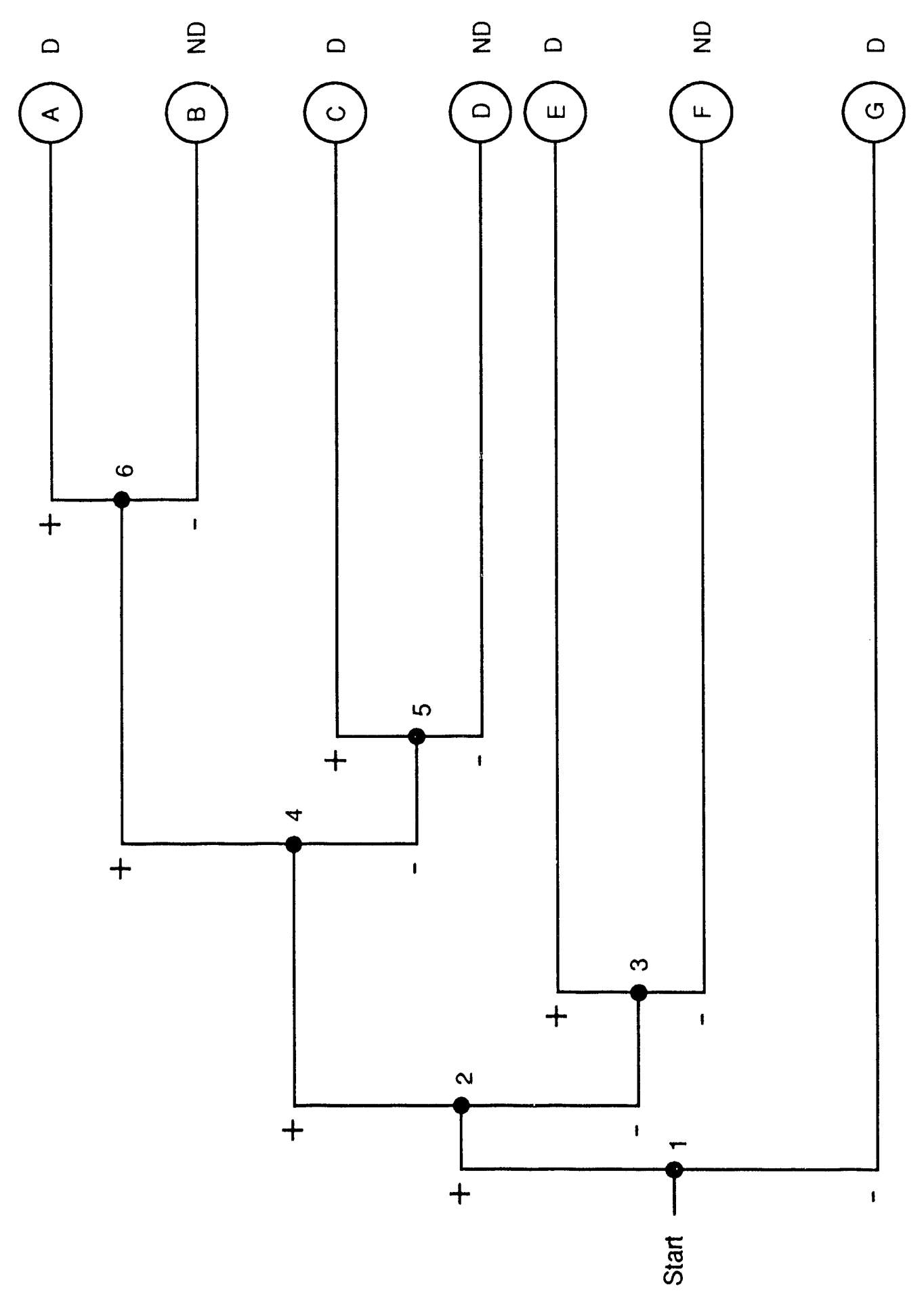

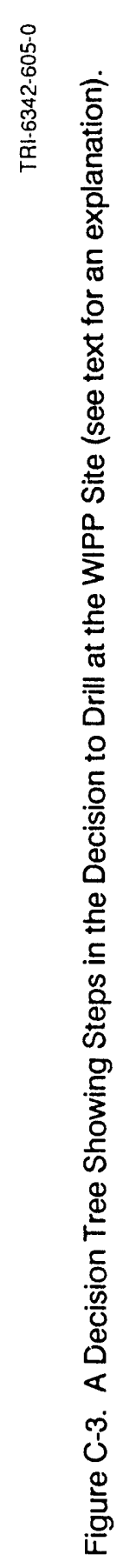


Probabilities $\rho_{i}, 1 \leq i \leq 6$, are in general to be regarded as functions of tine: taking values in the interval $(0,1)$.

The seven distinct pathways through the decision tree (Figure C-3) are Iabelled A-G and are so marked on the right-hand side of the figure; also shown are the outcomes of each pathway (either " $D$ " for drilling, or "ND" for no drilling). The probability of each outcome is computed easily: for example, pathways leading to drilling, probabilities $P(C), P(F)$, and $P(G)$, are respectively $\rho_{1} \rho_{2}\left(1-\rho_{4}\right) \rho_{5}, \rho_{1}\left(1-\rho_{2}\right) \rho_{3}$, and $\left(1-\rho_{1}\right)$. Thus, discounting $P(A)$ for the reason mentioned above, the probability per attempted borehole that inadvertent drilling actually occurs is

$\Pi_{\mathrm{d}}(t)=\mathrm{P}(\mathrm{C})+\mathrm{P}(\mathrm{E})+\mathrm{P}(\mathrm{G})=\rho_{1}\left[\rho_{2}\left(1-\rho_{4}\right) \rho_{5}+\left(1-\rho_{2}\right) \rho_{3}\right]+\left(1-\rho_{1}\right) \cdot(C .6)$

Recalling the meanings of $\rho_{i}$ s in Eq. (C.6), these quantities need only be assurned to $h$ ve the following properties:

- $\rho_{1}, \rho_{2}$, and $\rho_{4}$ are decreasing functions of time with values $=1$ at $t=t_{0}$

and

- $\rho_{1} \rightarrow 0$ as $\left(t-t_{0}\right) \geq \tau_{1}$, where $\tau_{1}$ is a characteristic lifetime of the markers/monuments against removal by humans or covering by sediments;

- $\rho_{2} \rightarrow 0$ as $\left(t-t_{0}\right) \geq \tau_{2}$, where $\tau_{2}$ is a characteristic lifetime of the symbols on the markers or monuments against defacement by vandals or erosion;

- $\rho_{4} \rightarrow 0$ as $\left(t-t_{0}\right) \geq \tau_{4}$, where $\tau_{4}$ is a characteristic lifetime of the meaning of the symbols on the markers/monuments in cultural memory;

- $\rho_{3}$ and $\rho_{5}$ are constants in the range $(0,1)$. (Note: This assumption is not weak; it implies that human decision-making behavior will not change for many thousands of years. Actually, these probabilities are likely to change rapidly on a time-scale of 10,000 years because each decision to drill would balance current levels of caution against current incentives to explore or current levels of curiosity. But because of these rapid changes, it is plausible to assume that the time averages of the derivatives of $\rho_{3}$ and $\rho_{5}$ are zero.)

Given these five assumptions and Eq. (C.6), it follows that 


$$
\begin{gathered}
\Pi_{d}\left(t_{0}\right)=0, \quad \Pi_{d}(t) \geq 0 \text { for } t>t_{0} \text { and } \\
\Pi_{d}(t) \rightarrow 1 \text { as }\left(t-t_{0}\right) \geq \tau_{\max },
\end{gathered}
$$

where $\tau_{\max }=\max \left(\tau_{1}, \tau_{2}, \tau_{4}\right)$. Evidently, $\tau_{\max }$ can be identified with $t_{1}$, "end" of the period of passive control. Furthermore, if $\rho 3 \geq \rho 5, \Pi_{d}(t)$ is a non-decreasing function of time, i.e.,

$$
\mathrm{d} / \mathrm{dt} \Pi_{\mathrm{d}}(t) \geq 0
$$

Eqs. (C.6)-(C.8) demonstrate that under the five stated assumptions about the probabilities in the decision model (Figure $\mathrm{C}-3$ ), the failure-rate function for the first time of inadvertent exploratory drilling will be bounded by a curve, $\lambda_{\mathrm{m}} \Pi_{\mathrm{d}}(t)$, which has quantitative properties similar to the sketch (Curve B, Figure C-2). The demonstration also suggests that several qualitatively different characteristic lifetimes of the

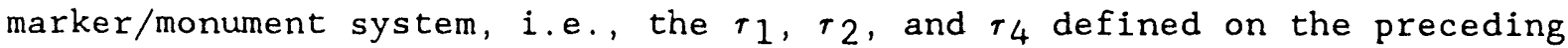
page, enter into a determination of the length of the period of passive control.

Curves $C$ and D. These curves represent analytic failure-rate functions that are intended to mimic the behavior of Curve $B$ by a function that increases inearly with time up to $t=t_{1}$ and thereafter remains constant at some arbitrarily chosen $\lambda_{\mathrm{m}}$ :

$$
\begin{aligned}
r(t) & =0 \text { if } t<t_{0}, \\
& =\lambda_{m}\left(t-t_{0}\right) /\left(t_{1}-t_{0}\right) \text { if } t_{0} \leq t<t_{1}, \\
& =\lambda_{m} \text { if } t \geq t_{1} .
\end{aligned}
$$

In Curve $C, \lambda_{m}$ and $t_{1}$ are arbitrary; in Curve $D, \lambda_{m}=\lambda *$ and $t_{1}=t_{m}$. Integration of Eq. (C.9) and Fq. (C.2) gives a modified Rayleigh distribution of the form,

$$
\begin{aligned}
F(t)= & 0 \text { if } t<t_{0}, \\
= & 1-\exp \left(-\lambda_{m}\left(t-t_{0}\right)^{2} / 2\left(t_{1}-t_{0}\right)\right) \\
& \text { if } t_{0} \leq t<t_{I}:
\end{aligned}
$$




$$
\begin{aligned}
& =1-\exp \left(-\lambda_{m}\left(t_{1}-t_{0}\right) / 2-\lambda_{m}\left(t-t_{1}\right)\right) \\
& \quad \text { if } t \geq t_{1},
\end{aligned}
$$

for the $C D F$ for first time of inadvertent drilling of the site. The elementary probability of inadvertent drilling of the site is found from Eq. (C.10) by setting $t=t_{m}=10,000$ years. The mean waiting time, $\dot{T}$, until first drilling occurs can also be obtained in a closed form for the models shown in Curves $C$ and $D$ :

$$
\begin{aligned}
\overline{\mathrm{T}} & =t_{0}+\left(t_{1}+1 / \lambda_{\mathrm{m}}-t_{0}\right) \exp \left[-\lambda_{\mathrm{m}}\left(t_{1}-t_{0}\right) / 2\right] \\
& +\left(\pi\left(t_{1}-t_{0}\right) / 2 \lambda_{m}\right)^{1 / 2} \mathrm{P}\left[3 / 2, \lambda_{m}\left(t_{1}-t_{0}\right) / 2\right]
\end{aligned}
$$

where $\mathrm{P}[\mathrm{a}, \mathrm{x}]$ stands for the Incomplete Gamma Function (Abramowitz and Stegun, 1964, formula 6.51, p. 260).

Some numerical examples will illustrate properties of the models represented by Curves $C$ and $D$. For Curve $C$, choose $t_{0}=100$ years, $t_{1}=4,000$ years, and $\lambda_{\mathrm{ln}}=\lambda *=3.6 \times 10^{-4} / \mathrm{yr}$. Then $\overline{\mathrm{T}} \simeq 4,600$ years, there is about a 6 -percent chance of no drilling in 10,000 years, and (assuming a renewal process) the expected number of drillings in 10,000 years is about 2.9. To see the properties of Curve $D$, simply change $t_{1}$ to 10,000 years. Then $\overline{\mathrm{T}} \simeq 6,900$ years, about a 17 -percent chance of no drilling in 10,000 years exists, and the expected number of drillings in the period of performance is about 1.8. Sensitivity of the model to maximum exploration rate, $\lambda_{\mathrm{m}}$, is demonstrated by letting $\lambda_{\mathrm{m}}=0.5 \lambda *$ in Curve $\mathrm{C}$; in this case, $\bar{T} \simeq 7,480$ years, there is about a 24 -percent chance of no drilling, and the expected number of drillings in the period of performance is about 1.4 .

\section{Uncertainty in Probability-Model Parameters}

\section{CLOSURE PROBLEM}

The probability models developed in the last section for inadvertent drilling of the WIPP site illustrate a conceptual problem associated with most probability models: the appearance of parameters that may themselves be uncertain variables as constants in the analytic form of a probability model. This problem can be called the "closure problem" because the appearance of uncertain parameters in models intended to predict uncertainty of system state variables results in a lack of closure in the accounting of 
all sources of uncertainty that is required in performance assessments. For example, the model associated with Curve $C$ of Figure $\mathrm{C}-2$ had two free parameters: $t_{1}$, the end of the period of passive control, and $\lambda_{m}$, the maximum exploration rate (attempted boreholes/yr) during the period of performance. Obviously, uncertainty in these two free parameters is large and some attempt must be made to quantify this uncertainty if the model is ever to be used in a practical performance assessment.

The closure problem is especially acute for those parameters associated with probability models of anthropogenic events and processes; appeal to professional judgment may be the only way of assigning values to the parameters. But elicitation of professional judgment alone will not be enough; some means of translating that judgment into quantitative measures of the uncertainty in the parameters, e.g., CDFs for the parameters, is also required. The closure problem may not be so critical for those parameters associated with probability models of measurable physical properties of the system (e.g., rock hydraulic conductivity and radionuclide solubility); in principle at least, sufficient measurements can be taken of the physical property to enable construction of an empirical CDF which may be adequate to quantify the associated uncertainty. But in almost every instance, some recourse to professional judgment must be made.

Methodologies for formally eliciting professional judgment or expert opinion exist (e.g., Hora and Iman, 1989) and at least one well-established principle, Maximum Entropy Formalism (Jaynes, 1978; Cook and Unwin, 1986; Unwin et al., 1989), is recognized by which the information resulting from application of these methodologies can be converted into CDFs for uncertain parameters or variables. Once these CDFs are obtained (and provided that the CDFs no longer contain imprecise parameters), the closure problem can be solved in one of two ways:

1) Expand the system's state-variable vector (Chapter 3) to include all uncertain parameters in the probability models, incorporate CDFs for uncertain probability-model parameters into the joint CDF for the state variables, and proceed with Monte Carjo simulation by methods indicated in Chapter 3.

2) Regard the probability distributions that arise from a probability model with uncertain (imprecise) parameters as distributions conditioned upon the realization of definite values of those parameters; then remove the conditioning through use of the parameter's CDFs and integration over the range of the parameters. 
The second way of solving the closure problem is best explained by an example.

Example. Suppose that occurrence of a certain kind of event is to be modeled as a Poisson process; that is, the probability that the event occurs $\mathrm{n}=0,1,2, \ldots$ times in a fixed time period $t$ is given by

$$
P(n \mid \lambda)=\frac{(\lambda t)^{n}}{n !} e^{-\lambda t}
$$

where $\lambda$ is an uncertain parameter that is to be determined directly from data concerning past occurrences of the event or from expert interpretations of that data. Now suppose that, because of limited data or differences in interpretations of the data, the only quantitative statement about $\lambda$ that experts in the subject matter of the event are willing to endorse is that $\lambda$ lies between two numbers, say $\lambda_{1}$ and $\lambda_{2}>\lambda_{1}$. Faced with this situation, the performance-assessment analyst could first use the Maximum Entropy Formalism to justify choosing the uniform distribution,

$$
\begin{aligned}
\mathrm{p}(\lambda) & =1 /\left(\lambda_{2}-\lambda_{1}\right) \text { if } \lambda \varepsilon\left(\lambda_{1}, \lambda_{2}\right), \\
& =0 \quad \text { otherwise, }
\end{aligned}
$$

for the parameter $\lambda$, and could next remove reference to the uncertain parameter in Eq. (C.12) by computing the unconditional probability,

$$
\begin{aligned}
P_{u}(n) & =\int_{\lambda}^{\lambda} P(n \mid \lambda) p(\lambda) d \lambda \\
& =[1 /(b-a) n !] \int_{a}^{b} x^{n} e^{-x} d x, n=0,1,2, \ldots
\end{aligned}
$$

where $b=\lambda_{2} t, a=\lambda_{1} t$. The unconditional probability in Eq. (C.13) and the associated CDF for first time of occurrence of the event, could be used then in place of the Poisson process, Eq. (C.12), with an uncertain parameter. liote that no uncertain parameters appear in Eq. (C.13). Also note that use of this method for solving the closure problem may lead to rather complicated analytic expressions for the probabilities to be associated with some of the erent variables and it may be necessary to use numerical integration to remove the conditioning. In the present example, the integral in Eq. (C.13) can be evaluated in terms of the incomplete gamma functions (Abramowitz and Stegun, 1964, formula 6.5.3). The unconditional 
elementary probability of the event treated in this example takes the simple form,

$$
1-P_{u}(0)=1-\left(e^{-a}-e^{-b}\right) /(b-a) .
$$

Solving the closure problem by either of the two methods mentioned above will complicate the process of screening elementary probabilities against the 0.0001 cutoff probability allowed by EPA (EPA, 1985, Appendix B; also, Chapter 3 herein). Obviously, if parameters in a probability model of an agent are uncertain, the elementary probability associated with the agent can take on a range of values and, upon assignment of prior CDFs to the uncertain parameters, will itself become a random variable. The question of how to apply the cutoff probability to screen a random variable immediately arises. Because EPA has provided no guidance for answering this question, its resolution must depend upon the judgment of the analyst and circumstances of the probability model being studied. The author thinks screening elementary probabilities by determining whether the cutoff probability does or does not lie within the calculated range of uncertainty of the elementary probability would almost always be conservative; if that range includes the cutoff probability, the event would be retained for inclusion in the performance-assessment analyses; whereas, if the cutoff probability lies above the upper limit of the range, the event could be eliminated. 


\section{REFERENCES}

Abramowitz, M., and I. A. Stegun. 1964. Handbook of Mathematical Functions, AMS 55. Washington, DC: National Bureau of Standards, U.S. Department of Commerce.

Bertram-Howery, S. G., and R. L. Hunter, eds. 1989. Preliminary Plan for Disposal-System Characterization and Long-Term Performance Evaluation of the Waste Isolation Pilot Plant. SAND89-0178. Albuquerque, NM: Sandia National Laboratories.

Bertram-Howery, S. G., and P. N. Swift. 1990. Status Report: Potential for Long-Term Isolation by the Waste Isolation Pilot Plant Disposal System. SAND90-0616. Albuquerque, NM: Sandia National Laboratories.

Campbe11, J. E., and R. M. Cranwe11. 1988. "Performance Assessment of Radioactive Waste Repositories." Science 239: 1389-1392.

Cook, I., and S. D. Unwin. 1986. "Controlling Principles for Prior Probability Assignments in Nuclear Risk Assessment." Nuclear Science and Engineering 94: $107-119$.

Cranwel1, R. M., J. E. Campbell, J. C. Helton, R. L. Iman, D. E. Longsine, N. R. Ortiz, G. E. Runkle, and M. J. Shortencarrier. 1982a. Risk Methodology for Geologic Disposal of Radinactive Waste: Final Report. SAND81-2573, NUREG/CR2452. Sandia National Laboratories, Albuquerque, NM (revised report printed 1987).

Cranwel1, R. M., R. V. Guzowski, J. E. Campbe11, and N. R. Ortiz. 1982b. Risk Methodology for Geologic Disposal of Radioactive Waste: Scenario Selection Procedure. SAND80-1429, NUREG/CR-1667. Sandia National Laboratories, Albuquerque, NM (revised report printed April 1990).

DOE. 1988. (see U.S. Department of Energy 1988).

DOE and State of New Mexico. 1981. (see U.S. Department of Energy and State of New Mexico 1981).

Earth Technology Corporation. 1988. Final Report for Time Domain Electromagnetic (TDEM) Surveys at the WIPP Site. SAND87-7144. Albuquerque, NM: Sandia National Laboratories.

Elandt-Johnson, R. C., and N. L. Johnson. 1980. Survival Models and Data Analysis. New York: John Wiley and Sons. 
EPA. 1985. (see U.S. Environmental Protection Agency 1985).

Feller, William. 1966. An Introduction to Probability Theory and Its Applications, Volume II. New York: John Wiley and Sons, Inc.

Guzowski, R. V. 1990. Preliminary Identification of Scenarios That May Affect the Escape and Transport of Radionuclides From the Waste Isolation Pilot Plant, Southeastern New Mexico. SAND89-7149. Albuquerque, NM: Sandia National Laboratories.

Hammersley, J. M., and D. C. Handscomb. 1964. Monte Carlo Methods. New York: John Wiley and Sons, Inc.

Harr, M. E. 1987. Reliability-Based Design In Civil Engineering. New York: McGraw-Hill.

Hora, S. C., and R. L. Iman. 1989. "Expert Opinion in Risk Analysis: The NUREG-1150 Methodology." Nuclear Science and Engineering 102: 323-331.

Hunter, R. L. 1989. Events and Processes For Constructing Scenarios For the Release of Transuranic Waste From the Waste Isolation Pilot Plant, Southeastern New Mexico. SAND89-2546. Albuquerque, NM: Sandia National Laboratories.

Hunter, R. L., and C. J. Mann, eds. 1989. Techniques for Determining Probabilities of Events and Processes Affecting the Performance of Geologic Repositories, Literature Review. NUREG/CR-3964, SAND86-0196. Washington, DC: U.S. Nuclear Regulatory Commission.

Hunter, R. L., R. M. Cranwe11, and M. S. Y. Chu. 1986. Assessing Compliance With the EPA High-Level Waste Standard: An Overview. NUREG/CR-4510, SAND86-0121. Washington, DC: U.S. Nuclear Regulatory Commission.

IAEA. 1981. (see International Atomic Energy Agency 1981).

Iman, R. L., and W. J. Conover. 1980. "Sma11 Sample Sensitivity Analysis Techniques for Computer Mode1s, with an Application to Risk Assessment." Communications in Statistics A9: 1749-1842.

Iman, R. L., and W. J. Conover. 1982. Sensitivity Analysis Techniques -- SelfTeaching Curriculum. SAND81-1978. Albuquerque, NM: Sandia National Laboratories. 
Iman, R. L., and J. C. Helton. 1985. A Comparison of Uncertainty and Sensitivity Analys is Techniques for Computer Mode1s. SAND84-1461, NUREG/CR3904. Albuquerque, NM: Sandia National Laboratories.

International Atomic Energy Agency. 1981. Concepts and Examples of Safety Analysis for Radioactive Waste Repositories in Continental Geological Formations. Safety Series No. 58. Vienna, Austria: International Atomic Energy Agency.

Jaynes, E. T. 1978. "Where Do We Stand on Maximum Entropy?" in The Maximum Entropy Formalism. Eds. R. D. Levine and M. Tribus. Cambridge, MA: The MIT Press. $15-117$.

Kalos, M. H., and P. A. Whitlock. 1986. Monte Carlo Methods, Volume I: Basics. New York: John Wiley and Sons, Inc.

Lappin, A. R., R. L. Hunter, eds.; D. P Garber, P. B. Davies, assoc. eds . 1989. Systems Analysis, Long-Term Radionuclide Transport, and Dose Assessments, Waste Isolation Pilot Plant (WIPP), Southeastern New Mexico; March 1989. SAND89-0462. Albuquerque, NM: Sandia National Laboratories.

Marietta, M. G., S. G. Bertram-Howery, D. R. Anderson, K. F. Brinster, R. V. Guzowski, H. Iuzzolino, and R. P. Rechard. 1989. Performance Assessment Methodology Demonstration: Methodology Development for Evaluating Compliance With EPA 40 CFR 191, Subpart B, for the Waste Isolation Pilot Plant. SAND89-2027. Albuquerque, NM: Sandia National Laboratories.

Nowak, E. J., J. R. Tillerson, and T. M. Torres. 1990. Initial Reference Seal System Design: Waste Isolation Pilot Plant (WIPP). SAND90-0355. Albuquerque, NM: Sandia National Laboratories.

NRC. 1986. (see U.S. Nuclear Regulatory Commission 1986).

Rechard, R. P. 1989. Review and Discussion of Code Linkage and Data Flow in Nuclear Waste Compliance Assessments. SAND87-2833. Albuquerque, NM: Sandia National Laboratories.

Rechard, R. P., W. Beyeler, R. D. McCurley, D. K. Rudeen, J. E. Bean, J. D. Schreiber. 1990. Parameter Sensitivity Studies of Selected Components of the Waste Isolation Pilot Plant Repository/Shaft System. SAND89-2030. Albuquerque, NM: Sandia National Laboratories.

Ross, B. 1987. A First Survey of Disruption Scenarios For a High-Level Waste Repository at Yucca Mountain, Nevada. SitND85-7117. Albuqueique, NM: Sandia National Laboratorics. 
Ross, S. M. 1985. Introduction to Probability Models. 3rd ed. New York: Academic Press, Inc.

Thompson, B. G. J., C. J. Frizelle, D. B. Nicholls, and M. C. Thorne. 1988. A Method of Overcoming the Limitations of Conventional Scenario-Based Risk Assessments By Using Monte-Carlo Simulation of Possible Future Environmental Changes. DOE Disposal Assessments Technical Report, TR-DOE-12. London, UK: UK Government Department of Environment (HMIP).

U.S. Department of Energy. 1988. Nuclear Waste Policy Act (Section 113), Site Characterization Plan, Yucca Mountain Site, Nevada Research and Development Area, Nevada. DOE/RW-0199, Volume VII, Part B. Washington, DC: U.S. Department of Energy.

U.S. Department of Energy and State of New Mexico. 1981. Agreement for Consultation and Cooperation Between the U.S. Department of Energy and the State of New Mexico on the Waste Isolation Pilot Plant, modified 11/30/84, $8 / 4 / 87$, and $3 / 22 / 88$.

U.S. Environmental Protection Agency. 1985. "Environmental Standard for the Management and Disposal of Spent Nuclear Fuel, High-Level and Transuranic Radioactive Waste; Final Rule." 40 CFR Part 191. Federal Register, 50: $38066-38089$.

U.S. Nuclear Regulatory Commission. 1986. "Disposal of High-Level Radioactive Wastes in Geologic Repositories; Conforming Amendments." 10 CFR Part 60. Federal Register, June 30, 1986, p. 60-PK-12 to 60-PR-24.

Unwin, S. D., E. G. Cazzoli, R. E. Davis, M. Khatib-Rahbar, M. Lee, H. Nourbakhsh, C. K. Park, and E. Schmidt. 1989. "An Information-Theoretic Basis for Uncertainty Analysis: Application to the QUASAR Severe Accident Study." Reliability Engineering and System Safety 26: 143-162. 


\section{Distribution}

\section{FEDERAL AGENCIES}

U. S. Department of Energy (5)

Office of Environmental Restoration and Waste Management

Attn: Leo P. Duffy, EM-1

Jill E. Lytle, EM-30

Mark Duff, EM-34

Steve Schneider, EM-34

Clyde Frank, EM-50

Washington, DC 20585

U.S. Department of Energy (5)

WIPP Task Force

Attn: Mark Frei (2)

G. H. Daly

Sandi Fucigna

Jay Rhoderick

12800 Middlebrook Rd.

Suite 400

Germantown, MD 20874

U.S. Department of Energy (4)

Office of Environment, Safety and Health

Attn: Raymond P. Berube, EH-20

Carol Borgstrum, EH-25

Ray Pelletier, EH-231

Kathleen Taimi, EH-232

Washington, DC 20585

U. S. Department of Energy (4)

WIPP Project Integration office

Attn: W. J. Arthur III

L. W. Gage

P. J. Higgins

D. A. Olona

P.O. Box 5400

Albuquerque, NM 87115-5400

U. S. Department of Energy (10)

WIPP Project Site Office (Carlsbad)

Attn: A. Hunt (4)

M. McFadden

V. Daub (4)

K. Hunter

P.O. Box 3090

Carlsbad, NM 88221-3090
U. S. Department of Energy, (5)

Office of Civilian Radioactive Waste

Management

Attn: Deputy Director, RW-2

Associate Director, RW-10

Office of Program Administration and

Resources Management

Associate Director, RW-20

office of Facilities

Siting and

Development

Associate Director, RW-30

Office of Systems

Integration and

Regulations

Associate Director, RW-40 Office of External

Relations and Policy

Office of Geologic Repositories

Forrestal Building

Washington, DC 20585

U. S. Department of Energy

Attn: National Atomic Museum Library Albuquerque Operations Office

P.O. Box 5400

Albuquerque, NM 87185

U. S. Department of Energy

Research \& Waste Management Division

Attn: Director

P.O. Box E

Oak Ridge, TN 37831

U. S. Department of Energy (2)

Idaho Operations Office

Fuel Processing and Waste

Management Division

735 DOE Place

Idaho Fails, ID 83402

U.S. Department of Enerpy

Savannah River Operations office

Defense Waste Processing

Facility Project Office

Attn: W. D. Pearson

P.O. Box A

Aiken, SC 29802 
U.S. Department of Energy (2)

Richland Operations Office

Nuclear Fuel Cycle $\&$ Production Division

Attn: R. E. Gerton

825 Jadwin Ave.

P.O. Box 500

Richland, WA 99352

U.S. Department of Energy (3)

Nevada Operations Office

Attn: J. R. Boland

D. Livingston

P. K. Fitzsimmons

2753 S. Highland Drive

Las Vegas, NV 87183-8518

U.S. Department of Energy (2)

Technical Information Center

P.O. Box 62

Oak Ridge, TN 37831

U.S. Department of Energy

Chicago Operations Office

Attn: J. C. Haugen

9800 South Cass Avenue

Argonne, IL 60439

U.S. Department of Energy

Los Alamos Area Office

52835 th Street

Lus Alamos, NM 87544

U.S. Department of Energy

Rocky Flats Area Office

Attn: W. C. Rask

Gary Huffman

Tom Lukow

P.O. Box 928

Golden, CO 80402-0928

U.S. Department of Energy

Dayton Area Office

Attn: R. Grandfield

P.O. Box 66

Miamisburg, OH 45343-0066

U.S. Department of Energy

Attn: Edward Young

Room E- 178

GAO/RCED/GTN

Washington, DC 20545
U.S. Environmental Protection Agency (2)

Office of Radiation Protection Programs (ANR - 460)

Attn: Richard Guimond (2)

Washington, D.C. 20460

U.S. Nuclear Regulatory Commission (4)

Division of Waste Management

Attn: N. Eisenberg

B. J . Youngblood

S. Copland

R. Ballard

Mail Stop 4-H-3

Washington, DC 20555

U.S. Nuclear Regulatory Commission (4)

Advisory Committee on Nuclear Waste

Attn: Dade Moeller

Martin J. Steindler

Paul W. Pomeroy

William J. Hinze

7920 Norfolk Avenue

Bethesda, MD 20814

Defense Nuclear Facilities Safety Board

Attn: Dermot Winters

600 E. Street NW

Suite 675

Washington, DC 20004

Katherine Yuracko

Energy and Science Division

Office of Management and Budget

725 17th Street NW

Washington, DC 20503

U.S. Geological Survey

Conservation Division

Attn: W. Melton

P.O. Box 1857

Roswe11, NM 88201

U.S. Geological Survey (2)

Water Resources Division

Attn: Cathy Peters

Suite 200

4501 Indian School, NE

Albuquerque, NM 87110 


\section{STATE AGENCIES}

Bureau of Land Management 101 E. Mermod

Carlsbad, NM 88220

Bureau of Land Management New Mexico State office

P.O. Box 1449

Santa Fe, NM 87507

Environmental Evaluation Group (5)

Attn: Robert Neill

Suite F-2

7007 Wyoming Blvd., N.E.

Albuquerque, NM 87109

New Mexico Bureau of Mines

and Mineral Resources (2)

Attn: F. E. Kottlowski, Director

J. Hawley

Socorro, NM 87801

New Mexico Department of Energy \& Minerals

Attn: Librarian

2040 S. Pacheco

Santa Fe, NM 87505

New Mexico Radioactive Tasl. Force (2)

(Governor's WIPP Task Force)

Attn: Anita Lockwood, Chairman

Chris Wentz, Coordinator/Policy Analyst

2040 Pacheco

Santa Fe, NM 87505

Bob Forrest

Mayor, City of Carlsbad

P.O. Box 1569

Carlsbad, NM 88221

Chuck Bernard

Executive Director

Carlsbad Department of Development

P.O. Box 1090

Carlsbad, NM 88221
Robert M. Hawk (2)

Chairman, Hazardous and Radioactive Materials Committee

Room 334

State Capitol

Sante Fe, NM 87503

Judy Espinosa (2)

Secretary of the Environment

New Mexico Environment Department

P.O. Box 968

$1190 \mathrm{St}$. Francis Drive

Santa Fe, NM 87503-0968

New Mexico Environment Department (2)

Attn: Pat McCausland

WIPP Project Site

P.O. Box 3090

Carlsbad, NM 88221

\section{ADVISORY COMMITTEE ON NUCLEAR FACILITY SAFETY}

John F. Ahearne

Executive Director, Sigma Xi

99 Alexander Drive

Research Triangle Park, NC 27709

James E. Martin

109 Observatory Road

Ann Arbor, MI 48109

Dr. Gerald Tape

Assoc. Universities

1717 Massachusetts Ave. NW

Suite 603

Washingtor:, DC 20036

DOE BLUE RIBETON PANEL

Thomas Bahr, Director

New Mexico State University

New Mexico Water Resources Research Institute

Box 3167

Las Cruces, NM 88003 


\author{
Robert Bishop \\ Nuclear Management Resources Council \\ 1776 I Street, NW \\ Suite 300 \\ Washington, DC 20006-2496 \\ Arthur Kubo \\ BDM Corporation \\ 7915 Jones Branch Drive \\ McLean, VA 22102 \\ Leonard Slosky \\ Slosky \& Associates \\ Bank Western Tower \\ Suite 1400 \\ 1675 Broadway \\ Denver, CO 80202 \\ Newal Squyres \\ Holland \& Hart \\ P.O. Box 2527 \\ Boise, ID 83701
}

WIPP PANEL OF NATIONAL RESEARCH COUNCIL'S BOARD ON RADIOACTIVE WASTE MANAGEMENT

Charles Fairhurst, Chairman

Department of Civil and

Mineral Engineering

University of Minnesota

500 Pillsbury Dr. SE

Minneapolis, MN 55455-0220

John O. Blomeke

Route 3

3833 Sandy Shore Drive

Lenoir City, TN 37771

John D. Bredehoeft

Western Region Hydrologist

Water Resources Division

U.S. Geological Survey (M/S 439)

345 Middlefield Road

Menlo Park, CA 94025

Karl. P. Cohen

928 N. California Avenue

Palo Alto, CA 94303
Fred M. Ernsberger

$1325 \mathrm{NW}$ 10th Avenue

Gainsville, FL 32601

Rodney C. Ewing

Department of Geology

University of New Mexico

200 Yale, NE

Albuquerque, NM 87131

B. John Garrick

Pickard, Lowe \& Garrick, Inc.

2260 University Drive

Newport Beach, CA 92660

Leonard F. Konikow

U.S. Geological Survey

431 National Center

Reston, VA 22092

Jeremiah O'Driscoll

505 Valley Hill Drive

Atlanta, GA 30350

Christopher Whipple

Clement International Corp.

160 Spear St.

Suite 1380

San Francisco, CA 94105-1535

National Research Council (3)

Board on Radioactive

Waste Management

Attn: Peter B. Myers, Staff Director (2)

Dr. Geraldine J. Grube

2101 Constitution Avenue

Washington, DC 20418

\section{PERFORMANCE ASSESSMENT PEER REVIEW PANEL}

G. Ross Heath

College of Ocean and

Fishery Sciences HN-15

583 Henderson Hall

University of Washington

Seattle, WA 98195 
Thomas H. Pigford

Department of Nuclear Engineering

4159 Etcheverry Hall

University of California

Berkeley, CA 94720

Thomas A. Cotton

JK Research Associates, Inc.

4429 Butterworth Place, NW

Washington, DC 20016

Robert J . Budnitz

President, Future Resources

Associates, Inc.

2000 Center Street

Suite 418

Berkeley, CA 94704

C. John Mann

Department of Geology

245 Natural History Bldg.

1301 West Green Street

University of Illinois

Urbana, IL 61801

Frank W. Schwartz

Department of Geology and Mineralogy

The Ohio State University

Scott $\mathrm{Hall}$

1090 Carmack Rd.

Columbus, OH 43210

\section{FUTURES SOCIETIES EXPERT PANEL}

Theodore S. Glickman

Resources for the Future

1616 P St., NN

Washington, JC 20036

Norman Rosenberg

Resources for the Future

1616 P St., NW

Washington, DC 20036

Max Singer

The Potomac Organization, Inc.

5400 Greystone St.

Chevy Chase, MD 20815
Maris Vinovskis

Institute for Social Research

Room 4086

University of Michigan

426 Thompson St

Ann Arbor, MI 48109-1045

Gregory Benford

University of California, Irvine

Department of Physics

Irvine, CA 92717

Craig Kirkwood

College of Business Administration

Arizona State University

Tempe, AZ 85287

Harry Otway

Health, Safety, and Envir. Div.

Mail Stop K-491

Los Alamos National Laboratory

Los Alamos, NM 87545

Martin J. Pasqualetti

Department of Geography

Arizona State University

Tempe, AZ 85287-3806

Michael Baram

Bracken and Baram

33 Mount Vernon st.

Boston, MA 02108

Wende 11 Bel1

Department of Sociology

Yale University

1965 Yale Station

New Haven, CT 06520

Bernard L. Cohen

Department of Physics

University of Pittsburgh

Pittsburgh, PA 15260

Ted Gordon

The Futures Group

80 Glastonbury Blvd.

Glastonbuxy, CT 06033 
Duane Chapman

5025 S. Building, Room S5119

The World Bank

$1818 \mathrm{H}$ Street NW

Washington, DC 20433

Victor Ferkiss

23 Sage Brush Circle

Corrales, NM 87048

Dan Reicher

Senior Attorney

Natural Resources Defense Council

1350 New York Ave. NW, \#300

Washington, DC 20005

Theodore Taylor

P.O. Box 39

3383 Weatherby nd.

West Clarksville, NY 14786

\section{NATIONAL LABORATORIES}

Argonne National Labs

Attn: A. Smith, D. Tomasko

9700 South Cass, B1dg. 201

Argonne, IL 60439

Battelle Pacific Northwest

Laboratories (6)

Attn: D. J. Bradley

J. Relyea

R. E. Westerman

S. Bates

H. C. Burkholder

L. Pederson

Battelle Boulevard

Richland, WA 99352

Lawrence Livermore National

Laboratory

Attn: G. Mackanic

P.O. Box 808, MS L-192

Livermore, CA 94550

Los Alamos National Laboratories Attn: B. Erdal, CNC-11

P.O. Box 1663

Los Alamos, NM 87544
Los Alamos National Laboratories Attn: A. Meijer

Mail Stop J514

Los Alamos, NM 87545

Los Alamos National Laboratories HSE - 8

Attn: M. Enoris

L. Soholt

J. Wenzel

P.O. Box 1663

Los Alamos, NM 87544

Los Alamos National Laboratories HSE - 7

Attn: A. Drypolcher

S. Kosciewiscz

P.O. Box 1663

Lns Alamos, NM 87544

Oak Ridge National Labs

Martin Marietta Systems, Inc.

Attn: J. Setaro

P.O. Box 2008, B1dg. 3047

Oak Ridge, TN 37831-6019

Oak Ridge National Laboratory

Attn: R. E. Blanko

E. Bondietti

Box 2008

Oak Ridge, TN 37831

Savannah River Laboratory (6)

Attn: N. Bibler

E. L. Albenisius

M. J. Plodinec

G. G. Wicks

C. Jantzen

$\mathrm{J}$. A. Stone

Aiken, SC 29801

Savannah River Plant (2)

Attn: Richard G. Baxter Building 704.S

K. W. Wierzbicki

Building 703-H

Aiken, SC 29808-0001 
CORPORATI: 'NS/MEMBERS OF THE PUBLIC

Benchmark Environmental Corp. (3)

Attn: John Hart

C. Frederickson

K. Lickliter

4501 Indian School Rd., NE

Suite 105

Albuquerque, NM 87110

Deuel and Associates, Inc.

Attn: R. W. Prindle

7208 Jefferson, NE

Albuquerque, NM 87109

Disposal Safety, Inc.

Attn: Benjamin Ross

Suite 314

1660 L Street NW

Washington, DC 20006

$E$ G \& G Idaho (3)

1955 Fremont Street

Attn: C. Atwood

C. Hertzler

T'. I. Clements

Idaho Falls, ID 83415

Geomatrix

Attn: Kevin Coppersmith

100 Pine Street \#1000

San Francisco, CA 94111

Golden Associates, Inc. (3)

Attn: Mark Cunnane

Richard Kossik

Ian Miller

4104 148th Avenue NE

Redmond, WA 98052

In-Situ, Inc. (2)

Attn: S. C. Way

C. McKee

209 Grand Avenue

Laramie, WY 82070
INTERA Technologies, Inc. (3)

Attn: G. E. Grisak

J. F. Pickens

A. Haug

Suite \#300

6850 Austin Center Blvd.

Austin, TX 78731

INTERA Technologies, Inc.

Attn: Wayne Stensrud

P.O. Box 2123

Carlsbad, NM 88221

INTERA, INC.

Attn: William Nelson

101 Convention Center Drive

Suite 540

Las Vegas, NV 89109

IT Corporation ( 3 )

Attn: R. F. McKinney (2)

P. Drez

Regional office - Suite 700

5301 Central Avenue, NE

Albuquerque, NM 87108

IT Corporation

R. J . Eastmond

$825 \mathrm{~J}$ adwin Ave.

Richland, WA 99352

IT Corporation (2)

Attn: D. E. Deal

P.O. Box 2078

Carlsbad, NM 88221

Pacific Northwest Laboratory

Attn: Bill Kennedy

Battelle Blvd.

P.O. Box 999

Richland, WA 99352

RE/SPEC, Inc.

Attn: W. Coons

Suite 300

4775 Indian School NE

Albuquerque, NM 87110 
RE/SPEC, Inc. (7)

Attn: L. L. Van Sambeek

D. B. Blankenship

G. Callahan

T. Pfeifle

J. L. Ratigan

P.O. Box 725

Rapid City, SD 57709

Reynolds Elect/Engr. Co., Inc. Building 790, Warehouse Row Attn: E. W. Kendall

P.O. Box 98:21

Las Vegas, NV 89193-8521

Roy F. Weston, Inc.

CRWM Tech. Supp. Team

Attn: Clifford J. Noronha 955 L'Enfant Plaza, S.W.

North Building, Eighth Floor

Washington, DC 20024

\section{Science Applications International} Corporation

Attn: Howard R. Pratt, Senior Vice President

10260 Campus Point Drive

San Diego, CA 92121

Science Applications International Corporation

Attn: Michael B. Gross

Suite 1250

Ass't. Vice President

160 Spear Street

San Francisco, CA 94105

Science Applications International

Corporation (2)

Attn: George Dymme1

Chris G. Pflum

101 Convention Center Dr.

Las Vegas, NV 89109

Southwest Research Institute

Center for Nuclear Waste Regulatory Analys is (4)

Attn: P. K. Nair (3)

B. Sagar (1)

6220 Culebra Road

San Antonio, Texas 78228-0510
Systems, Science, and Software (2)

Attn: E. Peterson

Box 1620

P. Lagus

La Jolla, CA 92038

TASC

Attn: Steven G. Oston

55 Walkers Brook Drive

Reading, MA 01867

Tech. Reps., Inc. (4)

Attn: Janet Chapman

$\mathrm{T}$. Cameron

D. Marchand

J . Stikar

5000 Marble NE

Suite 222

Albuquerque, NM 87110

Tolan, Beeson, \& Associates

Attn: Terry L. Tolan

2320 W. $15 \mathrm{tr}$ Avenue

Kennewick, hA 99337

TRW Environmental Safety Systems (TESS)

Attn: Ivan Saks

10306 Eaton Place

Suite 300

Fairfax, VA 22030

Westinghouse Electric Corporation (7)

Attn: Library

L. Trego

W. P. Poirier

L. Fitch

V. F. Likar

R. Cook

R. F. Kehrman

P.O. Box 2078

Carlsbad, NM 88221

Westinghouse Hanford Company

Attn: Don Wood

P.O. Box 1970

Richland, WA 99352 
Weston Corporation

Attn: David Lechel

Suite 1000

5301 Central Avenue, NE

Albuquerque, NM 87108

Western Water Consultants

Attn: D. Fritz

1949 Sugarland Drive \#134

Sheridan, WY 82801-5720

Western Water Consultants

Attn: P. A. Rechard

P.O. Box 4128

Laramie, WY 82071

Neville Cook

Rock Mechanics Engineering

Mine Engineering Dept.

University of California

Berkeley, CA 94720

Dennis W. Powers

Star Route Box 87

Anthony, TX 79821

Shirley Thieda

P.O. Box 2109, RR1

Bernalillo, NM 87004

Jack Urich

c/o CARD

144 Harvard SE

Albuquerque, NM 87106

\section{UNIVERSITIES}

University of Arizona

Attn: J. G. McCray

Department of Nuclear Engineering

Tucson, AZ 85721

University of California

Mechanical, Aerospace, and

Nuclear Engineering Department (2)

Attn: W. Kastenberg

D. Browne

5532 Boelter Hall

Los Angeles, CA 90024
University of Hawaii at Hilo

Attn: S. Hora

Business Administration

Hilo, HI 96720-4091

University of New Mexico (1)

Geology Department

Attn: Library

Albuquerque, NM 87131

University of New Mexico

Research Administration

Attn: H. Schreyer

102 Scholes Hall

Albuquerque, NM 87131

Pennsylvania State University

Materials Research Laboratory

Attn: Della Roy

University Park, PA 16802

Texas A\&M University

Center of Tectonophysics

College Station, TX 77840

University of Wyoming

Department of Civil Engineering

Attn: V. R. Hasfurther

Laramie, WY 82071

University of Wyoming

Department of Geology

Attn: J. I. Drever

Laramie, WY 82071

University of Wyoming

Department of Mathematics

Attn: R. E. Ewing

Laramie, WY 82071

\section{LIBRARIES}

Thomas Brannigan Library

Attn: Don Dresp, Head Librarian

$106 \mathrm{~W}$. Hadley St.

Las Cruces, NM 88001

Hobbs Public Library

Attn: Marcia Lewis, Librarian

509 N. Ship Street

Hobbs, NN 88248 
New Mexico State Library

Attn: Ingrid Vollenhofer

P.O. Box 1629

Santa Fe, NM 87503

New Mexico Tech

Martin Speere Memorial Library

Campus Street

Socorro, NM 87810

New Mexico Junior College

Pannel1 Library

Attn: Ruth Hill

Lovington Highway

Hobbs, NM 88240

Carlsbad Municipal Library

WIPP Public Reading Room

Attn: Lee Hubbard, Head Librarian

$101 \mathrm{~S}$. Halagueno St.

Carlsbad, NM 88220

University of New Mexico

General Library

Government Publications Department

Albuquerque, NM 87131

\section{NEA/PSAC USER'S GROUP}

Timo K. Vieno

Technical Research Centre of Finland (VTT)

Nuclear Engineering Laboratory

P.O. Box 169

SF-00181 Helsinki

FINLAND

Alexander Nies (PSAC Chairman)

Gesellschaft für Strahlen- und

Institut für Tieflagerung

Abteilung für Endlagersicherheit

Theodor-Heuss-Strasse 4

D-3.300 Braunscheweig

GERMANY

Eduard Hofer

Gesellschaft für Reaktorsicherheit

(GRS) $\mathrm{MBH}$

Forschungsgelände

D-8046 Garching

GERMANY
Takashi Sasahara

Environmental Assessment Laboratory Department of Environmental Safety

Research

Nuclear Safety Research Center,

Tokai Research Establishment, JAERI

Tokai-mura, Naka-gun

Ibaraki-ken

JAPAN

Alejandro Alonso

Cátedra de Tecnología Nuclear

E.T.S. de Ingenieros Industriales

José Gutiérrez Abascal, 2

E-28006 Madrid

SPAIN

Pedro Prado

CIEMAT

Instituto de Tecnologia Nuclear

Avenida Complutense, 22

E-28040 Madrid

SPAIN

Miguel Angel Cuñado

ENRESA

Emilio Vargas, 7

E-28043 Madrid

SPAIN

Francisco Javier Elorza

ENRESA

Emilio Vargas, 7

E-28043 Madrid

SPAIN

Nils A. Kjellbert

Swedish Nuclear Fuel and Waste

Management Company (SKB)

Box 5864

S-102 48 Stockholm

SWEDEN

Björn Cronhjort

Swedish National Board for Spent

Nuclear Fuel (SKN)

Sehlsedtsgatan 9

S-115 28 Stockholm

SWEDEN 
Richard A. Klos

Paul-Scherrer Institute (PSI)

$\mathrm{CH}-5232$ Villingen PSI

SWITZERLAND

Charles McCombia

NAGRA

Parkstrasse 23

CH-5401 Baden

SWITZERLAND

Brian G. J. Thompson

Department of the Environment

Her Majesty's Inspectorate of Pollution

Room A5.33, Romney House

43 Marsham Street

London SW1P 2PY

UNITED KINGDOM

Trevor J. Sumerling

INTERA/ECL

Chiltern House

45 Station Road

Henley-on-Thames

Oxfordshire RG9 1A.T

UNITED KINGDOM

Richard Codell

U.S. Nuclear Regulatory Commission

Mail Stop 4-H-3

Washington, D.C. 20555

Paul W. Eslinger

Battelle Pacific Northwest

Laboratories (PNL)

P.O. Box 999, MS K2-32

Richland, WA 99352

Andrea Sa1telli

Commission of the European Communities

Joint Resarch Centre od Ispra

I-21020 Ispra (Varese)

ITALY
Shaheed Hossain

Division of Nuclear Fuel Cycle and Waste Management

International Atomic Energy Agency

Wagramerstrasse 5

P.O. Box 100

A- 1400 Vienna

AUSTRIA

Daniel A. Galson

Division of Radiation Protection and Waste Management

38, Boulevard Suchet

F-75016 Paris

FRANCE

\section{FOREIGN ADDRESSES}

Studiecentrum Voor Kernenergie

Centre D'Energie Nucleaire

Attn: A. Bonne

SCK/CEN

Boeretang 200

B - $2400 \mathrm{Mol}$

BELGIUM

Atomic Energy of Canada, Ltd. (4)

Whiteshell Research Estab.

Attn: Peter Haywood

John' Tait

Michael E. Stephens

Bruce W. Goodwin

Pinewa, Manitoba, CANADA

ROE $1 \mathrm{LO}$

D. K. Mukerjee

Ontario Hydro Research Lab

800 Kipling Avenue

Toronto, Ontario, CANADA

M8Z 5S4

Ghislain de Marsily

Lab. Géologie Appliqué

Tour 26, 5 étage

4 Place Jussieu

F-75252 Paris Cedex 05, FRANCE

Jean-Pierre Olivier

OECD Nuclear Energy Agency (2)

38, Boulevard Suchet

F-75016 Paris, FRANCE 
D. Alexandre, Deputy Director ANDRA

31 Rue de la Federation

75015 Paris, FRANCE

Claude Sombret

Centre D'Etudes Nucleaires

De La Vallee Rhone

CEN/VALRHO

S.D.H.A. BP 171

30205 Bagnols-Sur-Ceze

FRANCE

Bundesministerium fur Forschung und Technologie

Postfach 200706

5300 Bonn 2

GERMANY

Bundesanstalt fur Geowissenschaften und Rohstoffe

Attn: Michael Langer

Postfach 510153

3000 Hannover 51

GERMANY

Hahn-Mietner-Institut fur

Kernforschung

Attn: Werrer Lutze

G1ienicker Strasse 100

100 Berlin 39

GERMANY

Institut fur Tieflagerung (4)

Attn: K. Kuhn

Theodor-Heuss-Strasse 4

D- 3300 Braunschweig

GERMANY

Kernforschung Karlsruhe

Attn: K. D. Closs

Postfach 3640

7500 Karlsruhe

GERMANY

Physikalisch-Technische Bundesanstalt Attn: Pater Brenneke

Postfach 3345

D- 3300 Braunschweig

GERMANY
D. R. Knowles

British Nuclear Fuels, plc

Risley, Warrington, Cheshire WA3 6AS

1002607 GREAT BRITAIN

Shingo Tashiro

Japan Atomic Energy Research

Insitute

Tokai-Mura, Ibaraki-Ken

319-11 JAPAN

Netherlands Energy Research Foundation

ECN (2)

Attn: Tuen Deboer, Mgr.

L. H. Vons

3 Westerduinweg

P.O. Box 1

1755 ZG Petten, THE NETHERLANDS

Johan Andersson

Statens Kärnkraftinspektion

SKI

Box 27106

S-102 52 Stockholm, SWEDEN

Fred Karisson

Svensk Karnbransleforsorjning $A B$

SKB

Box 5864

S-102 48 Stockholm, SWEDEN 


\section{INTERNAL}

1

20

1511

1520

1521

1521

3151

3200

6000

6232

6233

6233

6300

6301

6310

6310A

6311

6312

6312

6313

6315

6316

6317

6320

6340

6340

6340A

6341

6341

6341

6341

6342

6342

6342

6342

6342

6342

6342

6342

6342

6342

6342

6342

6342

6342

6342

6342

6342
A. Narath

O. E. Jones

D. K. Gartling

L. W. Davison

J. G. Arguello

H. S. Morgan

S. M. Wayland

N. R. Ortiz

D. L. Hartley

W. R. Wawersik

J. C. Eichelberger

J. L. Krumhans 1

$T$. O. Hunter

E. Bonano

T. E. Blejwas, Acting

L. E. Shephard

A. L. Stevens

G. E. Barr

F. W. Bingham

L. S. Costin

P. C. Kaplan

R. P. Sandoval

S. Sinnock

R. E. Luna, Acting

W. D. Weart

S. Y. Pickering

A. R. Lappin

J. M. Covan

D. P. Garber

R. C. Lincoln

Sandia WIPP Central Files (100)

D. R. Anderson

B. M. Butcher

L. S. Gomez

M. Gruebel

R. Guzowski

R. D. Klet.t

M. G. Marietta

D. Morrison

A. C. Peterson

R. P. Rechard

P. Swift

M. Tierney (25)

K. M. Trauth

B. L. Baker*

J. Bean*

J. Berglund $x$

W. Beyeler*
6342

6342

6342

6342

6342

6342

6342

6342

6342

6342

6342

6342

6342

6342

6342

6342

6342

6342

6343

6344

6344

6344

6344

6344

6344

6344

6345

6345

6345

6346

6346

6346

6400

6413

6415

6415

6416

6621

9300

9310

9325

9325

9330

9333

9333

$8523-2$

3141

3151
R. Blaine*

T. Blaine*

K. Brinster*

K. Byle*

L. Clements*

J. Garner*

A. Gilkey*

A. Hsia*

H. Iuzzolino*

$\mathrm{J}$. Logothetis*

R. McCurley*

J. Orona*

J. Rath*

P. Roache*

D. Rudeen*

J. Sandha*

J. Schreiber*

P. Vaughn*

T. M. Schultheis

R. L. Beauheim

P. B. Davies

S. J. Finley

E. Gorham

A. M. LaVenue

C. F. Novak

S. W. Webb

R. Beraun

L. Brush

M. A. Molecke

D. E. Munson

E. J . Nowak

J. R. Tillerson

D. J. McCloskey

J. C. Helton

R. M. Cranwel1

R. L. Iman

M.S.Y. Chu

L. D. Tyler

J. E. Powell

J. D. Plimpton

J. T. McIlmoyle

R. L. Rutter

J. D. Kennedy

o. Burchett

J. W. Mercer

2 Central Technical Files

S. A. Landenberger (5)

Document Processing (8) for DOE/OSTI

G. C. Claycomb

(3) 

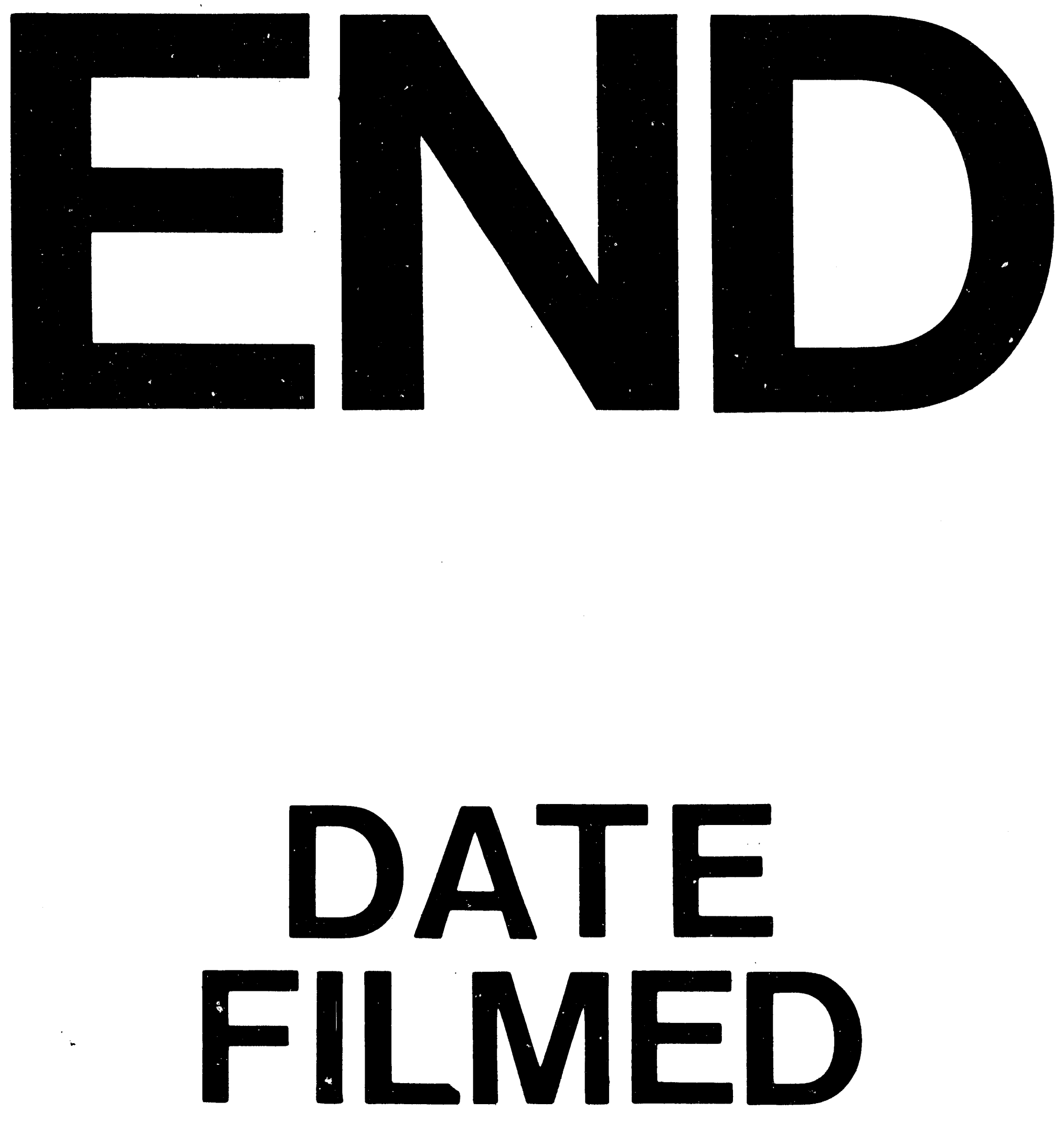

$+$

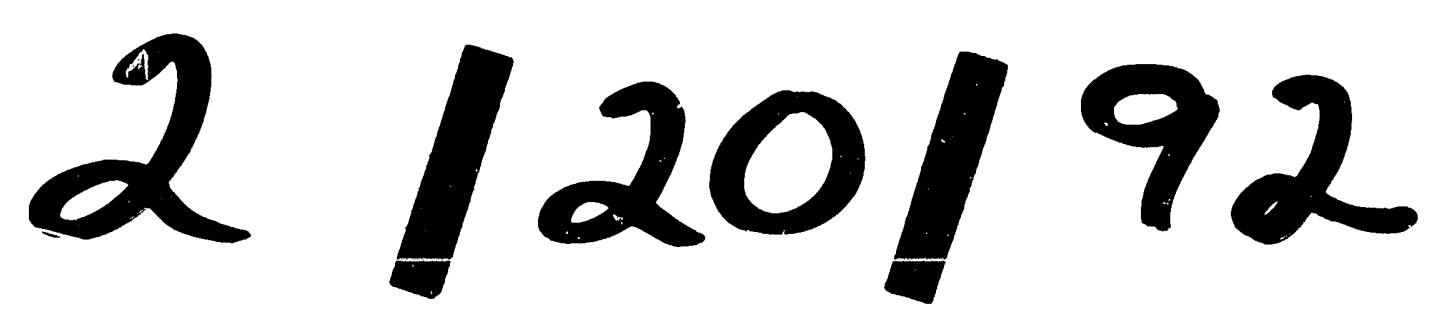


